\title{
The Allocation of Authority in Organizations: A Field Experiment with Bureaucrats*
}

\author{
Oriana Bandiera, Michael Carlos Best, Adnan Qadir Khan, \& Andrea Prat
}

January 2021

\begin{abstract}
We design a field experiment to study how the allocation of authority between frontline procurement officers and their monitors affects performance both directly and through the response to incentives. In collaboration with the government of Punjab, Pakistan, we shift authority from monitors to procurement officers and introduce financial incentives to a sample of 600 procurement officers in 26 districts. We find that autonomy alone reduces prices by $9 \%$ without reducing quality and that the effect is stronger when the monitor tends to delay approvals for purchases until the end of the fiscal year. In contrast, the effect of performance pay is muted, except when agents face a monitor who does not delay approvals. Time use data reveal agents' responses vary along the same margin: autonomy increases the time devoted to procurement and this leads to lower prices only when monitors cause delays. By contrast, incentives work when monitors do not cause delays. The results illustrate that organizational design and anti-corruption policies must balance agency issues at different levels of the hierarchy.
\end{abstract}

*Bandiera: London School of Economics o.bandiera@lse.ac.uk, Best: Columbia University and NBER michael.best@columbia.edu, Khan: London School of Economics a.q.khan@lse.ac.uk, Prat: Columbia University andrea.prat@columbia.edu. This experiment was preregistered in the Social Science Registry at https://www.socialscienceregistry.org/trials/610. Its pre-analysis plan and a filled in version of the pre-analysis plan are available there also. We are grateful to the World Bank, the International Growth Centre, and the JPAL Governance Initiative for financial support. We thank Ahsen Omar Majid, Sher Afghan Asad, Maha Rehman, Ameera Jamal, Omar Gondal, Khawaja Hussain Mahmood, Subhan Khalid, Sophia Tahir Mir, Ovais Siddiqui, Noor Sehur, Zain ul Abideen, Ahsan Farooqui, Natasha Ansari and Reem Hasan for outstanding research assistance in Lahore, and Hamza Husain, Sakshi Gupta and Advitha Arun for outstanding research assistance at Columbia. We thank the Government of Punjab and in particular Naeem Sheikh, Imdad Bosal, Umer Saif, Zubair Bhatti and Ali Bahadar Qazi for their collaboration over the years. We thank many seminar participants and especially Abhijit Banerjee, Ernesto Dal Bo, Bob Gibbons, Imran Rasul, and Guido Tabellini for helpful comments and discussion. All errors are our own. 


\section{Introduction}

Organizations bring together people with different interests, information and skills to work towards a common goal. To achieve this, organizations make two interdependent choices: how to allocate decision making rights to agents at different layers of the organization's hierarchy, and how to monitor and motivate their behavior.

Organization theory, from the foundational work of Coase (1937) and Simon (1951) to the recent contributions reviewed by Bolton \& Dewatripont (2013) and Gibbons \& Roberts (2013), points to the allocation of authority as one of the choices at the core of organization design. By contrast, field work, guided by the single-layer principal-agent framework, tends to focus on performance rewards, while holding the architecture of the organization fixed (see, e.g. Bandiera et al. , 2011; Finan et al. , 2017, for reviews).

This paper brings the two design choices-incentive provision and authority allocation - together by means of a large-scale field experiment conducted in collaboration with the government of Punjab, Pakistan. Our context is public procurement, an activity that represents approximately $12 \%$ of GDP in the average OECD country, and which is notoriously subject to agency problems: Procurement officers are tasked with buying goods they do not use with money they do not own (Laffont \& Tirole, 1994) and they operate in an environment characterized by contract incompleteness and high transaction costs (Bajari \& Tadelis, 2001). How best to tackle this is subject to intense debate, with one camp strongly in favor of strict rules and intense monitoring (OECD, 2009) and the other arguing in favor of simplification and autonomy (Kelman, 1990). We study how the allocation of authority between officers and their monitors, who face their own agency issues, determines performance.

Our sample covers over 20,000 purchases, made by 600 procurement officers across the province over the course of two years and monitored by 26 offices of the Accountant General. To maintain comparability we focus on purchases of generic goods and develop an online reporting system to collect detailed information on the attributes of each purchase. ${ }^{1}$ The outcome of interest is price conditional on quantity and the precise nature of the good being purchased, including delivery speed and transport costs.

A simple framework illustrates how procurement outcomes depend on incentives and the allocation of authority between officers and monitors. Both agents are defined by a

\footnotetext{
${ }^{1}$ Despite the fact that each purchase of these generic goods is small, cumulatively they account for a large share of procurement expenditures. As table 1 shows, they account for $53 \%$ of a typical office's budget.
} 
type that determines whether they are aligned with the organization. The equilibrium price is a function of the strength of incentives and the officers' and monitors' types. If these are equal, shifting authority from the monitor to the officer lowers prices because it eliminates the "competing bandits" problem (Shleifer \& Vishny, 1993). A fortiori, prices will fall whenever the officer is better aligned and will rise only if the monitor is better aligned. This is where the complexity of the organization comes into play: In the simple principal-agent model the monitor is perfectly aligned with the principal and would not impose inefficient monitoring costs on the organization.

Performance pay for the officer always decreases prices but the effect size depends on the monitor's type. If he is misaligned, the officer cannot do much to reduce prices as these are mostly kept high by the monitor.

To create variation in the policy parameters we randomly allocate 600 procurement officers to four groups: a control group, an autonomy group, a pay for performance group and a group that gets both. The autonomy treatment shifts decision making rights from the monitors to the officers by removing the monitor's discretion over the list of documents that they can demand as part of the audit, and by giving the officers full decision rights over purchases in cash up to $10 \%$ of the average PO budget. The pay for performance treatment is a rank order tournament within district and administrative department which pays prizes ranging from half a month's salary to two months' salary on the basis of value for money.

The experiment lasts two years and we stagger the introduction of the two treatments so that performance pay is offered from the first year whilst autonomy only kicks in in the second year. This allows us to use the control group in the first year as a benchmark for the status quo and to build a proxy for the monitor's type because each district has its own monitors.

Our findings are as follows. First, consistent with the fact that procurement officers are given orders to fill based on the needs of the organization, the treatments do not affect the composition, quantity or attributes of the items purchased.

Second, autonomy reduces prices by $9 \%$ on average either on its own or in combination with performance pay. Performance pay on its own reduces prices by $3 \%$ but we cannot reject the null that the effect is equal to zero. Our findings are consistent with and provide micro foundations for the result that autonomy, but not incentives, is correlated with performance in bureaucracies (Rasul \& Rogger, 2018; Rasul et al. ,2019), that autonomous schools have better performance (Bloom et al. , 2015a,b) and that reducing discretion in environmental inspections increases costs without reducing pollution (Duflo et al. ,2018). To benchmark the effects we compare the savings from our treatments to the cost of public 
goods. Our point estimates suggest that the savings from the autonomy treatment from the relatively small group of offices in our experiment are sufficient to fund the operation of five schools or to add 75 hospital beds. This is twice the savings from the combined treatment and six times the savings from the incentive treatment. Despite the modest savings, the rate of return from the incentives treatment is $45 \%$ since the small per-purchase savings are applied to a large base of expenditure.

Guided by the model we allow the effects to vary with the monitor's type, which we measure with the share of transactions approved at the very end of the fiscal year (Liebman \& Mahoney, 2017). This captures both inefficiency, ie. a slow monitor, and corruption, i.e. a monitor who holds officers up until their budget lapses. We find that performance pay reduces prices by $6 \%$ when the monitor approves transactions quickly over the year while the effect goes to zero when the monitor holds up more than $48 \%$ of transactions until the end of the fiscal year. The effect of autonomy has the opposite pattern: it is zero when the monitor is "good" and it reduces prices up to $20 \%$ when the monitor is "bad".

Time use data reveal that the officers' response to treatment follows a similar pattern: all treated officers devote more time to procurement but those in the incentive group only do so when the monitor is "good" while those in the autonomy group put in extra time when the monitor is "bad". The experimental design also allows us to measure the impact of officers on procurement outcomes: using treatment assignment as an instrument for time devoted to procurement we find that this reduces prices. A back of the envelope calculation indicates that these changes explain $72 \%$ of the effect of incentives and $62 \%$ of the effect of autonomy. In addition, we find that shifting autonomy from "bad" monitors to officers reduces delays and the likelihood that the monitor waits until the very end of the year to approve a purchase.

Taken together the results indicate that the two policy instruments are effective under different circumstances: giving autonomy to the agent is desirable when it means taking it away from an extractive monitor while incentives are ineffective in this case because the agent has limited control over prices, and vice versa. In line with this, the effect of the combined treatment always falls between the other two.

Our findings point to the importance of understanding the drivers of bureaucrats' behavior when seeking to improve performance in the public sector. The findings echo the cross-country patterns documented in Bosio et al. (2020) who show that laws that constrain procurement outcomes are effective in most low income countries but harmful in richer countries. Policies based on the assumption that most bureaucrats are corrupt are likely to backfire when this is not in fact the case, for instance by distorting incentives 
to undertake socially optimal actions for fear of reputational damage (Leaver, 2009) or of being punished for breaking the rules (Shi, 2008). The results also speak to recent studies that use observational variation to show how anti-corruption measures such as audits are ineffective or even detrimental once the response of private sector agents is taken into account (Yang, 2008; Gerardino et al. , 2017; Lichand \& Fernandes, 2019). Our paper also contributes to the debate on the optimal amount of discretion in procurement (Szucs, 2017; Coviello et al. , 2018).

The remainder of the paper proceeds as follows. In section 2 we present the empirical context for our experiment, and section 3 describes the experimental design. Section 4 develops the conceptual framework we use to guide our empirical analysis. Section 5 presents our results, and our conclusions are in section 7.

\section{Context and Data}

\subsection{Procurement in Punjab}

Our study takes place in Punjab, Pakistan. The province of Punjab is home to 110 million people and is divided into 36 administrative districts. Our study took place in 26, covering $80 \%$ of the population and the largest districts. ${ }^{2}$ Each government office has one employee who is designated as the Procurement Officer (PO). He or she wields the legal authority to conduct small and medium sized procurement purchases. ${ }^{3}$ Offices are allocated budgets under a range of accounting headers (salary, repairs, utilities, etc.)—including procurement-and are not permitted to move budget across categories with very limited exceptions. Before making payments to vendors, the POs are required to submit their purchases for pre-audit approval by an independent agency of the federal government known as the Accountant General's office (AG). The AG has offices in each of the districts of the province, monitoring the purchase of offices in that district.

A typical procurement process for the purchase of a generic item like the ones we study proceeds in five steps, as summarized in panel A of figure 1. First, an employee of the office makes a request for the purchase of an item (for example, a teacher might request the purchase of pens for the classroom). Second, the PO approves the purchase and surveys the market for vendors who can supply the required item and solicits quotes for the item. Once the PO has received enough quotes for the item, he/she chooses which vendor to

\footnotetext{
${ }^{2}$ These districts were chosen on the basis of logistical feasibility, being geographically contiguous and ruling out the most remote districts. Appendix figure A.5 shows the location of the offices.

${ }^{3}$ The title of this position is known as the "Drawing and Disbursement Officer" of the office.
} 
allocate the contract to. ${ }^{4}$ Third, the vendor delivers the items to the public body and the $\mathrm{PO}$ verifies receipt of the items. Fourth, the PO prepares the necessary documentation of the purchase and presents it to the AG office. Fifth, the AG reviews the paperwork. If the AG is satisfied with the documentation, he/she sanctions the payment and gives the PO a check made out to the vendor. If the AG is not satisfied, he/she can demand more thorough documentation that the purchase was made according to the rules. This ability to delay approvals is the key source of the AG's power over POs.

\subsection{Measuring Bureaucratic Performance}

The government of Punjab considers that the primary purpose of public procurement is to ensure that "...the object of procurement brings value for money to the procuring agency..." (Punjab Procurement Regulatory Authority, 2014). In line with this, we developed a measure of bureaucratic performance that seeks to measure value for money in the form of the item-variety-adjusted unit prices paid for the items being purchased by POs. The backbone of our approach is to collect detailed data on the attributes of the items being purchased with which to measure the precise variety of the items being purchased.

We proceed in two steps. First, we restrict attention to homogeneous goods for which detailed enough data are able to adequately measure the variety of the item being purchased (similar to the approach taken in Bandiera et al. 2009 and Best et al. 2019). Second, we partnered with the Punjab IT Board (PITB) to build an e-governance platform-the Punjab Online Procurement System (POPS). This web-based platform allows offices to enter detailed data on the attributes of the items they are purchasing. We trained over a thousand civil servants in the use of POPS and the departments we worked with required the offices in our experimental sample (as described below) to enter details of their purchases of generic goods into the POPS system. To ensure the accuracy of the data we randomly visited offices to physically verify the attributes entered into POPS and collect any missing attributes required. ${ }^{6}$

After running the POPS platform for the two years of the project and cleaning the data entered by the officers, our analysis dataset consists of the 25 most frequently purchased goods: a total of 21,503 purchases of 25 homogeneous goods. Dropping the top and bot-

\footnotetext{
${ }^{4}$ For very small purchases, only one quote is needed. For most of the purchases we consider, POs must obtain three quotes and then choose the cheapest one.

${ }^{5}$ To do this, we chose accounting codes from the government's chart of accounts that we expected to contain mostly or exclusively generic goods. The list of accounting codes is contained in appendix table A.1.

${ }^{6}$ Somewhat surprisingly, our random audits did not uncover any instances of misreporting of goods' attributes.
} 
tom $1 \%$ of unit prices results in a dataset of 21,183 observations. ${ }^{7}$ Figure 2 shows summary statistics of the purchases in the POPS dataset. The 25 items are remarkably homogeneous goods such as printing paper and other stationery items, cleaning products, and other office products. While each individual purchase is small, these homogeneous items form a significant part of the procurement budgets of our offices. As table 1 shows, generic goods are $53 \%$ of the typical office's budget.

Despite the homogeneous nature of the items being purchased, prices are quite different. Figure 2 shows this variation for each product, and figure A.1 shows the joint distribution of prices paid and the standardized price of each purchase (a measure of the item's variety that can be interpreted as the predicted expected price if the item had been purchased in the control group as described in section 5.1). Both figures display variation in prices, even for items of the same variety, suggesting different bureaucrats are paying different amounts for identical products. This degree of price dispersion for very homogeneous goods is not uncommon in the public sector, similar levels have been documented in the United Kingdom (National Audit Office, 2006), Italy (Bandiera et al. , 2009) and Russia (Best et al. , 2019).

To elicit procurement officers' perceptions of their incentives to perform procurement well, we asked officers what types of errors would be detrimental to their career progress. Since civil servants in Punjab are not typically paid based on their performance, the main incentive they face to perform well is that their performance is considered when decisions are made on their postings and to progress up the civil service hierarchy. Specifically, two of the options we asked officers about are how detrimental overpaying in their procurement purchases would be, and how detrimental failing to complete the required documentation would be. Appendix figure A.2 shows the results. While the officers respond that both transgressions would be detrimental for their careers, they report that having incomplete documentation is a severe impediment much more often than overpaying. This stands in clear contrast to the government's stated goal when conducting public procurement-to achieve value for money (Punjab Procurement Regulatory Authority, 2014), and motivates our two treatments. ${ }^{8}$

\footnotetext{
${ }^{7}$ The majority of these outliers are the result of officers adding or omitting zeros in the number of units purchased.

${ }^{8}$ Paragraph 4 of Punjab's procurement rules (Punjab Procurement Regulatory Authority, 2014) states "Principles of procurements.- A procuring agency, while making any procurement, shall ensure that the procurement is made in a fair and transparent manner, the object of procurement brings value for money to the procuring agency and the procurement process is efficient and economical."
} 


\section{Experimental Design}

\subsection{Design of Experimental Treatments ${ }^{9}$}

In the status quo, the authority to approve purchases and pay vendors lies with the Accountant General (AG). Our autonomy treatment shifted decision-making power over which documents can be required in order to issue a payment to a vendor away from the AG. To achieve this, we conducted focus groups with Procurement Officers (POs) and their staff to elicit their demand for policy changes to empower them to achieve greater value for money. We then brought their proposals to the government and reached an agreement on which policy changes to implement. ${ }^{10}$

Our treatment altered the procurement process to limit the AG's power in two ways. First, we offered each PO a cash balance of Rs. 100,000 (USD 1,000), over which they had full authority. That is, they could use this money to make payments to vendors without having to seek pre-audit approval from the AG, thus completely removing the AG's authority over the documentation of this part of the office's spending, as illustrated in the top path in panel B of figure $1 .^{11}$

Second, we created and distributed a checklist of the documents that the AG can lawfully require in order to approve a purchase, even when the payment is not to be made with petty cash, as shown in the bottom path in panel B of figure 1 . The list limits the AG's authority to decide which documents are required for payment by restricting them to the documents in the checklist. The finance department endorsed and sent the checklist to the offices, making it a credible signal of what the requirements were. The AG was also informed by the finance department that these were the requirements it wanted the AG to check during pre audits. ${ }^{12}$

Giving more autonomy to procurement officers can improve outcomes by reducing payment delays, allowing them to buy from a wider range of vendors and generally avoid

\footnotetext{
${ }^{9}$ This experiment was preregistered in the Social Science Registry at https://www.socialscienceregistry.org/trials/610. Its pre-analysis plan and a filled in version of the pre-analysis plan are available there also.

${ }^{10}$ The importance of these policy changes is confirmed in our endline survey. Figure A.3 shows the responses the control group gave when asked to allocate 100 points between a set of potential reasons for the lack of value for money in public procurement. The three most important reasons are that budgets are released late, that POs do not have enough petty cash to make purchases quickly, and that the AG's requirements are not clear.

${ }^{11}$ Petty cash is still subject to all the same legal scrutiny and documentary requirements as ordinary spending during post audit after the conclusion of the financial year. The only difference is that it does not require pre-audit approval by the AG.

${ }^{12}$ To increase the power of these treatments, a third component attempted to improve the frequency and regularity of budget releases. However, as we document in appendix figure A.4, it was not possible to implement this.
} 
mark-ups imposed by the AG. Autonomy, however, also makes it easier for POs to embezzle funds and limits the AG's discretion in identifying and combatting new loopholes POs may attempt to exploit to circumvent procurement rules. Finally, while our treatment is tailored to the institutional context, it is easily adaptable to any situation in which an agent's decision making power is constrained by another agent.

Our incentives treatment aligned POs' incentives with the government's by providing them with financial incentives to improve value for money. Officers' performance was evaluated by a committee established for this purpose. The committee was co-chaired by the President of the Institute of Chartered Accountants Pakistan (ICAP), a well-respected, senior, private-sector monitor, and the director of the Punjab Procurement Regulatory Authority (PPRA). Delegates from each of the line departments, the finance department, and the research team rounded out the committee. Based on common practice in the private sector, the committee was tasked with ranking the procurement officers' performance by applying a wholistic assessment to the officer's performance at achieving the aims of public procurement. To seed the discussions, the research team provided an initial ranking of the procurement officers according to our measure of value added described in section 2.2, though the committee were told they had absolute freedom to alter the ranking.

Based on the committee's ranking, bonuses were paid. The gold group, comprising the top $7.5 \%$ of officers, received two months' salary. The silver group, the next $22.5 \%$ of officers, received one month's salary. The bronze group, the next $45 \%$ of officers, received half of a month's salary. Finally, the remaining $25 \%$ of officers did not receive an honorarium. The committee met twice a year. Based on the interim rankings at the middle of the year, officers received payments of half of the bonus amounts, which were then credited against the bonuses received in the final ranking at the end of the year.

We made several design choices to increase the salience, credibility and feasibility of this treatment that are worth noting. First, we chose a form of incentives that is allowed under the existing rules so that it is both feasible and easily scaleable should the government choose to do so. Second, we chose a prize structure that meant that $75 \%$ of officers received a prize. Third, we chose to have the committee meet twice a year. Together, these meant that many POs would experience receiving a prize, and that the bonuses were salient during the second half of the year when the bulk of procurement expenditure takes place. Moreover, the incentive treatment was in place during the pilot year to build credibility so officers already had experience with the treatment when the second, focal year began. 


\subsection{Experimental Population and Randomization}

The experiment was conducted in collaboration with several agencies of the government of Punjab. The Punjab Procurement Regulatory Authority (PPRA), the Punjab Information Technology Board (PITB), the Accountant General's (AG) office, and the finance department worked with us to design and oversee the treatments. We sampled offices from the four largest front-line departments-Higher Education, Health, Agriculture, and Communication \& Works. Within these departments we sampled from offices with procurement budgets in the 2012-13 fiscal year of at least Rs. 250,000 (USD 2,500).

In June 2014, we randomized 688 offices into the four treatment arms, stratifying by district $\times$ department to ensure balance on geographical determinants of prices and the composition of demand. Offices were told by their departments that they were part of a study to evaluate the impact of policy reforms under consideration for rollout across the province and that their participation was mandatory, including entering data into the POPS system and cooperating with occasional survey team visits. With this backing, 587 offices, or $85 \%$ of the sample, participated in trainings on the POPS system and on the implications of their treatment status for how they conduct procurement.

Table 1 presents summary statistics on a range of variables in the participating offices. The table shows that the participation rate is balanced across the treatment arms, as are the vast majority of office characteristics and budgetary variables available in the finance department's administrative data. We regress each variable on dummies for the three treatments and report the coefficients along with their robust standard errors in parentheses and p-values from a randomization inference test of the null of a zero effect. For each variable we also report the F-statistic on the test that all treatments have no effect with its corresponding $\mathrm{p}$-values using the asymptotic variance, and the randomization inference $\mathrm{p}$-value. Of the 24 variables presented, the hypothesis that all treatments have no effect is rejected for only one variable-the number of accounting entities the office controls, and so we control for this in our estimation of treatment effects. ${ }^{13}$

Participating offices' compliance with the requirement to enter data into the POPS system was also balanced. Figure A.8 estimates office-level measures of POPS compliance and shows that their full distributions are balanced across treatments, while table A.7 shows that the mean compliance rate varies across accounting categories, but even controlling for this, is balanced across treatments. Overall, we conclude that the randomiza-

\footnotetext{
${ }^{13}$ This is likely to have occurred because the office that controls a small number of accounting entities was incorrect in the administrative data used for the randomization. When this occurred, we assigned accounting entities to the treatment received by their actual office. Since offices with more accounting entities have a greater chance of having one incorrectly recorded, this can lead to this imbalance.
} 
tion produced a balanced sample and that compliance was high and balanced across the treatment arms.

Table A.2 summarizes the timeline of the project. The 2014-15 fiscal year was the pilot year for the project. The POs were informed of the project and introduced to POPS. All POs were invited to receive training on the use of POPS and to start entering data into the system. The incentives treatment was in place so that the members of that treatment group would experience receiving the bonuses, but the autonomy treatment was not. ${ }^{14}$ Then, in year 2 (the 2015-16 fiscal year), the autonomy treatment was also rolled out. The experiment ended at the end of June 2016, following which we conducted an endline survey and gathered missing data.

\section{Conceptual Framework}

The literature on the "organization of corruption" (Shleifer \& Vishny, 1993; Guriev, 2004; Banerjee et al. ,2012) studies situations where multiple potentially corrupt agents may be involved in a public deliberation. The ultimate outcome is determined by the motivations of the individual agents as well as the organizational architecture of the deliberation process. The literature studies equilibrium behavior under different architectures and suggests ways to design institutions that are more robust to the risk of corruption.

Inspired by this literature, we consider a highly stylized procurement process where a public body must buy one unit of a good of a given quality. Two agents may be involved in the process: a purchasing officer (the PO) and a monitor (the accountant general, AG). We consider two arrangements: an autonomous PO making decisions on his own (autonomy); and a PO making decisions that are subject to the veto power of an AG (non-autonomy).

Both the PO and the AG can be "aligned" or "misaligned". Aligned agents behave in the interest of the citizens. This might be due to some form of intrinsic motivation, or from differential career concerns. Misaligned agents instead behave sub-optimally either because they are corrupt and they prefer higher prices in exchange for bribes or other favors (active waste), or because they are lazy and their desire to minimize effort results in inefficient processes that lead to higher prices (passive waste).

Our model can be interpreted within the framework developed by Bosio et al. (2020), where a PO faces multiple suppliers, one of whom is an insider. Even though the good is sold with a competitive mechanism, the PO has some latitude in excluding a supplier.

\footnotetext{
${ }^{14}$ Discussions between the research team and the government about the precise nature of the treatment and how to implement it were still ongoing.
} 
A non-aligned supplier may accept a bribe to exclude all suppliers but the insider, thus driving up the auction price. We simplify Bosio et al. (2020) by holding quantity constant and we extend by adding an agent, the AG. The exclusion decision would be made by the PO in the autonomy case or be a function of the individual actions of the PO and the AG in the non-autonomy case. An example of passive waste is a public body who acts so slowly that suppliers demand higher prices because they know they will be paid late. While the present model makes assumptions directly on equilibrium prices, Appendix $\mathrm{C}$ offers a micro-founded version that starts from the utility functions of the PO and the AG. ${ }^{15}$

Under the autonomy arrangement, the price paid depends on whether the PO is aligned (the price is $p_{A}$ ) or misaligned $\left(p_{M}\right)$, with the assumption that $p_{M}>p_{A}$. In the nonautonomy case, the outcome depends on the type of both agents: $p_{A A}$ (both PO and AG are aligned), $p_{A M}$ (aligned PO, misaligned AG), $p_{M A}$ (misaligned PO, aligned AG), and $p_{M M}$ (both misaligned). Agent type has the expected monotonic effect. Better types reduce the purchase price: $p_{A A}<p_{A M}<p_{M M}$, and $p_{A A}<p_{M A}<p_{M M}$. Under both arrangements good POs obtain the best possible price: $p_{A A}=p_{A}=c$, where $c$ is the minimal possible price at which the supplier is willing to sell. ${ }^{16}$

We also make four assumptions about the agency relationship between the AG and PO:

- Good Monitor Effect: $p_{M A}<p_{M}$. A good monitor has a positive discipline effect on a bad agent: an aligned AG makes a misaligned PO behave better than he would if he was not monitored (either because she makes him less corrupt or more efficient).

- Bad Monitor Effect: $p_{A M}>c$. The bad monitor has a detrimental effect on good agents: a misaligned AG increases the price obtained by a good PO. In the active waste case, the negative effect may come from demanding a bribe for authorizing the purchase. In the passive waste case, it comes from slowing down the process, thus leading the supplier to demand a higher price.

- Competing Bandits Effect: $p_{M M} \geq p_{M}$ : This is the corruption effect identified by Shleifer \& Vishny (1993). The amount of corruption is increasing in the number of corrupt agents with veto power, the rationale being similar to the industrial organization effect that double marginalization has on price in the sale of complementary

\footnotetext{
${ }^{15}$ The micro-foundation in Appendix $\mathrm{C}$ also goes beyond the binary types used here. Both the PO and the AG have continuous types and therefore the model will give rise to a continuum of equilibrium prices.

${ }^{16}$ One could also assume that imposing an aligned AG on top of an aligned PO would add some red tape anyway, therefore leading to $p_{A A}>p_{A}$. The key results are unchanged if such effect is smaller than the effect of imposing a misaligned AG on top of an aligned PO - a natural assumption.
} 
products. In the present setting, adding a misaligned AG on top of a misaligned PO will lead to higher prices.

- Complementarity Between Types: $p_{M M}-p_{A M} \leq p_{M A}-c$. There is some complementarity between the types of the two agents. The price reduction due to having an aligned $\mathrm{PO}$ rather than a misaligned $\mathrm{PO}$ is smaller if the AG is misaligned. This is because a misaligned AG is more likely to appropriate any benefit created by an aligned PO. For instance, if the PO decreases his bribe demand, a misaligned AG will increase hers. ${ }^{17}$

The two experimental treatments can be interpreted within the model. The incentive treatment provides POs with better alignment: we assume that all POs behave like aligned POs. The effect of the autonomy treatment is to take the AG out of the picture thus moving from the non-autonomy arrangement to the autonomy arrangement. The combined treatment performs both operations at the same time. Obviously, one could assume that the treatments have a more nuanced effect. For instance, the incentive treatment could affect only a percentage of POs. Or the autonomy effect could make the PO independent with a certain probability. The results would be qualitatively similar.

Let the share of POs that are misaligned be $\theta_{P O}$ and the share of AGs that are misaligned be $\theta_{A G}$. We obtain the following average prices

\begin{tabular}{c|c|c|}
\multicolumn{1}{c}{ No Incentive } & \multicolumn{2}{c}{ Incentive } \\
\cline { 2 - 3 } No Autonomy & $\begin{array}{l}\theta_{P O} \theta_{A G} p_{M M}+\theta_{P O}\left(1-\theta_{A G}\right) p_{M A} \\
+\left(1-\theta_{P O}\right) \theta_{A G} p_{A M}+\left(1-\theta_{P O}\right)\left(1-\theta_{A G}\right) c\end{array}$ & $\theta_{A G} p_{A M}+\left(1-\theta_{A G}\right) c$ \\
\cline { 2 - 3 } Autonomy & $\theta_{P O} p_{M}+\left(1-\theta_{P O}\right) c$ & $c$ \\
\cline { 2 - 3 } & &
\end{tabular}

The effect of the autonomy treatment is

$$
\Delta_{A}=\theta_{P O} \theta_{A G}\left(p_{M}-p_{M M}\right)+\left(1-\theta_{P O}\right) \theta_{A G}\left(c-p_{A M}\right)+\theta_{P O}\left(1-\theta_{A G}\right)\left(p_{M}-p_{M A}\right)
$$

and it can be decomposed into three parts. The first term captures the bandit competition effect which arises in a share $\theta_{P O} \theta_{A G}$ of monitor-officer pairs. Autonomy eliminates this and reduces prices $\left(p_{M}-p_{M M}<0\right)$. The second term captures the effect of having a bad monitor control a good officer. This occurs in a share $\left(1-\theta_{P O}\right) \theta_{A G}$ of pairs and eliminating it reduces prices as $c-p_{A M}<0$. The third term captures the effect of having a good

\footnotetext{
${ }^{17}$ For our comparative statics results, we require the good- and bad-monitor effects to hold as strict inequalities. Instead the conditions for the competing bandit effect and the complementarity between agent types can also be equalities.
} 
monitor control a bad officer. This occurs in a share $\left(1-\theta_{A G}\right) \theta_{P O}$ of pairs and eliminating it increases prices as $p_{M}-p_{M A}>0$.

The overall effect can be positive or negative and it depends on the relative ratio of aligned $\mathrm{AG}^{\prime} \mathrm{s}$ and aligned $\mathrm{PO}$ 's

Proposition 1. The autonomy treatment increases the expected price paid if and only if the $A G$ is relatively more aligned than the $P O$. The condition is

$$
\theta_{A G}<\bar{\theta}_{A G}\left(\theta_{P O}\right)
$$

where $\bar{\theta}_{A G}\left(\theta_{P O}\right)>0$ is the solution to:

$$
\frac{\theta_{A G}}{1-\theta_{A G}}=\frac{\theta_{P O}\left(p_{M}-p_{M A}\right)}{-\left(\theta_{P O}\left(p_{M}-p_{M M}\right)+\left(1-\theta_{P O}\right)\left(c-p_{A M}\right)\right)} .
$$

Proposition 1 captures a basic intuition: having a monitoring system is a good idea if and only if the monitor is on average "better" than the monitored. An aligned monitor keeps prices down through the discipline mechanism that she imposes on misaligned PO's (the good monitor effect). A misaligned monitor inflates prices through the introduction of a bribe if the PO was aligned and did not demand one (the bad monitor effect) and double marginalization if the PO was misaligned and was already asking for a bribe (the competing bandit effect). The net effect is found by comparing the probability that the $\mathrm{AG}$ is aligned with the probability that the $\mathrm{PO}$ is aligned. ${ }^{18}$

Note that if the AG is as aligned as the PO, autonomy is always a good idea:

Corollary 1. If the $A G$ is as aligned as the $P O\left(\theta_{A G}=\theta_{P O}\right)$, the autonomy treatment strictly decreases the expected price paid.

The corollary is due to the competing bandits effect. Imposing a monitor of the same quality as the monitored is not going to help and can only hurt through double marginalization. In order for monitoring to reduce prices it must be that the AG is discretely more aligned than the PO.

Turning to the second treatment, incentivizing the PO can never hurt as it will always motivate him to reduce the price. However, the effect is dampened if the PO is monitored by a misaligned AG.

Proposition 2. The incentive treatment always decreases the average price paid but the size of the effect is smaller if the AG is more likely to be misaligned and goes to zero if a misaligned AG has full control on price $\left(p_{M M}=p_{A M}\right)$.

\footnotetext{
${ }^{18}$ If the bandit competition effect is absent and the the bad monitor effect is relatively low, then $\bar{\alpha}(\pi)<1$.
} 
The three theoretical results can be visualized in Figure 3. The plot depicts the effect of the two treatments as a function of the types of the two agents. The plot is drawn for values of the parameters that satisfy the four assumptions above. ${ }^{19}$ A treatment is "beneficial" if the expected price change is a reduction of at least $5 \%$ of the minimal price $c$. Conversely, a treatment is "detrimental" it if induces a price increase of at least $5 \%$. A treatment has a "negligible effect" if the average price change is between $-5 \%$ and $+5 \%$. Proposition 1 means there are parameter values where autonomy is beneficial and where autonomy is detrimental - and an area in between where its effect is negligible. The Corollary means that along the $45^{\circ}$ line where the two agents have the same type, autonomy cannot be detrimental: if both agents are honest, the treatment does not do much; if both agents are sufficiently dishonest, the treatment is beneficial. Proposition 2 implies that incentive can be beneficial - if the AG is sufficiently honest - or have a negligible effect.

If the two treatments are combined, the effect is determined by the individual effects but there may be synergies. One can show that the price reduction of the combined treatment is at least as large as the price reduction of each individual treatment (See Proposition 3 in Appendix B for a formal statement). The combination of the two treatments must be as good as the better of the two individual treatments because the incentive treatment never hurts when the PO is on his own and, if it helps, it helps at least as much as it would when the AG is present given that the AG is not treated. There may be some strict complementarity if both agents are misaligned, as the incentive treatment becomes more effective once any price reduction generated by the PO cannot be undone by the AG.

\section{Procurement Performance}

With the conceptual framework of section 4 to guide the analysis, this section analyzes the overall impacts of the experiment on bureaucratic performance. The main task of a procurement officer is to receive requests for goods from his/her colleagues and purchase them at a good price. Therefore a priori we don't expect other aspects of procurement performance to be affected by the treatments since the demand for the good is coming from a different officer than the person in charge of procurement. Nevertheless we investigate the impact of the treatments on a range of procurement performance outcomes.

\footnotetext{
${ }^{19}$ We assume that $p_{A}=p_{A A}=c=100, p_{M M}=138, p_{A M}=135, p_{M A}=113, p_{M}=123$.
} 


\subsection{Measuring Good Varieties}

To be able to isolate the effects of the treatments on the prices procurement officers pay, we need to be able to compare purchases of exactly the same item. Otherwise, we risk conflating differences in the precise variety of the goods being purchased with the prices paid for them. Moreover, the treatments may have affected the varieties of goods POs purchase and these are treatment effects we are interested in in their own right.

The goods in our sample are chosen precisely because they are extremely homogeneous. Nevertheless, there may still be some differentiation across items and so we use four measures of the variety of the goods being purchased. First, we use the full set of attributes collected in POPS for each good. This measure has the advantage of being very detailed, but comes at the cost of being high-dimensional. Our three other measures reduce the dimensionality of the variety of controls. To construct our second and third measures, we run hedonic regressions using data from the control group to attach prices to each of the goods' attributes. We run regressions of the form

$$
p_{\text {igto }}=\mathbf{X}_{\text {igto }} \lambda_{g}+\rho_{g} q_{i g t o}+\gamma_{g}+\varepsilon_{\text {igto }}
$$

where $p_{i g t o}$ is the log unit price paid in purchase $i$ of good $g$ at time $t$ by office $o, q_{\text {igto }}$ is the quantity purchased, $\gamma_{g}$ are good fixed effects, and $\mathbf{X}_{i g t o}$ are the attributes of good $g$.

Our second, "scalar" measure of good variety uses the estimated prices for the attributes $\hat{\lambda}_{g}$ to construct a scalar measure $v_{\text {igto }}=\sum_{j \in A(g)} \hat{\lambda}_{j} X_{j}$ where $A(g)$ is the set of attributes of item $g . v_{\text {igto }}$ can therefore be interpreted as the expected price paid for a good with these attributes if purchased by the control group. Our third, "coarse" measure studies the estimated $\hat{\lambda}_{g} \mathrm{~s}$ for each item and partitions purchases into high and low price varieties based on the $\hat{\lambda}_{g}$ s that are strong predictors of prices in the control group. Finally, our "machine learning" measure develops a variant of a random forest algorithm to allow for non-linearities and interactions between attributes that the hedonic regression (1) rules out. Appendix D provides further details.

\subsection{Identification}

To estimate the treatment effects on bureaucratic performance we estimate equations of the form

$$
y_{i g t o}=\alpha+\sum_{k=1}^{3} \eta_{k} \text { Treatment }_{o}^{k}+\mathbf{X}_{i g t o} \beta+\rho_{g} q_{i g t o}+\delta_{s}+\gamma_{g}+\varepsilon_{i g t o}
$$

where $y_{\text {igto }}$ is the outcome of interest in purchase $i$ of good $g$ at time $t$ by office $o$; $q_{i g t o}$ is 
the log quantity purchased, capturing good-specific bulk discounts; $\delta_{s}$ and $\gamma_{g}$ are stratum and good fixed effects, respectively; and $\mathbf{X}_{\text {igto }}$ are purchase-specific controls. We weight regressions by expenditure shares in the control group so that treatment effects can be interpreted as effects on expenditure, and the residual term $\varepsilon_{i g t o}$ is clustered at the cost centre level. ${ }^{20}$

The random allocation of offices to treatments means that the coefficients $\eta_{k}$ estimate the causal effect of treatment $k$ on unit prices under the assumption of stable unit treatment values (SUTVA) (Rubin, 1980; Imbens \& Rubin, 2015). This might be violated if, for example, the AG extracts more from the offices in the control group because it is more difficult to extract from offices in the autonomy treatment. In practice, this is unlikely to affect our estimates because, as shown in Appendix figure A.6, AG officers have typically fewer than $20 \%$ of their cost centers in any treatment group.

The fact that we observe offices before and after the roll out of autonomy also allows us to test SUTVA directly. To do so we estimate whether price increases between year 1 (before the roll out of the autonomy treatment) and year 2 (after the roll out) are larger when the AG monitoring an office monitors a larger share of offices receiving the autonomy treatment. As shown in Appendix figure A.7, if anything, the point estimate is negative, supporting the SUTVA assumption.

As discussed above, when we are interested in studying prices, we need to ensure that we are comparing purchases of exactly the same varieties of items. If, however, the treatments directly affect the varieties of items being purchased, the $\eta_{k}$ coefficients in equation (2) with price as the outcome estimate a combination of the treatment effects on prices and the composition of purchases. ${ }^{21}$ With this in mind, below we directly estimate treatment effects on the varieties of items being purchased. These effects are interesting in their own

\footnotetext{
${ }^{20}$ Cost centres are accounting entities to which budget is formally assigned. In most cases each office is a cost centre, but in some cases an office is in charge of two or three cost centres. When this happens all cost centres under the same office are allocated to the same treatment.

${ }^{21}$ To see this, consider a simplified version of our setting. Suppose that purchases are associated with potential prices $p(D, V)$ depending on a binary treatment $D \in\{0,1\}$ and binary good variety $V \in\{0,1\}$, and with potential quality levels $V(D)$ depending on treatment. The random assignment in the experiment implies that the potential outcomes are independent of treatment status conditional on the randomization strata $S_{i}:\left\{p_{i}(D, V), V_{i}(D)\right\} \perp D_{i} \mid S_{i}$. We can now see that a comparison of expected prices between treated and control units conditional on item type combines a treatment effect on price with a potential composition effect coming from changes in the set of purchases of high or low type in treatment versus control units

$$
\begin{aligned}
\mathbb{E}[p \mid D=1, V=1]-\mathbb{E}[p \mid D=0, V=1]= & \underbrace{\mathbb{E}[p(1,1) \mid V(1)=1]-\mathbb{E}[p(0,1) \mid V(1)=1]}_{\text {treatment effect on price }} \\
& +\underbrace{\mathbb{E}[p(0,1) \mid V(1)=1]-\mathbb{E}(p(0,1) \mid V(0)=1)}_{\text {composition effect } \neq 0 \text { ? }}
\end{aligned}
$$
}


right and also allow us to gauge the magnitude of the potential composition effect described above. To do this, we estimate equation (2) with our scalar, coarse, and machine learning variety measures as outcomes. ${ }^{22}$

Two additional concerns relating to the varieties of items being purchased may affect our interpretation of treatment effects on prices as effects on the performance of the PO. First, POs may pay low prices but buy inappropriate goods that are ill suited to the needs of the office they are serving. However, as table 2 shows, there are no effects of the treatments on the varieties of items being purchased. Therefore, while the goods purchased may well be badly matched to the needs of the end users in the offices, the degree of mismatch is not affected by the treatments.

Second, changes in PO behavior may cause supply-side responses by government suppliers, in which case changes in equilibrium prices reflect both the effects of changes in demand by POs and changes in supply by vendors. While this is likely in markets for products in which the government is a large buyer (see, for example, Duggan \& Scott Morton, 2006 for evidence that pharmaceutical producers' private-sector prices respond to government procurement), the products in our sample are extremely homogeneous and consumed throughout the economy, so the government's market share is likely to be small. Moreover, our experimental subjects are only part of the total demand for these products from the government.

\subsection{Average Treatment Effects}

We begin by studying the impact of the experiment on the prices and the varieties of goods purchased. Table 2 shows the average treatment effects estimated using equation (2) using data from the second year of the project, in which all treatments were in place. Below each coefficient we report its standard error clustered by office in parentheses and the p-value from randomization inference under the null hypothesis of no treatment effect for any office in square brackets. ${ }^{23}$ Columns 1-3 estimate treatment effects on the scalar, coarse and machine learning measures of good variety, respectively. Columns 4-8 estimate treatment effects on log unit prices paid. Column 4 estimates treatment effects without controlling for the variety of good purchased. In the remaining columns we control for the item's variety using the full set of good attributes (column 5), the scalar (column 6), coarse (column 7) and machine learning (column 8) good variety measures.

Somewhat surprisingly, table 2 shows no evidence that the experiment affected the

\footnotetext{
${ }^{22} \mathrm{~A}$ similar concern applies to the quantity purchased in each order. In appendix table A.3 we show that the experiment did not affect the size of each order.

${ }^{23}$ We thank Alwyn Young (2019) for producing the randcmd package for Stata that greatly facilitates this.
} 
varieties of goods being purchased. Eight of the nine coefficients in columns 1-3 have pvalues above 0.25 , and in all three columns the p-value on the hypothesis that none of the treatments affected good variety in any office is insignificant at $5 \%$. This is likely because offices' demand is relatively inelastic from year to year and because the procurement officer is charged with acquiring a particular good at a good price and has limited discretion over which variety of good is purchased.

Since good varieties are not affected by the treatment, they also don't cause any bias from composition changes when estimating price effects (as discussed in section 5.2). ${ }^{24}$ Therefore, when studying prices, we include controls for the variety of goods being purchased to improve power, but also show that our price results are robust to omitting controls for the good variety being purchased.

Turning to the treatment effects on prices, three key findings emerge from table (2). First, the point estimates of the impacts of the treatments are negative for all three treatments. However, the average impact of the incentives treatment is statistically indistinguishable from zero. This surprising finding for the incentives treatment already hints at how important it is that people who are incentivized have the autonomy to respond to the incentives they are provided, a theme we return to in section 6 .

Second, the autonomy treatment reduces average unit prices paid by $8-9 \%$, indicating that giving bureaucrats greater autonomy leads them to use it in the interests of taxpayers by procuring the goods they purchase at lower prices. Viewed through the lens of the model in section 4, this implies that the accountant general is sufficiently misaligned with the principal relative to the misalignment of the procurement officer $\left(\theta_{A G}>\bar{\theta}_{A G}\left(\theta_{P O}\right)\right)$ that removing the waste caused by complying with the monitoring activities of the accountant general more than offsets the loss of the benefits the accountant general's monitoring provides.

Third, the findings on the impact of the treatments on quality-adjusted prices paid are robust to alternative measures of the variety of good being purchased or not controlling for the goods' varieties. Intuitively, the asymptotic standard errors of the estimates are smaller when using the lower-dimensional measures of good variety as the model has more degrees of freedom. However, the p-values from randomization inference are smallest when using the full vector of good attributes as controls, consistent with the finding

\footnotetext{
${ }^{24}$ As an alternative way of controlling for the composition of purchases, we exploit the data from year 1 of the project to estimate treatment effects of the introduction of autonomy through a difference in differences approach. This allows us to control for office fixed effects so that we exploit only within-office changes, allowing us to hold constant the component of the composition effect $\mathbb{E}[p(0,1) \mid H]$ that comes from officelevel variation in the types of items demanded. Appendix table A.4 shows the results. The table shows again that there are no discernible effects on the varieties of the goods being purchased, and that the treatment effects on prices are, if anything, slightly larger than in table 2.
} 
in Young (2019) that the benefits of using randomization inference are largest when the estimated models are high-dimensional.

We also do not find evidence that the experiment had delayed effects due to procurement officers learning over time that the treatments were effective. In appendix table A.5 we reestimate the effects of the treatments, interacting them with the time at which the purchase was made and the order in which the purchases were made. We find no evidence that the treatments had any dynamic effect on procurement performance. The estimated treatment effects at the beginning of the year are indistinguishable from the overall effects in table 2, and all the interaction terms are indistinguishable from zero at $5 \%$ significance. This also suggests that POs did not try to game the incentive treatment by reducing prices early on to win an interim prize and then recouping their losses later in the year. ${ }^{25}$

The results in table 2 lead us to conclude that the treatments lowered prices paid without affecting the varieties of the items being purchased. We might naturally expect that if the prices at which goods can be procured go down, offices react by increasing demand for goods. On the other hand, since the demand for goods is coming from end users, while the procurement officer simply fulfills their orders, we might not expect these lower prices to pass through to end users' demand.

To investigate the impacts of the treatments on the quantities purchased and expenditure, we value each purchase using the counterfactual prices we estimate each purchase would have been made at had it been made by an office in the control group-the scalar variety measure. That is, for each purchase, the counterfactual expenditure is $e_{\text {igto }}=\exp \left(v_{\text {igto }}+q_{\text {igto }}\right)$ where $v_{\text {igto }}$ is the scalar good variety measure, and $q_{\text {igto }}$ is the log number of units purchased. We then aggregate the data to the good-month-office level and estimate good-specific treatment effects by multivariate regression with the following specification for each item

$$
e_{g t o}=\sum_{k=1}^{3} \eta_{k g} \operatorname{Treatment}_{o}^{k}+\gamma_{s}+\xi_{t}+\varepsilon_{g t o}
$$

where $e_{g t o}$ is the quantity purchased of good $g$ in month $t$ by office $o$; the $\eta_{k g}$ are goodspecific treatment effects; $\gamma_{s}$ and $\xi_{t}$ are stratum and month fixed effects respectively; and $\varepsilon_{g t o}$ are residuals clustered by office. Table 3 shows the results. For each good, we display

\footnotetext{
${ }^{25}$ While we do not find evidence of experience effects, we $d o$, however, find that the experiment had larger effects on offices for whom generic goods form a larger share of their annual budget, as shown in table A.6. These are offices where purchasing generics is a larger part of the job of the procurement officer and so the treatments have a bigger impact as one would expect.
} 
the estimated $\eta_{k g}$ coefficients and their standard errors clustered by office, as well as the F-statistic for the hypothesis that all three $\eta_{k g} \mathrm{~s}$ are equal to zero and its p-value in square brackets. We also display F-statistics for the hypothesis that each treatment has zero effect on any item, and the F-statistic on the hypothesis that none of the treatments affect any of the items.

Of the 75 estimated $\eta_{k g}$ treatment effects, only two are statistically significant at the $5 \%$ level, consistent with what would be expected purely by chance, and for all but three items, we fail to reject the hypothesis that all three treatments have no effect. Similarly, we cannot reject the hypotheses that each treatment affects none of the items or the hypothesis that no treatment affects any item. As a result, we conclude that there is no evidence that any of the treatments affected the composition of offices' expenditure or the overall amount they purchase. Of course, this inelastic demand could be because end users truly have inelastic demand (for example due to capacity constraints) or because of agency issues within the office whereby price reductions achieved by the procurement officer are not passed through to end users, however distinguishing between these two remains an open question.

A final margin along which procurement officers might respond is by changing the timing of their procurement. If there is predictable seasonality in prices, the incentives treatment might cause procurement officers to shift purchases into lower-price times of the year. If monitoring by the AG leads to delays in procurement, we might expect the autonomy treatment to permit procurement officers to make purchases more quickly. On the other hand, table 3 suggests offices' demand is inelastic with respect to price, and so if the timing of demand is also inelastic (e.g. goods are required to coincide with the start of the school year) then we might not expect our experiment to affect the timing of procurement.

Figure 4 shows estimates of treatment effects on the timing of deliveries and expenditure. The estimates are from seemingly unrelated regressions of the form

$$
1\left\{\text { Month }_{i}=m\right\}=\alpha+\beta_{A} \text { Autonomy }_{i}+\beta_{I} \text { Incentives }_{i}+\beta_{B} \text { Both }_{i}+\gamma_{g}+\gamma_{s}+\varepsilon_{i}
$$

where $\gamma_{g}$ are good fixed effects, $\gamma_{s}$ are randomization strata fixed effects, and $\varepsilon_{i}$ are residuals clustered by office. The figures show the $95 \%$ confidence intervals of the estimated $\beta_{A}, \beta_{I}$ and $\beta_{B}$ with $\mathrm{p}$-values of $\chi^{2}$ tests of the hypothesis that each treatment's effect is 0 in all months, and the hypothesis that all treatments have no effect in all months. The $95 \%$ confidence intervals include zero for all months and treatments except the autonomy treatment in December. Moreover, we are unable to reject the hypotheses that each treat- 
ment has zero effect in all months or the hypothesis that none of the treatments affect the probability of delivery in any month.

Overall, we conclude that on average, providing procurement officers with additional autonomy led to reduced prices without having an effect on the variety of goods purchased, the amount or composition of goods purchased, or the timing of procurement expenditure. We also do not see evidence for strong effects of the incentives treatment on any outcome.

To benchmark these findings, figure 5 shows a cost benefit evaluation of the implied savings. Savings are calculated as $\frac{-\eta_{k}}{1+\eta_{k}} \sum_{o}$ Expenditure $_{o} \times$ Treatment $_{o}^{k}$ where $\eta_{k}$ are the estimated treatment effects in table 2 and Expenditure ${ }_{o}$ is the total spending by office $o$ on generic goods (standard errors are calculated by the delta method). The solid lines denote savings net of the cost of the incentives treatment, while dashed lines are gross savings.

The figure reinforces our findings. The incentives treatment led to modest savings, while the autonomy and combined treatments led to large savings. The point estimate of the savings from the autonomy treatment is larger than the upper bound of the $95 \%$ confidence interval on the net savings from the incentives treatment. For comparison, the figure also shows the cost of operating 150 hospital beds, and the cost of operating 10 schools. Our point estimates suggest that the savings from the autonomy treatment from the relatively small group of offices in our experiment are sufficient to fund the operation of an additional 5 schools or to add 75 hospital beds.

For the incentives and combined treatments, the figure also shows the implied rates of return on the performance pay bonus payments. Despite the modest savings from the incentives treatment, these calculations imply a $45 \%$ rate of return on the incentives treatment since the small per-purchase savings are applied to a large base of expenditure. This rate of return is comparable to what Khan et al. (2016) find for performance payments to property tax inspectors in the same context.

Our findings are consistent with what our model in section 4 predicts will happen when the average monitor is relatively misaligned (high $\theta_{A G}$ ). In the next section we explore other implications of the model empirically to understand the effects of the experiment better and their implications for the design of monitoring of public officials more broadly. 


\section{Mechanisms}

\subsection{Monitor Alignment}

Our conceptual framework in section 4 makes clear that shifting authority to the agent lowers prices only when the incentives of the agents are better aligned than those of the monitor. It thus predicts that we should expect to see heterogeneity in the treatment effects according to the alignment of the accountant general $\theta_{A G}$. In particular, the model predicts that the beneficial effects of the autonomy treatment should be concentrated among POs monitored by a relatively misaligned AG (high $\theta_{A G}$ ) while the effects of the incentives treatment should be seen when the AG is well aligned (low $\theta_{A G}$ ). In this section we estimate heterogeneous treatment effects using a proxy for the alignment of the accountant general. ${ }^{26}$

Each district has its own AG office and so we construct a proxy for each district AG's misalignment that combines two elements. First, we note that the main power of the accountant general is to delay payments and require additional paperwork. Second, in Punjab, as is common around the world, government offices' budgets lapse at the end of the fiscal year if they remain unspent. As documented in Liebman \& Mahoney (2017) in the US context, lapsing budgets lead to a rush to spend at the end of the year. Combined with the first element, we expect this end of year rush to be stronger in districts where the accountant general delays payments more. Our proxy for the misalignment of the accountant general monitoring an office $\hat{\theta}_{A G, o}$ is therefore the fraction of purchases in the district in year 1 that were approved in the last month of the fiscal year. ${ }^{27}$

We augment equation (2) to include interactions with our proxy $\hat{\theta}_{A G, o}$ semi-parametrically using the approach of Robinson (1988) as follows

$p_{i g t o}=\beta v_{i g t o}+\rho_{g} q_{i g t o}+\delta_{s}$ Department $_{o} \times$ District $_{o}+\gamma_{g}+f\left(\hat{\theta}_{A G, o}\right)+\sum_{k=1}^{3}$ Treatment $_{o}^{k} \times t_{k}\left(\hat{\theta}_{A G, o}\right)+\varepsilon_{i g t o}$

where terms are as previously defined, $f(\cdot)$ is a non-parametric function of AG misalign-

\footnotetext{
${ }^{26}$ In our pre-analysis plan we did not pre-specify that we would study heterogeneity by the accountant general's type. As the experiment rolled out and we discussed its impacts with our study participants we came to realize the importance of the type of the accountant general in determining how the treatments, particularly the autonomy treatment, affected the way procurement officers were able to change the way they carried out procurement.

${ }^{27}$ Appendix figure A.10 shows that the variation in this measure is not driven by variation across districts in the rate at which POs submit bills at the end of the year. Even conditional on the share of bill submitted at the end of the year, there is significant variation in the share of bills approved at the end of the year. We measure the fraction of purchases approved in June in our POPS data. However, the results are robust to measuring this in the finance department's administrative data instead.
} 
ment, and $t_{k}(\cdot)$ are non-parametric treatment effect functions. ${ }^{28}$ Figure 6 shows the results. Three key findings emerge consistent with the predictions of the model. First, the incentives treatment does reduce prices when the monitor is relatively more aligned (low $\left.\hat{\theta}_{A G, o}\right)$, and the treatment effect of incentives shrinks to zero as monitors get less aligned. The treatment effect reaches zero when the June share is 0.48 . Second, the autonomy treatment reduces prices more strongly when the monitor is relatively misaligned, with the treatment effect shrinking to zero when the June share drops below 0.22 . The top of the figure shows the coefficients, standard errors, and p-values from difference-in-differences regressions using these thresholds to classify good and bad AG's, and we use these thresholds in our analysis going forward. ${ }^{29}$ Third, the broad range of AG misalignment over which the autonomy treatment is effective is suggestive that the competing bandits effect highlighted in corollary 1 is at play. We expand upon this below in section 6.2. Overall, the results are remarkably consistent with the predictions of the model, and suggest that the average effects of the treatments are more consistent with the average AG being relatively misaligned. ${ }^{30}$

${ }^{28}$ To implement this we follow Robinson's (1988) approach. Rewriting the model as $p_{\text {igto }}=$ $\mathbf{x}_{i g t o} \beta+f\left(\hat{\theta}_{A G, o}\right)+\sum_{k=1}^{3}$ Treatment $_{o}^{k} \times t_{k}\left(\hat{\theta}_{A G, o}\right)+\varepsilon_{i g t o}$ we proceed in four steps. First, we run treatment-group specific non-parametric regressions of $p_{\text {igto }}$ on $\hat{\theta}_{A G, o}$ to form conditional expectations $\mathrm{E}\left[p_{\text {igto }} \mid \hat{\theta}_{A G, o}\right.$, Treatment $\left._{o}^{k}\right] \simeq \hat{m}_{k}(\hat{\theta})$ and linear regressions of the control variables $\mathbf{x}_{\text {igto }}=$ $\alpha+\xi \hat{\theta}_{A G, o}+\sum_{k=1}^{3}\left(\eta_{k}\right.$ Treatment $_{o}^{k}+\zeta_{k}$ Treatment $\left._{o}^{k} \times \hat{\theta}_{A G, o}\right)+\varepsilon_{\text {igto }}$ to form conditional expectations $\mathrm{E}\left[\mathbf{x}_{\text {igto }} \mid \hat{\theta}_{A G, o}\right.$, Treatment $\left._{o}^{k}\right] \simeq \hat{j}(\hat{\theta})$. Second, we regress $p_{\text {igto }}-\hat{m}_{k}(\hat{\theta})=\left[\mathbf{x}_{\text {igto }}-\hat{j}(\hat{\theta})\right] \beta+\varepsilon_{\text {igto }}$. Third, we non-parametrically regress $p_{\text {igto }}-\mathbf{x}_{\text {igto }} \hat{\beta}=r_{k}\left(\hat{\theta}_{A G, o}\right)+\varepsilon_{\text {igto }}$ separately in the control group $(k=0)$ and the three treatment groups. Fourth, we form the estimates $\hat{f}\left(\hat{\theta}_{A G, o}\right)=\hat{r}_{0}\left(\hat{\theta}_{A G, o}\right)$ and $\hat{t}_{k}\left(\hat{\theta}_{A G, o}\right)=$ $\hat{r}_{k}\left(\hat{\theta}_{A G, o}\right)-\hat{r}_{0}\left(\hat{\theta}_{A G, o}\right), k=1, \ldots, 3$.

${ }^{29}$ Appendix figure A.11 and table A.9 use simple linear difference in differences specifications to explore the sharp jumps revealed by the nonparametric analysis and show its robustness to our alternative ways of controlling for item variety. Exploring one treatment at a time, we estimate treatment effect heterogeneity by interacting a dummy for facing a "bad" AG with treatment dummies $p_{\text {igto }}=\alpha+\eta$ Treatment $_{o}+$ $\zeta$ Treatment $_{o} \times$ BadAG $_{o}+\mathbf{X}_{\text {igto }} \beta+\rho_{g} q_{\text {igto }}+\delta_{s}+\gamma_{g}+\varepsilon_{\text {igto }}$ where all terms are as defined above, and we control for the scalar measure of item variety as part of $\mathbf{X}_{\text {igto. }}$. Panel A of figure A.11 studies the autonomy treatment, panel B the incentives treatment, and panel $\mathrm{C}$ the combined treatment. The horizontal axis shows the threshold percentage of approvals in June 2015 above which an AG is considered "bad". The points show the point estimates of $\zeta$ and the bars their 95\% confidence interval using standard errors clustered by office. The gray crosses show the randomization inference $\mathrm{p}$-value for the hypothesis that the effect is zero. Consistent with the non-parametric findings, the p-value falls below 0.05 at a June share of 0.22 in panels A and C, and 0.48 in panel B, so going forward we use these definitions of good/bad AGs.

${ }^{30}$ Table A.9 confirms the robustness of these findings to the four alternative methods of controlling for item variety. Table A.12 shows similar effects, particularly for the autonomy treatment, using an alternative proxy for AG type: the fraction of the control group who gave an autonomy/AG-related answer to the question "These are potential reasons for why DDOs don't achieve good value for money. In your experience how important is each of these?" in the endline survey shown in figure A.3. In particular, they answered "Only a limited number of vendors are willing to wait for delayed payment", "Vendors charge higher prices for delayed 
Figure 7 shows the implied heterogeneity of the cost benefit calculation for the treatments in districts with different levels of misalignment of the AG. The vertical axis measures for each district the total net savings by all districts with a less misaligned accountant general: $\sum_{d: j_{d} \leq x}\left[\left(\frac{-\eta_{k}\left(j_{d}\right)}{1+\eta_{k}\left(j_{d}\right)} \sum_{o \in d}\right.\right.$ Expenditure $_{o d} \times$ Treatment $\left.\left._{o}^{k}\right)-c_{d}\right]$ where $\eta_{k}\left(j_{d}\right)$ are estimated treatment effects of treatment $k$ when monitor misalignment is $j_{d}$ and $c_{d}$ is the ex ante cost of performance pay bonuses to offices in district $d$ (the number of offices in the district at each pay grade times the expected prize for each office). The figure shows large net savings from the incentives treatment, even at low levels of misalignment. By contrast, net savings from the autonomy and combined treatments are negligible in districts with low misalignment; they only accrue at high levels of monitor misalignment.

To better understand how the misalignment of the monitor matters for prices, we analyze the effects of the treatments on the main power that the AG has in the status quo-to delay and hold up approval of purchases. Figure 8 analyzes the impact on overall delays (the time that elapses between a purchase and its approval by the AG). Panel A shows a series of seemingly unrelated distributional regressions of the probability of delay of at least $j$ days in year 2 normalized by the probability of a delay of at least $j$ days in the control group in year 1 on treatment dummies, strata fixed effects $\gamma_{s}$ and good fixed effects $\gamma_{g}$ :

$$
\frac{1\left\{\text { delay }_{\text {igo }} \geq j\right\}}{\mathbb{P}(\text { delay } \geq j \mid \text { Control, Year } 1)}=\alpha+\sum_{k=1}^{3} \eta_{k} \text { Treatment }_{o}^{k}+\gamma_{s}+\gamma_{g}+\varepsilon_{i g o}
$$

The panel also shows the CDF of delays in the control group in year 1 for reference. We clearly see a decrease in very long delays in the autonomy treatment, and very little effect

payment", "AG/DAO requirements are not clear and they do not clear bills without inside connections or payment of speed money" or "DDOs do not have enough petty cash to make purchases quickly". Table A.13 shows robustness to three potential confounds our proxy for AG type may be picking up. Columns 2 \& 3 control additionally for the share of submissions submitted at the end of the fiscal year in case POs submitting transactions for approval late is the real driver of the share of transactions approved late in the year. Columns $4 \& 5$ control for the average delay POs experience, in case the hold-up at the end of the year is driven by general delays at the AG. Columns 6 \& 7 control for a measure of the PO's type in case places with bad AGs are matched with particularly good or bad POs. We estimate PO fixed effects using the year-1 data and the alternative measure is a dummy for the fixed effect being negative (below average). Note that since the incentives treatment was in place in year 1 the coefficients for the incentives and combined groups cannot be interpreted as heterogeneity by PO type. In all cases our estimates of the heterogeneity of the treatment effects by AG type are unaffected. Consistent with our findings on the overall effects in section 5.3, we find no heterogeneity of the treatment effects on the variety of items purchased or on the quantities demanded. Table A.10 shows the results of estimating the linear difference in differences specification with the scalar, coarse or machinelearning measure of item variety as outcomes, and shows no significant heterogeneity in the treatment effects. Table A.11 shows the results of estimating an extended version of equation (4) by multivariate regression. Specifically, for each item, we estimate $e_{\text {gto }}=\sum_{k=1}^{3}\left(\eta_{k} \operatorname{Treatment}_{o}^{k}+\zeta_{k} \operatorname{Treatment}_{o}^{k} \times \hat{\theta}_{A G, o}\right)+$ $\gamma_{s}+\xi_{t}+\varepsilon_{g t o}$. We find no consistent evidence that either the linear or interaction terms imply that the treatments affected the quantity demanded, regardless of the misalignment of the AG. 
in the other treatments. Panel B separates the effect of the autonomy treatment for good (June share $\leq 0.22$ ) and bad (June share $>0.22$ ) AGs, showing that the effect on long, costly delays is driven exclusively by offices facing a more misaligned monitor while POs facing a good AG only see reductions in shorter delays.

Since vendors have to make deliveries before being paid, these delays are costly to both the vendors and to the POs and one would naturally expect vendors to charge POs a markup for the delays. When POs in the autonomy group can pay vendors immediately in cash, the removal of these markups may contribute to the effect of the autonomy treatment on prices. However, note that the removal of these markups cannot fully account for the estimated treatment effect of autonomy. Even assuming that the petty cash allows POs to completely avoid delays of six months would require that vendors charge interest of $242 \%$ to account for the price savings, far above market interest rates. ${ }^{31}$

Nevertheless, this effect on overall delays could be driven by general inefficiency of the AG or by POs dragging their feet in submitting paperwork. We therefore focus on delays that are more clearly suggestive of holdup: purchases that are approved right at the end of the fiscal year. We analyze how the treatments change the probability that items purchased in different months are approved in June (the last month of the fiscal year) by estimating equations of the form

$$
\begin{aligned}
1\left\{\text { Approved in June }_{i g o}\right\}= & \alpha+\sum_{k=1}^{3} \sum_{m=J u l}^{\text {Jun }} \eta_{m k} \mathbf{1}\left\{\text { PurchaseMonth }_{i g o}=m\right\} \times \text { Treatment }_{o}^{k} \\
& +\sum_{m=J u l}^{J u n} \gamma_{m} \mathbf{1}\left\{\text { PurchaseMonth }_{i g o}=m\right\}+\gamma_{g}+\varepsilon_{i g o}
\end{aligned}
$$

Panel A shows the $\eta_{m k}$ coefficients for the autonomy treatment and also the raw distribution of delivery dates of purchases approved in June in the autonomy treatment (in orange) and control (in green) groups. It clearly shows that purchases at the beginning of the year (in July and August in particular) are much less likely to have to wait right until the end of the year to be approved, strongly suggesting that the holdup power of the AG has been decreased. Panel B runs the regression separately for good (June share $\leq 0.22$ ) and bad (June share $>0.22$ ) AGs, and shows that this reduction in holdup for purchases made at the beginning of the year is exclusively driven by the bad AGs. Overall, the re-

\footnotetext{
${ }^{31}$ To see this, note that a PO with a budget $B$ who faces an interest rate $r$ and a delay of $t$ years to pay vendors can spend a pre-markup amount of $S=B(1+r)^{-t}$. If that $\mathrm{PO}$ has the same spending but can make $100 \mathrm{~K}$ worth of spending in cash, then their total spending would be $B\left(1-\eta_{\text {Autonomy }}\right)=$ $(S-100 K)(1+r)^{t}+100 K$. To account for a saving of $\eta_{\text {Autonomy }}=0.085$ when the PO has the average budget of 1 million Rupees and the delay is $t=0.5$ years requires an annual interest rate of $242 \%$.
} 
sults suggest that monitor misalignment is a key driver of the effects of the experimental treatments, and that monitor misalignment affects prices through the ability of the AG to hold up purchases.

\subsection{Procurement Officer Alignment}

Our conceptual framework in section 4 shows the importance of the relative misalignment of the monitor for the impact of our experimental treatments. The model also suggests that the impacts are likely to be heterogeneous by the degree of misalignment $\theta_{P O}$ of the procurement officer. At baseline, we collected one potential proxy for the PO's type-the lab-in-the-field measure of dishonesty studied in Fischbacher \& Föllmi-Heusi (2013) and Hanna \& Wang (2017). However, as shown in appendix figure A.12, the POs' scores are not predictive of prices at baseline, suggesting these scores are not successfully capturing POs' $^{\prime}$ types. $^{32}$ Unsurprisingly, as table A.14 shows, the dice scores also do not predict heterogeneity in the treatment effects. ${ }^{33}$

The lack of heterogeneity by this proxy for Procurement Officer (PO) type does not, however, suggest that the POs in our setting are all well aligned. Viewed through the lens of our model in section 4, our results presented in section 6.1 on the heterogeneity of the treatment effects by AG alignment suggest that the average PO is relatively misaligned. The results in figure 6 reveal three distinct regions. For highly aligned AGs the incentives treatment reduces prices but the autonomy treatment does not. For intermediate values of $\theta_{A G}$ both treatments are effective, and for high values of $\theta_{A G}$ the autonomy treatment reduces prices but the incentives treatment does not. Comparing this to the theoretical predictions in propositions 1 and 2 and corollary 1 summarized in figure 3 , the empirical results are consistent with what the model predicts when the average PO is relatively misaligned (high $\theta_{P O}$ ), but not what we would expect if the POs are well aligned (low $\left.\theta_{P O}\right)$. With misaligned POs, $\mathrm{PO}$ incentives reduce prices under relatively well aligned AGs (2), and due to the competing bandit effect autonomy reduces prices even for intermediate levels of AG alignment by eliminating double marginalization (corollary 1).

There is also direct evidence that POs are relatively misaligned. Our endline survey asked POs about a range of potential mechanisms, focusing on how much time POs and their staff spend on procurement and how they allocate their time across different procurement tasks. Figure 10 shows that all three treatments increase the amount of time POs

\footnotetext{
${ }^{32}$ Despite there being significant variation across POs in their dice scores (as shown in panel A of figure A.12)

${ }^{33}$ Our pre-analysis plan also listed a range of officer-level (Tenure, pay scale, education) and office-level (distance from the AG, distance from the department HQ) traits that might predict heterogeneity. As detailed in the filled-in pre-analysis plan, these also did not predict heterogeneity in the treatment effects.
} 
report spending on procurement. POs in the autonomy treatment increase the time they spend on procurement by $16 \%$. Similarly, POs in the incentives treatment increase the time they spend on procurement by $14 \%$, and those in the combined treatment by $20 \% .{ }^{34}$ If POs were already well aligned, we would not expect them to increase their time allocation in response to the treatments. Moreover, appendix figure A.13 shows how the treatments change the way that POs allocate time across different tasks. Panel A shows that POs in the autonomy and combined treatments spend less time instructing their staff and negotiating approvals with the AG, consistent with the autonomy treatment restricting the AG's holdup power over the POs. Panel B shows that POs in the autonomy treatment are less interested in choosing vendors who are able to provide them credit or help them negotiate approvals at the AG. POs thus spend less time themselves on dealing with the AG and are able to focus on vendors who provide better goods rather than vendors who are able to help POs navigate the AG's office.

Changes in time use by POs are also able to explain the majority of the effects of the treatments on prices. Table 4 explores the relationship between prices paid and time spent on procurement, using the experimental allocations as instruments to isolate exogenous variation in time use. We study one treatment at a time. Panel A studies the autonomy treatment, panel B the incentives treatment, and panel $C$ the combined treatment. Columns 1-3 study overall effects. In column 1 we see that OLS estimates do not reject a null effect of time spent on prices. However, the IV estimates in column 2 do reveal an effect in the autonomy and incentives groups-an experimentally-induced additional percentage point of time spent on procurement reduces prices by $0.7 \%$.

Columns 4-6 study offices monitored by a relatively well aligned Accountant General (AG); and columns 7-9 study offices monitored by misaligned AGs. ${ }^{35}$ We see that time use only increases significantly in the autonomy group when the PO faces a bad AG (columns 7-9), consistent with the evidence that the autonomy treatment only reduces prices when the AG is bad. The IV estimate of the effect of time on prices, -0.012 combined with the first-stage estimate of the increase in time spent, 6.98 , suggests that increases in time spent account for a price decrease of $6.98 \times 0.012=0.084 \log$ points, $62 \%$ of the price decrease of $0.14 \mathrm{log}$ points when the AG is bad estimated in table A.9. Similarly, when the AG is good the estimates in columns 4-6 suggest that increases in time spent in the incentives treatment account for a price decrease of $8.3 \times 0.010=0.083 \log$ points, $72 \%$ of the $0.12 \mathrm{log}$ point price decrease estimated in table A.9. Overall, the experimental treatments induced POs to devote more effort to procurement, reducing prices whenever POs faced a mon-

\footnotetext{
${ }^{34}$ We cannot reject the hypothesis that the three increases are the same $(p=0.70)$.

${ }^{35}$ We use the share of June approvals measure discussed in section 6.1. A good AG has a June share of 0.22 or below in panels $\mathrm{A}$ and $\mathrm{C}$, and 0.48 or below in panel B
} 
itoring environment conducive to improved performance, but not when the monitoring environment prevents POs from improving performance, consistent with the theoretical framework in section 4 .

\section{Conclusion}

Recent advances in the empirical analysis of organizations have improved our understanding of the relationship between principals and agents and how management practices such as performance pay and decentralization shape organizations' performance. Most organizations, however, are more complex than the single-layer theoretical construct we use to analyze them. Control over rules and incentives that regulate agents' behavior resides with other agents at higher levels of the hierarchy rather than with the principal herself, and these agents might also be prone to act in their own interest.

Our experiment shows that the allocation of authority between agents at different levels of the hierarchy shapes the performance of the organization, and that this depends on the relative severity of misalignment of different agents. Similarly, the effect of providing incentives on performance also depends on how authority is allocated between agents. Hence, the two must be designed jointly to ensure compatibility. Shifting authority to frontline agents reduces the prices the bureaucracy pays for its inputs by $9 \%$ on average, and up to $15 \%$ when the monitor is more inefficient or corrupt. The mechanism through which this happens is the reduction of long delays in monitor approvals. This increases taxpayers' welfare at the expense of the monitors' and possibly also sellers' who were charging higher prices for longer waits.

The monitors and the monitored tend to come from the same culture, face the same institutional incentives and be exposed to the same temptations. In these circumstances, adding a monitor with veto power is a bad idea. If a country sees high levels of corruption, it is a natural reaction to call for more monitoring but it can do more harm than good as we now have two bandits instead of one. To do better, we must design more sophisticated institutions that are more robust to misaligned agents. For instance, ex post monitoring is less manipulable as the PO has less incentive to bribe a monitor who cannot veto the

purchase. The monitor can then be financially motivated to impose discipline by being promised a share of aggregate savings.

The results raise several questions for future research. First, if rules are so costly why do most bureaucracies use them? One possibility is that corruption "scandals" are much more damaging to the organization than the, potentially much larger, sum of small markups on a large volume of transactions. Our benchmarking exercise suggests that the 
cost created by corruption scandals must exceed 10 million rupees for the stringent rules to be a rational choice. Figure 11 provides evidence on whether such scandals, that is extremely high prices, are common in our treatment groups. The figure reports quantile treatment effect estimates. If autonomy made scandals more likely, we'd expect to see that the $9 \%$ average reduction was masking large increases in prices at the high quantiles of the price distribution. If anything, we see the opposite: the treatment effects of all three treatments are negative at the higher quantiles.

Second, we have studied the effect of shifting authority in an organization while keeping the selection of agents into the organization constant. It is well-known that different incentives attract different types of workers (Dal Bó et al. , 2013; Ashraf et al. , 2020; Deserrano, 2019), for instance performance pay typically attracts workers with better skills who can benefit from performance rewards (Lazear, 2000). In our case more autonomy might attract officers who are more prone to exploit it to their personal advantage. At the same time, giving more autonomy to officers implies taking it away from the monitors and therefore the treatment might attract monitors who are less likely to exploit their position for private gains.

The results have implications for the design and interpretation of field experiments within organizations. It is very common for researchers to replace the principal while implementing different policies, in order to achieve control. This is innocuous to the extent that they have the same objectives if not the same skills. However it is not innocuous if researchers effectively replace agents who have different incentives, rather than the principal. This has implications for the scalability of the results and can explain why interventions which are very successful when implemented by researchers do not work when implementation is delegated to managers or other agents. ${ }^{36}$

\footnotetext{
${ }^{36}$ Examples include the "camera" experiment by Duflo et al. (2012) that was successfully implemented by researchers but failed when implemented by the government, because staff who were supposed to enforce punishments failed to do so (Banerjee et al. ,2008). Similarly, incentive contracts offered to teachers in Kenya by an international NGO were effective whilst the same contracts failed when monitored by the government (Bold et al. , 2018)
} 


\section{References}

Ashraf, Nava, Bandiera, Oriana, Davenport, Edward, \& Lee, Scott S. 2020. Losing Prosociality in the Quest for Talent? Sorting, Selection, and Productivity in the Delivery of Public Services. American Economic Review, 110, 1355-1394.

BAJARI, PATRICK, \& TADElis, Steven. 2001. Incentives vs Transaction Costs: A Theory of Procurement Contracts. RAND Journal of Economics, 32, 387-407.

Bandiera, Oriana, Prat, Andrea, \& Valletti, Tommaso. 2009. Active and Passive Waste in Government Spending: Evidence from a Policy Experiment. American Economic Review, 99(4), 1278-1308.

BANDIERA, ORIANA, BARANKAY, IWAN, \& RASUl, IMRAN. 2011. Field Experiments with Firms. Journal of Economic Perspectivs, 25, 63-82.

Banerjee, A, Hanna, R, \& Mullainathan, S. 2012. Corruption. Chap. 27, pages 11091147 of: Handbook of Organizational Economics.

Banerjee, Abhijt V., Duflo, Esther, \& Glennerster, Rachel. 2008. Putting a Band-Aid on a Corpse: Incentives for Nurses in the Indian Public Health Care System. Journal of the European Economic Association, 6, 487-500.

Best, Michael Carlos, Hjort, Jonas, \& Szakonyi, David. 2019. Individuals and Organizations as Sources of State Effectiveness. Mimeo: Columbia University.

Bloom, Nicholas, Lemos, Renata, Sadun, Raffaela, \& Van Reenen, John. 2015a. Does Management Matter in Schools? Economic Journal, 125, 647-674.

Bloom, Nicholas, Propper, Carol, Seiler, Stephan, \& VAn Reenen, John. 2015b. The Impact of Competition on Management Quality: Evidence from Public Hospitals. Review of Economic Studies, 82, 457-489.

Bold, Tessa, Kimenyi, Mwangi, Mwabu, Germano, NG'Ang'A, Alice, \& SandeFUR, JUSTIN. 2018. Experimental Evidence on Scaling up Education Reforms in Kenya. Journal of Public Economics, 168, 1-20.

Bolton, PAtrick, \& DeWATripont, Mathias. 2013. Authority in Organizations: A Survey. Chap. 9, pages 342-372 of: GibBOns, Robert S., \& RoberTS, John (eds), The Handbook of Organizational Economics. Princeton University Press. 
Bosio, Erica, Djankov, Simeon, Glaeser, EdWArd, \& Shleifer, ANdrei. 2020. Public Procurement in Law and Practice. Mimeo: Harvard University.

COASE, RonalD. 1937. The Nature of the Firm. Economica, 4, 386-405.

Coviello, Decio, Guglielmo, Andrea, \& Spagnolo, Giancarlo. 2018. The Effect of Discretion on Procurement Performance. Management Science, 64, 715-738.

Dal Bó, Ernesto, Finan, Federico, \& Rossi, Martin A. 2013. Strengthening State Capabilities: The Role of Financial Incentives in the Call to Public Service. Quarterly Journal of Economics, 128, 1169-1218.

DESERRANO, ERIKA. 2019. Financial Incentives as Signals: Experimental Evidence from the Recruitment of Village Promoters in Uganda. American Economic Journal: Applied Economics, 11, 277-317.

Duflo, Esther, Hanna, Rema, \& Ryan, Stephen P. 2012. Incentives Work: Getting Teachers to Come to School. American Economic Review, 102, 1241-1278.

Duflo, Esther, Greenstone, Michael, Pande, Rohini, \& Ryan, Nicholas. 2018. The Value of Discretion in the Enforcement of Regulation: Experimental Evidence and Structural Estimates from Environmental Inspections in India. Econometrica, 86, 21232160.

Duggan, MARK, \& ScotT Morton, Fiona M. 2006. The Distortionary Effects of Government Procurement: Evidence from Medicaid Prescription Drug Purchasing. Quarterly Journal of Economics, 121, 1-30.

Finan, Fred, Olken, Ben, \& Pande, Rohini. 2017. The Personnel Economics of the Developing State. Chap. 6, pages 467-514 of: BANERJEe, ABHIJIT, \& Duflo, Esther (eds), Handbook of Economic Field Experiments, vol. 2. Elsevier.

Fischbacher, URS, \& FÖllmi-Heusi, FranZISKA. 2013. Lies in Disguise: an Experimental Study on Cheating. Journal of the European Economic Association, 11, 525-547.

Gerardino, Maria, Litschig, Stephan, \& Pomeranz, Dina. 2017 (10). Distortion by Audit: Evidence from Public Procurement. Mimeo: University of Zurich.

Gibbons, Robert, \& Roberts, JoHn. 2013. Economic Theories of Incentives in Organizations. Chap. 2, pages 100-158 of: GibBOns, ROBERT, \& ROBERTS, JOHN (eds), Handbook of Organizational Economics. Princeton University Press. 
Guriev, SERGeI. 2004. Red tape and corruption. Journal of Development Economics, 73(2), 489-504.

Hanna, Rema, \& WANG, Shing-Yi. 2017. Dishonesty and Selection into Public Service: Evidence from India. American Economic Journal: Economic Policy, 9(3), 262-90.

Imbens, Guido W., \& Rubin, Donald B. 2015. Causal Inference for Statistics, Social, and Biomedical Sciences. Cambridge University Press.

Kelman, Steve. 1990. Procurement and Public Management: The Fear of Discretion and the Quality of Government Performance. AEI Press.

Khan, Adnan Q., Khwaja, Asim I., \& Olken, Benjamin A. 2016. Tax Farming Redux: Experimental Evidence on Performance Pay for Tax Collectors. Quarterly Journal of Economics, 131, 219-271.

LAFFont, JeAn-JACQues, \& Tirole, JeAn. 1994. A Theory of Incentives in Procurement and Regulation. MIT Press.

Lazear, Edward. 2000. Performance Pay and Productivity. American Economic Review, 95, 1346-1361.

LeAver, Clare. 2009. Bureaucratic Minimal Squawk Behavior: Theory and Evidence from Regulatory Agencies. American Economic Review, 99(05), 572-607.

Lichand, Guilherme, \& Fernandes, Gustavo. 2019. The Dark Side of the Contract: Do Government Audits Reduce Corruption in the Presence of Displacement by Vendors? Tech. rept. Working Paper.

Liebman, Jeffrey B., \& Mahoney, Neale. 2017. Do Expiring Budgets Lead to Wasteful Year-End Spending? Evidence from Federal Procurement. American Economic Review, 107, 3510-3549.

NATIONAL AUDIT OfFice. 2006. Assessing the value for money of OGCbuying.solutions. https://www . nao.org. uk/wp-content/uploads/2006/12/0607103.pdf.

OECD. 2009. OECD Principles for Integrity in Public Procurement. Tech. rept. Organisation for Economic Co-operation and Development.

Punjab Procurement Regulatory Authority. 2014. Punjab Procurement Rules No.ADMN(PPRA) 10-2/2013.

https://ppra.punjab.gov.pk/system/files/Final $\% 20$ Notified $\% 20 \mathrm{PPR}-2014 \% 20 \%$ 28ammended\%20upto\%2006.01.2016\%29.pdf. 
Rasul, Imran, \& Rogger, Daniel. 2018. Management of Bureaucrats and Public Service Delivery: Evidence from the Nigerian Civil Service. Economic Journal, 128, 413-446.

Rasul, Imran, Rogger, Daniel, \& Williams, Martin J. 2019. Management, Organizational Performance, and Task Clarity:Evidence from Ghana's Civil Service. forthcoming, Journal of Public Administration Research and Theory.

Robinson, Peter. 1988. Root-N-Consistent Semiparametric Regression. Econometrica, 56, 931-954.

RubiN, DonalD B. 1980. Discussion of "Randomization Analysis of Experimental Data in the Fisher Randomization Test" by Basu. The Journal of the American Statistical Association, 75, 591-593.

SHI, LAN. 2008. The limit of oversight in policing: Evidence from the 2001 Cincinnati riot. Journal of Public Economics, 93(07), 99-113.

Shleifer, ANDrei, \& Vishny, Robert W. 1993. Corruption. Quarterly Journal of Economics, 108, 599-617.

SimON, HERBERT. 1951. A Formal Theory of the Employment Relationship. Econometrica, 19, 293-305.

SzUCS, Ferenc. 2017. Discretion and Corruption in Public Procurement. Mimeo: Stockholm University.

YANG, DEAN. 2008. Can Enforcement Backfire? Crime Displacement in the Context of Customs Reform in the Philippines. The Review of Economics and Statistics, 90(1), 1-14.

YOUNG, ALWYN. 2019. Channelling Fisher: Randomization Tests and the Statistical Insignificance of Seemingly Significant Experimental Results. Quarterly Journal of Economics, 134, 557-598. 


\section{Figures \& Tables}

Figure 1: Procurement Process Summary

\section{Panel A: Status Quo Procurement Process}

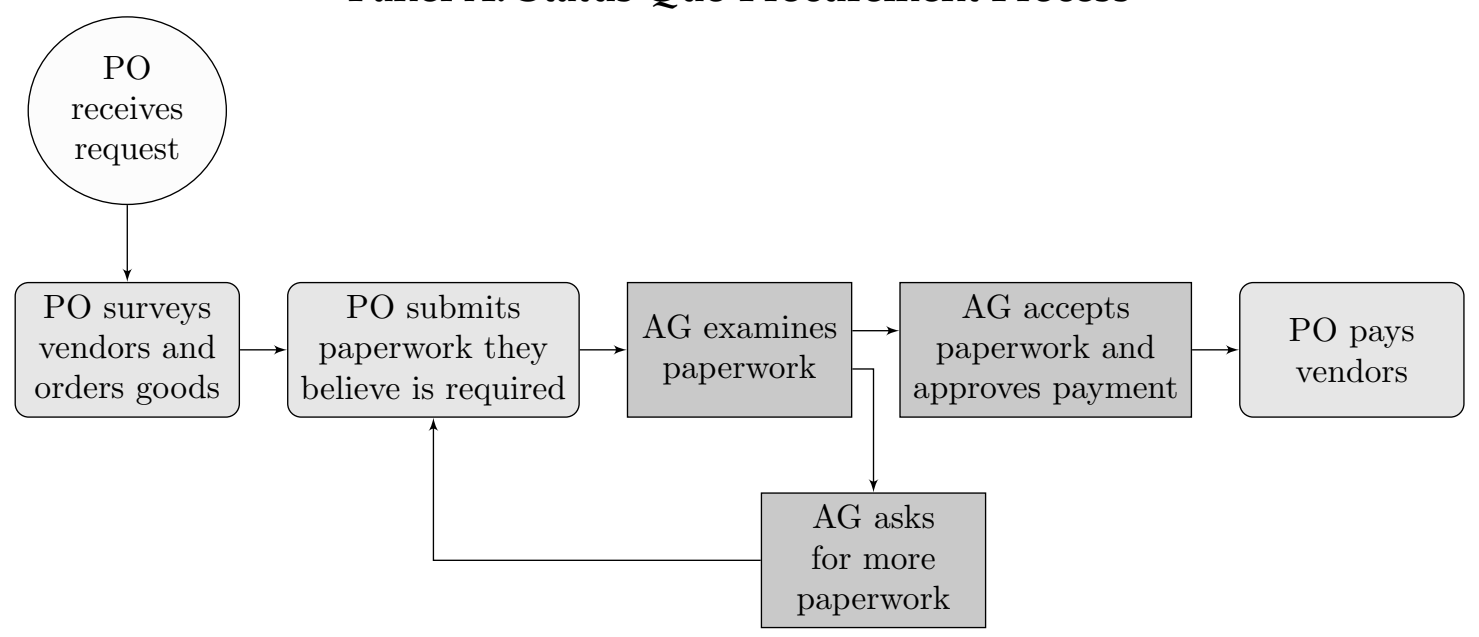

Panel B: Procurement Process Under Autonomy Treatment

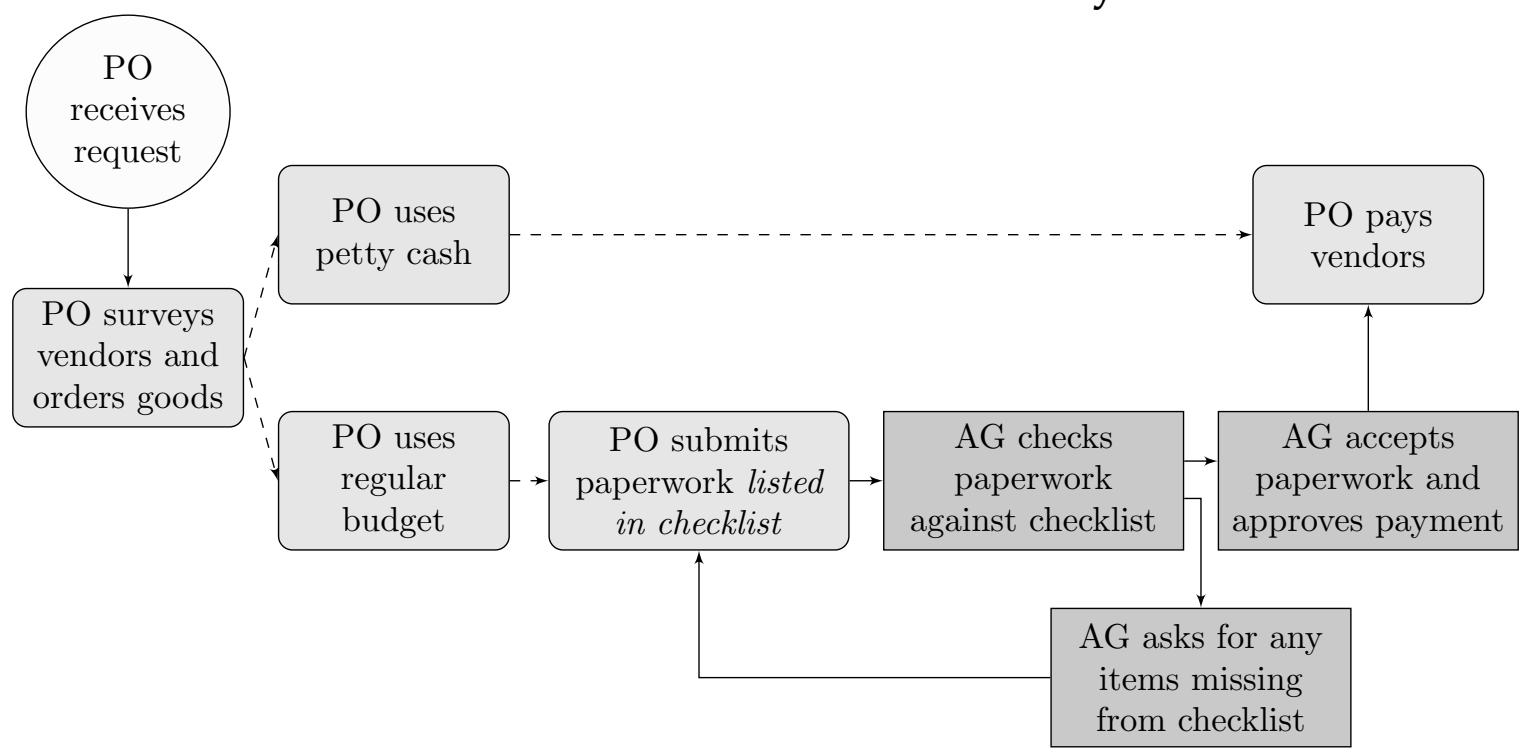




\section{FigURE 2: SUMMARY STATISTICS}

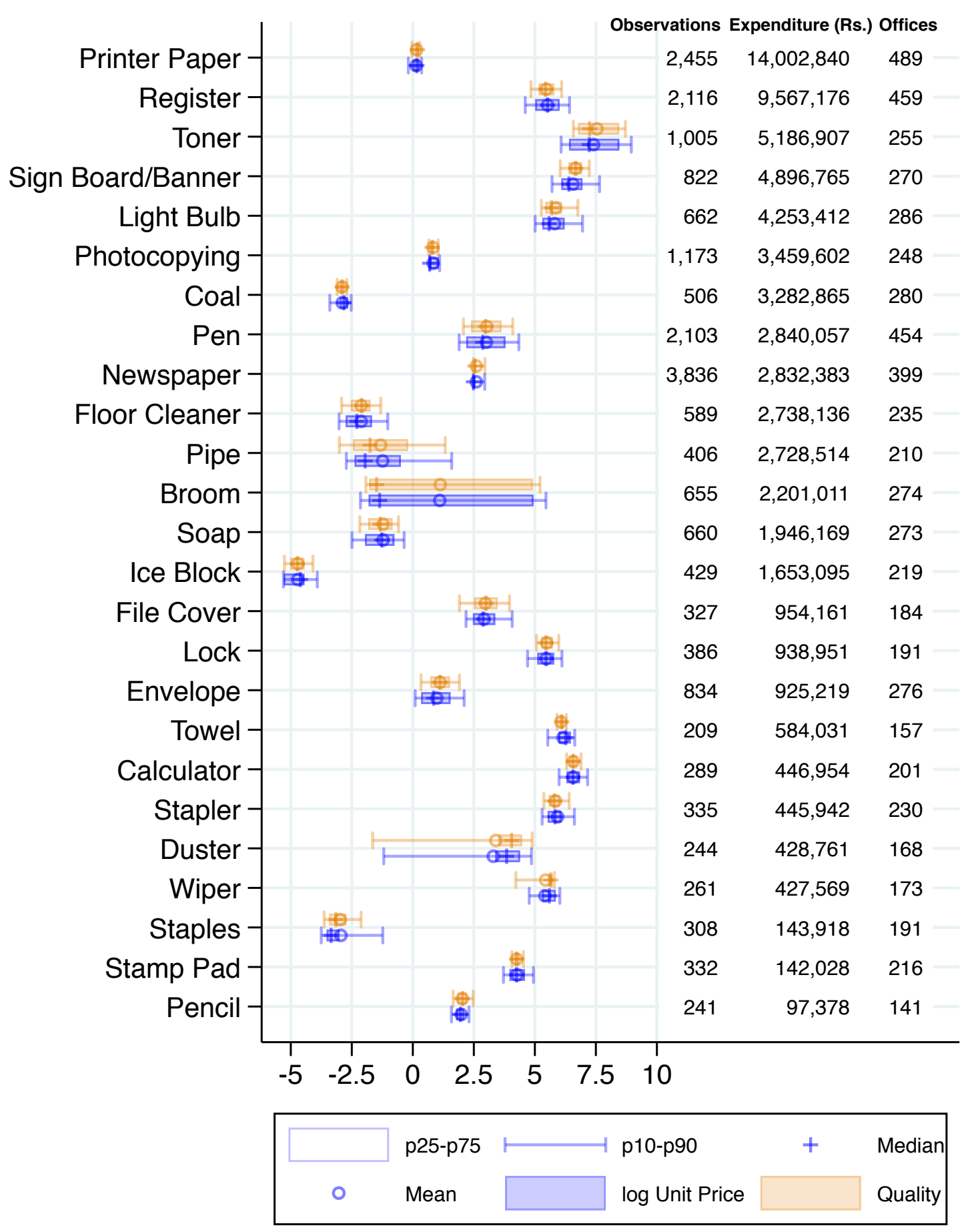

Notes: The figure displays summary statistics for the purchases of the goods in our cleaned purchase sample. The figure summarizes the log unit prices paid for the goods, the number of purchases of each good, and the total expenditure on the good (in Rupees) in the sample. 


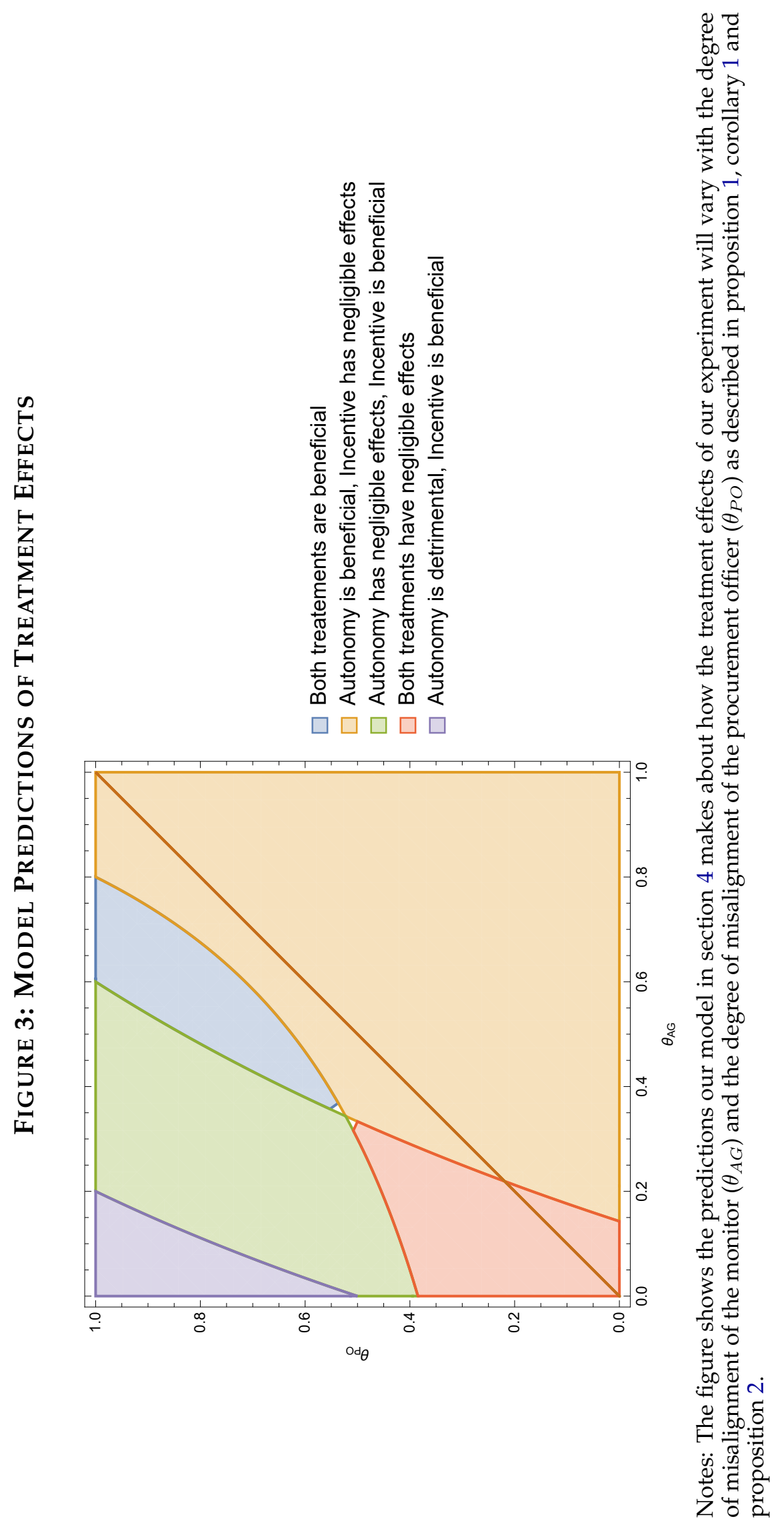




\section{Figure 4: The TIMING Of Deliveries AND EXPENDitUres is UNAFFECTED}

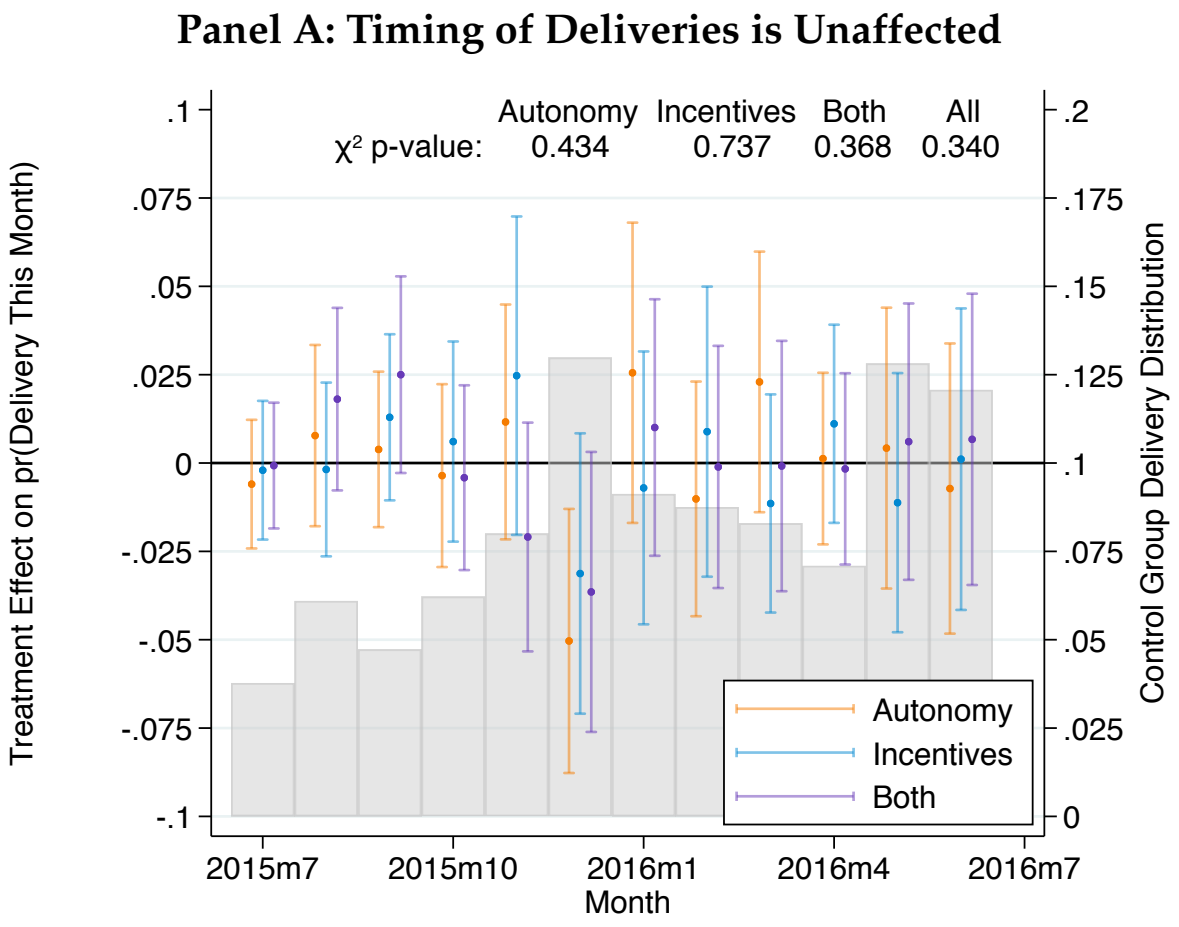

\section{Panel B: Timing of Expenditures is Unaffected}

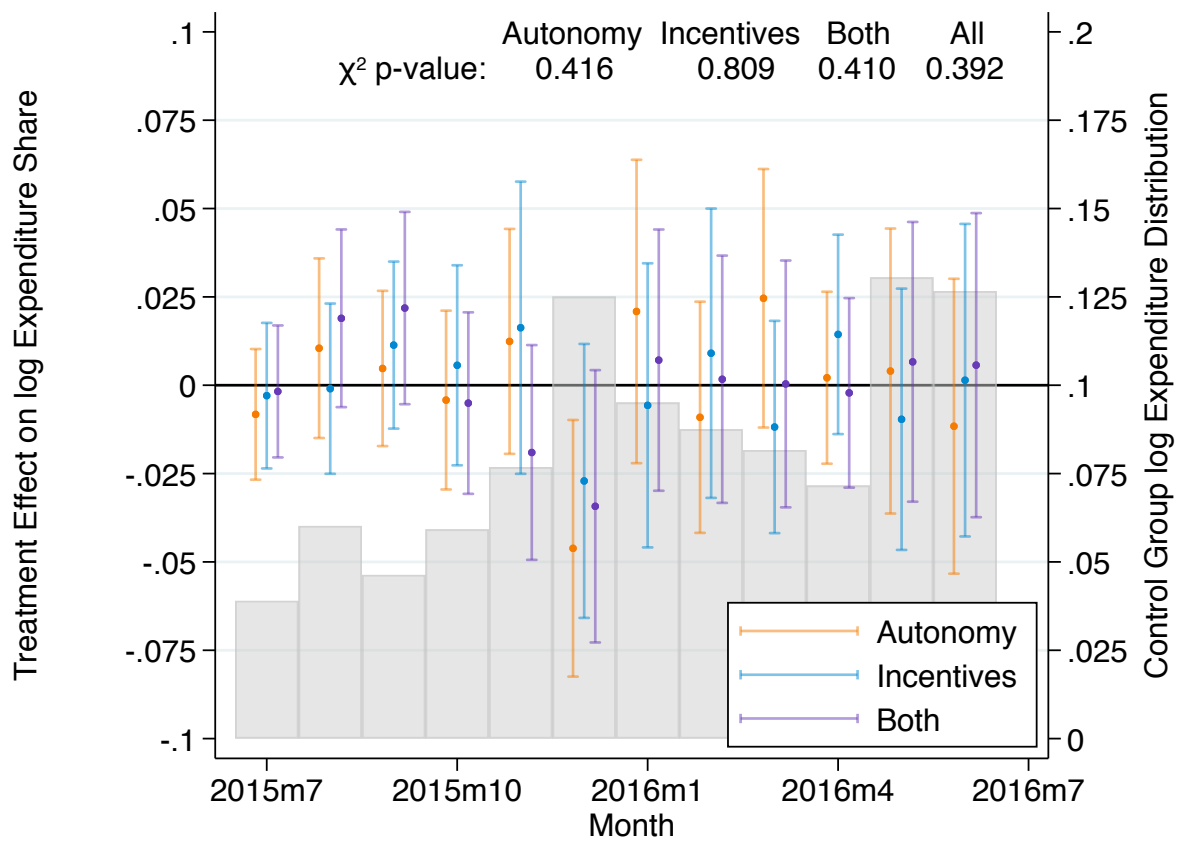

Notes: The figure shows estimates of treatment effects on the timing of deliveries and expenditure. The estimates are from seemingly unrelated regressions of the form

$$
1\left\{\text { Month }_{i}=m\right\}=\alpha+\beta_{A} \text { Autonomy }_{i}+\beta_{I} \text { Incentives }_{i}+\beta_{B} \text { Both }_{i}+\gamma_{g}+\gamma_{s}+\varepsilon_{i}
$$

where $\gamma_{g}$ are good fixed effects, $\gamma_{s}$ are randomization strata fixed effects, and $\varepsilon_{i}$ are residuals clustered by office. The figures show the $95 \%$ confidence intervals of the estimated $\beta_{A}, \beta_{I}$ and $\beta_{B}$ with p-values of $\chi^{2}$ tests of the hypothesis that each treatment's effect is 0 in all months, and the hypothesis that all treatments have no effect in all months. 
Figure 5: Cost Benefit ANALysis

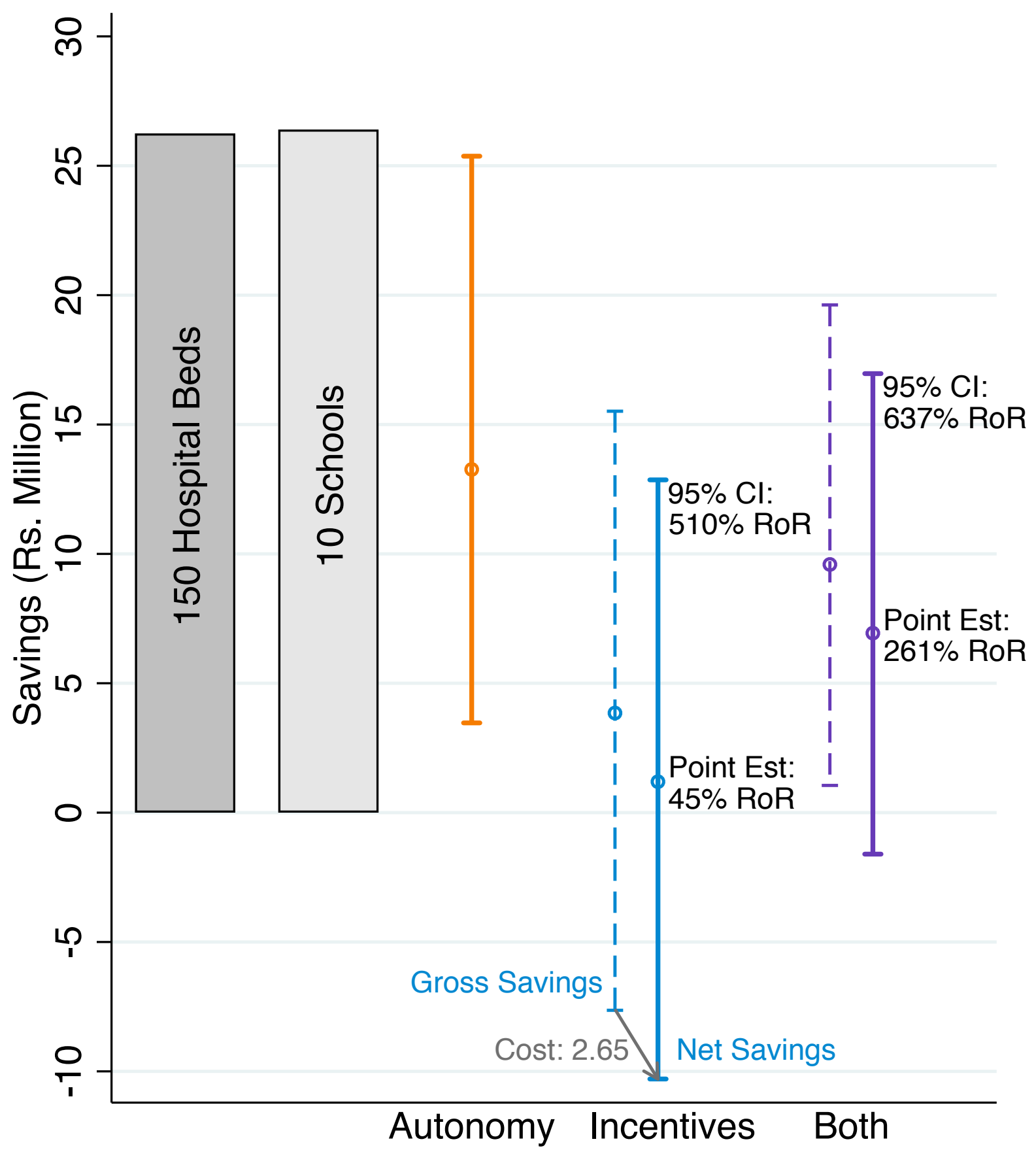

Notes: The figure shows a cost benefit analysis of the experiment. For each treatment, the vertical intervals denote total savings due to the experiment in millions of Rupees. Savings are calculated as $\frac{-\eta_{k}}{1+\eta_{k}} \sum_{o}$ Expenditure $_{o} \times$ Treatment $_{o}^{k}$ where $\eta_{k}$ are the estimated treatment effects in table 2 and Expenditure ${ }_{o}$ is the total spending by office $o$ on generic goods (standard errors are calculated by the delta method). The solid lines denote savings net of the cost of the incentives treatment, while dashed lines are gross savings. For the incentives and combined treatments, the figure also shows the implied rates of return on the performance pay bonus payments. For comparison, the figure also shows the cost of operating 150 hospital beds, and the cost of operating 10 schools. 


\section{Figure 6: Heterogeneity of Treatment Effects by Monitor Alignment}

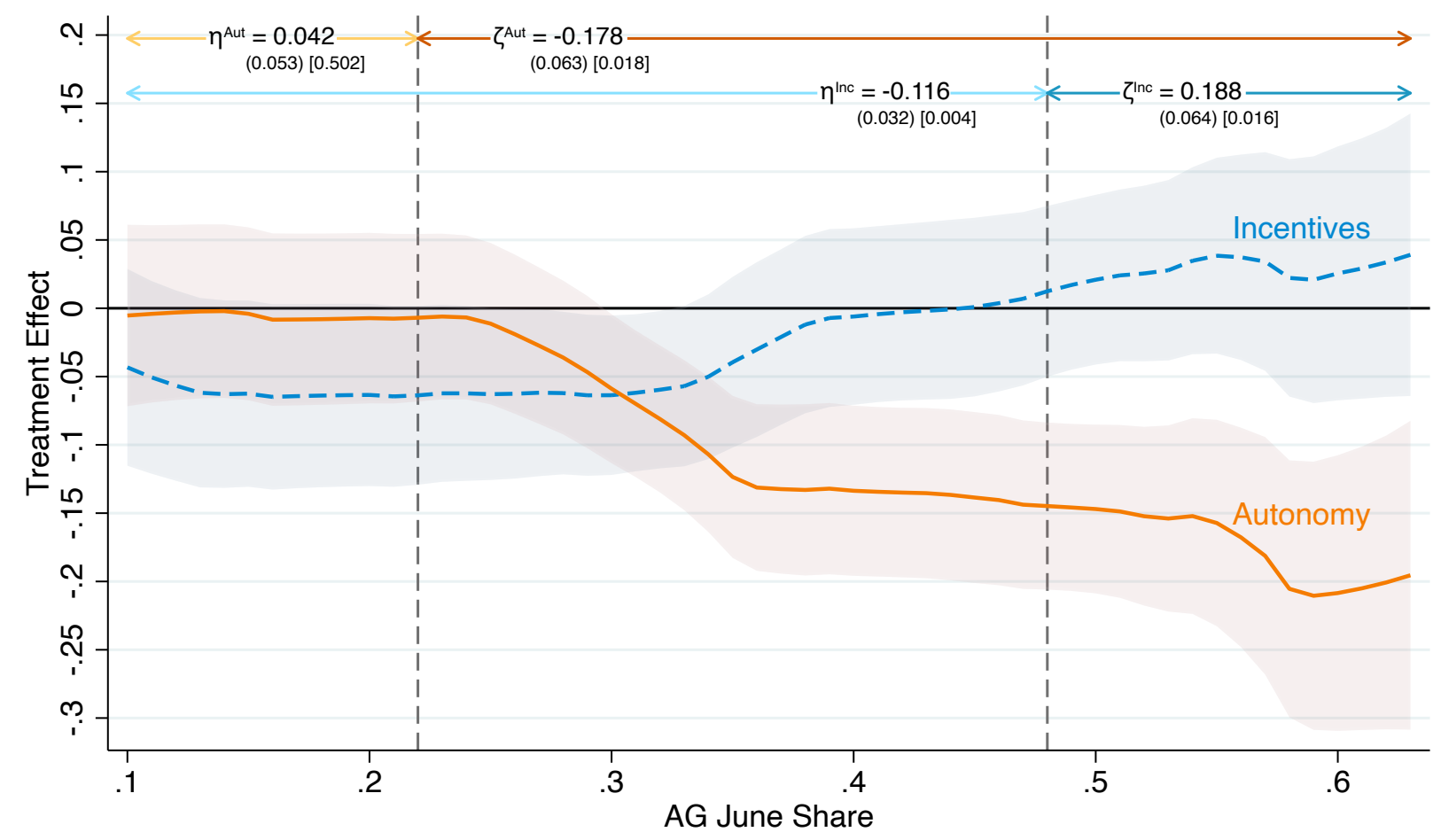

Notes: The figure shows heterogeneity of the treatment effects of autonomy and incentives by the degree of misalignment of the district's accountant general (AG). As discussed in section 6.1 AGs are classified according to the degree to which purchase approvals are bunched at the end of the fiscal year in June 2015 (year 1 of the project). The figure shows semi-parametric estimates of the treatment effects using the method in Robinson (1988) to estimate linear effects of the full set of controls and flexible non-parametric heterogeneous treatment effects by accountant general:

$$
p_{\text {igto }}=\mathbf{X}_{\text {igto }} \beta+\sum_{k=1}^{3} f_{k}\left(\text { AGJuneShare }_{o}\right) \times \text { Treatment }_{o}^{k}+\varepsilon_{\text {igto }}
$$

where $\mathbf{X}_{\text {igto }}$ includes the scalar item variety measure, good specific controls for purchase size, stratum FEs, and good fixed effects, and $f_{k}(\cdot)$ are nonparametric treatment effect functions. The top of the figure shows coefficients, clustered standard errors (in parentheses) and randomization inference p-values (in square brackets) from difference in differences regressions interacting treatment dummies with a dummy for facing a "bad" AG, decined as a June share of 0.22 for autonomy, and 0.48 for incentives. $p_{\text {igto }}=\alpha+\eta$ Treatment $_{o}+$ $\zeta$ Treatment $_{o} \times$ BadAG $_{o}+\mathbf{X}_{\text {igto }} \beta+\rho_{g} q_{\text {igto }}+\delta_{s}+\gamma_{g}+\varepsilon_{\text {igto }}$ where all terms are as defined above, and we control for the scalar measure of item variety as part of $\mathbf{X}_{\text {igto }}$. Appendix figure A.11 varies the thresholds used for defining a bad AG, justifying the use of 0.22 and 0.48 . 


\section{Figure 7: COST BENEFIT OF EXPERIMENT BY AG TYPE}

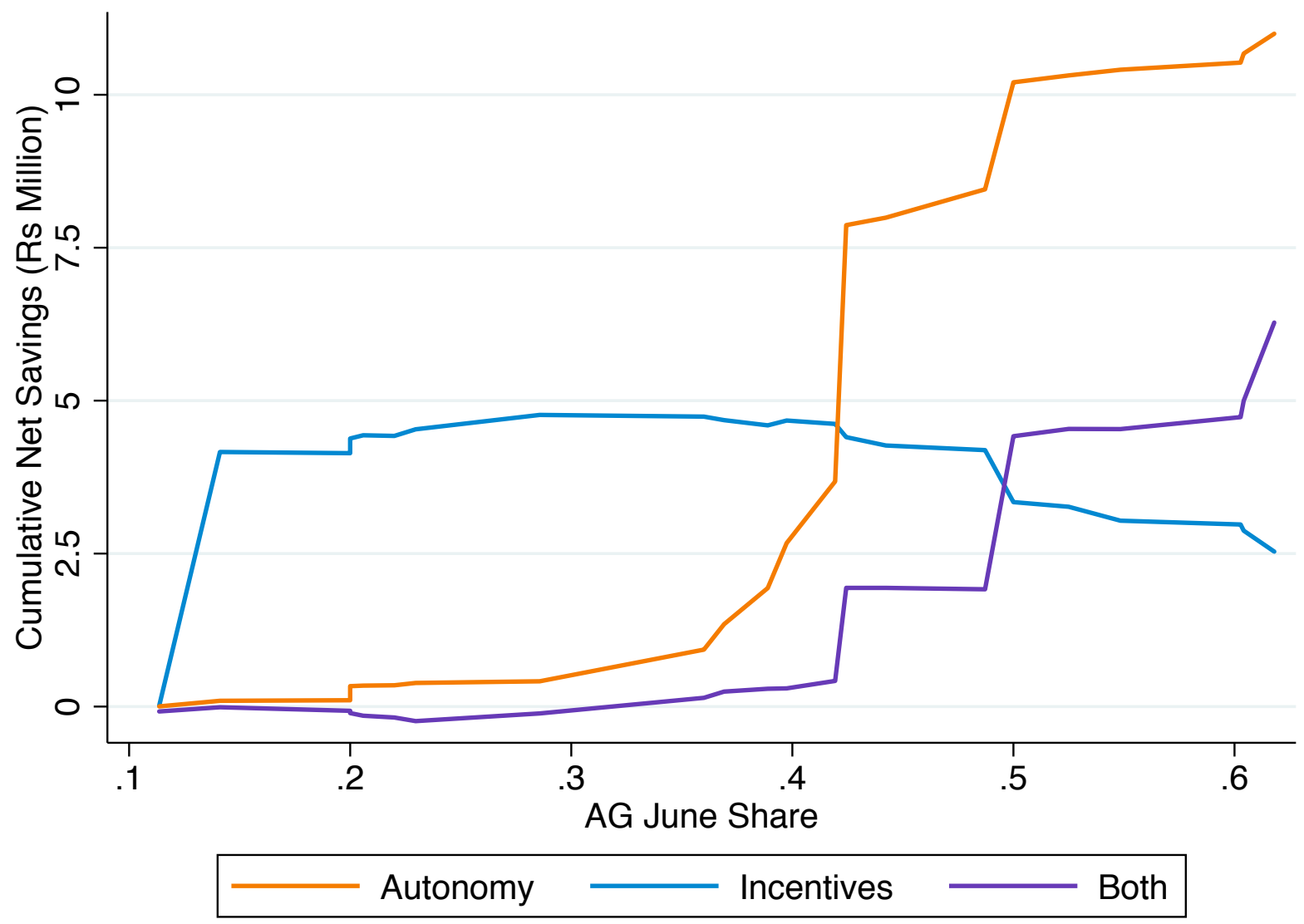

Notes: The figure shows the cost benefit of the experiments in districts with different levels of monitor alignment. The horizontal axis measures our proxy for the misalignment of a district's accountant general: the share of transactions approved in the last month of the fiscal year in the control group in year 1. Districts with a low AG June Share (low $j_{d}$ ) have more aligned monitors. The vertical axis measures the cumulative net savings by all districts with an accountant general who is less misaligned: $\sum_{d: j_{d} \leq x}\left[\left(\frac{-\eta_{k}\left(j_{d}\right)}{1+\eta_{k}\left(j_{d}\right)} \sum_{o \in d}\right.\right.$ Expenditure $_{o d} \times$ Treatment $\left.\left._{o}^{k}\right)-c_{d}\right]$ where $\eta_{k}\left(j_{d}\right)$ are estimated treatment effects of treatment $k$ when monitor misalignment is $j_{d}$ and $c_{d}$ is the ex ante cost of performance pay bonuses to offices in district $d$ (the number of offices in the district at each pay grade times the expected prize for each office). The figure shows large net savings for the incentives group at low levels of misalignment while net savings to the autonomy and both treatments only accrue at high levels of monitor misalignment. 


\section{Figure 8: Treatment EfFects on Approval Delays}

\section{Panel A: Overall Treatment Effects}

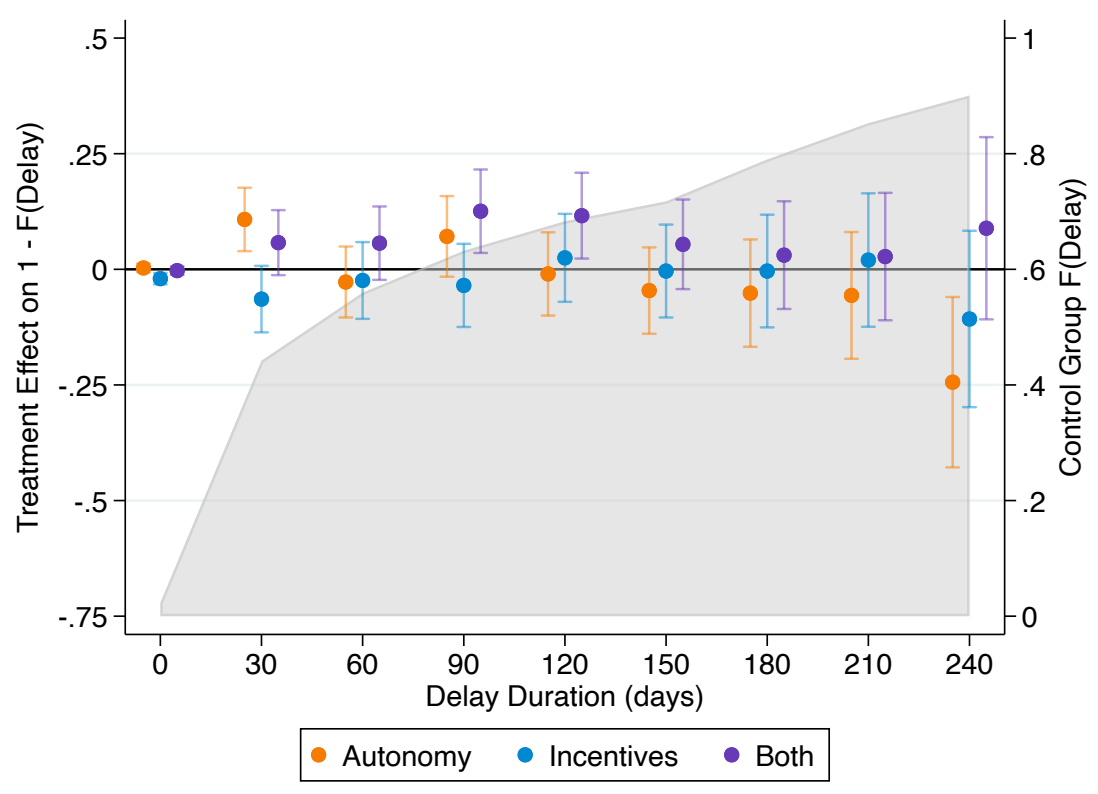

Panel B: Autonomy Effect by AG Type

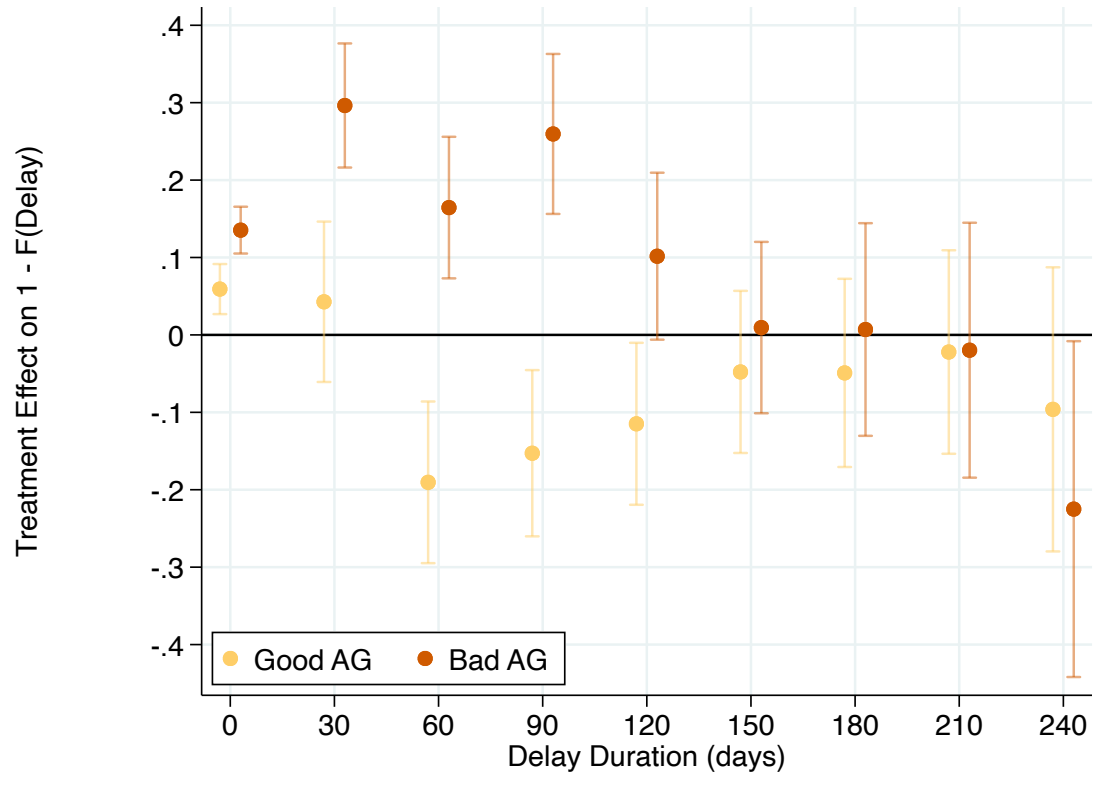

Notes: The figure shows the effects of the experiments on the delay between a purchased item's delivery and the approval of the purchase by the Accountant General (AG). Panel A shows a series of seemingly unrelated distributional regressions of the probability of delay of at least $j$ days in year 2 normalized by the probability of a delay of at least $j$ days in the control group in year 1 on treatment dummies, strata fixed effects $\gamma_{s}$ and good fixed effects $\gamma_{g}$ :

$$
\frac{1\left\{\text { delay }_{\text {igo }} \geq j\right\}}{\mathbb{P}(\text { delay } \geq j \mid \text { Control, Year } 1)}=\alpha+\sum_{k=1}^{3} \eta_{k} \text { Treatment }_{o}^{k}+\gamma_{s}+\gamma_{g}+\varepsilon_{i g o}
$$

the panel also shows the CDF of delays in the control group in year 1 for reference. Panel B extends this regression to separately estimate treatment effects for good (June share of approvals $\leq 0.22$ ) and bad (June share of approvals $>0.22$ ) AGs. 
Figure 9: EfFects of Autonomy Treatment on Hold UP at the ENd of the FISCAL YEAR

\section{Panel A: Overall Effect of Autonomy Treatment on Holdup}

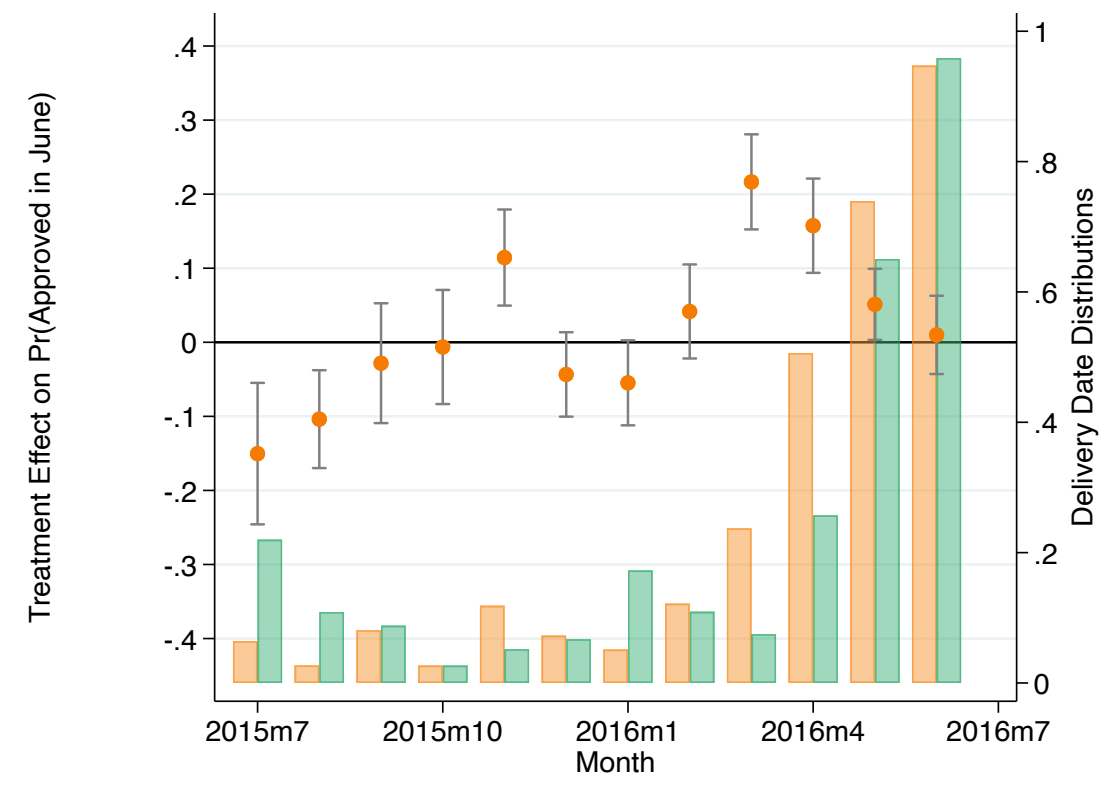

\section{Panel B: Autonomy Effect by AG Type}

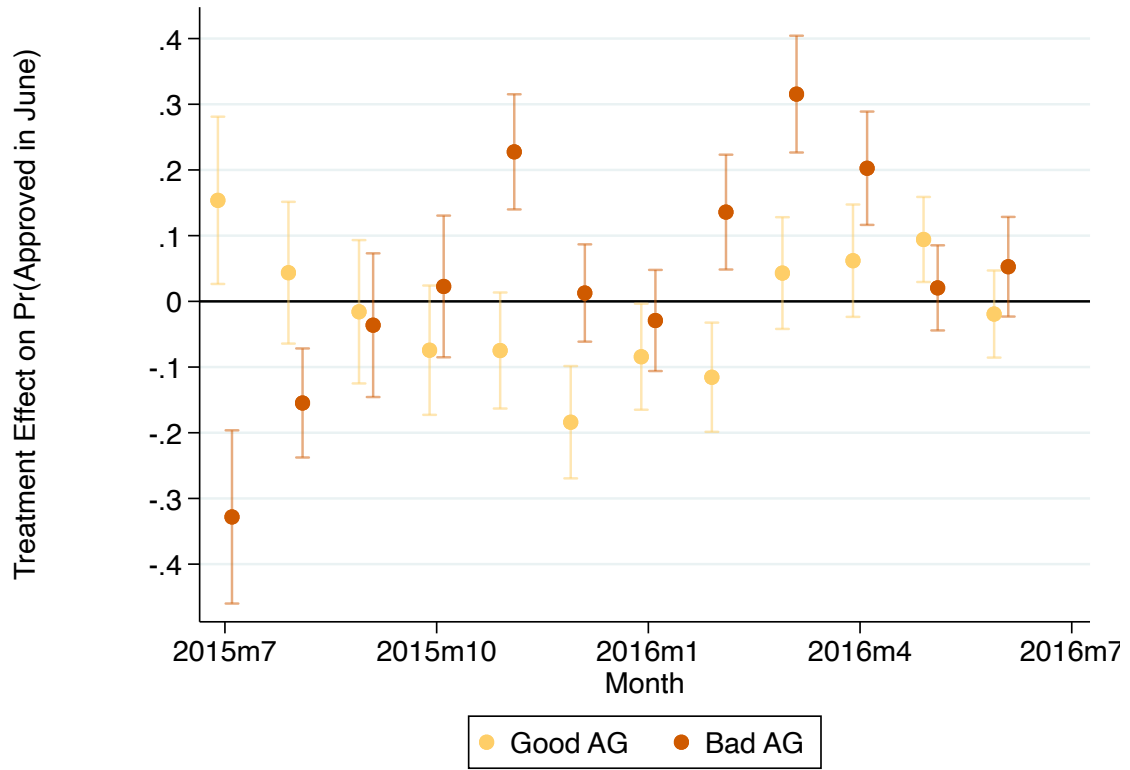

Notes: The figure shows the effects of the autonomy treatment on holdup by the AG at the end of the fiscal year. We focus on how the treatments change the probability that items purchased in different months are approved in June (the last month of the fiscal year).

$\mathbf{1}\left\{\right.$ Approved in June $\left._{i g o}\right\}=\alpha+\sum_{k=1}^{3} \sum_{m=J u l}^{J u n} \eta_{m k} \mathbf{1}\left\{\right.$ PurchaseMonth $\left._{i g o}=m\right\} \times$ Treatment $_{o}^{k}+\sum_{m=J u l}^{J u n} \gamma_{m} \mathbf{1}\left\{\right.$ PurchaseMonth $\left._{i g o}=m\right\}+\gamma_{g}+\varepsilon_{i g o}$

Panel A shows the $\eta_{m k}$ coefficients for the autonomy treatment and also the raw distribution of delivery dates of purchases approved in June in the autonomy treatment (in orange) and control (in green) groups. Panel B runs the regression separately for less aligned (below median) and more aligned (above median) AGs. 


\section{Figure 10: Time Allocated to Procurement}

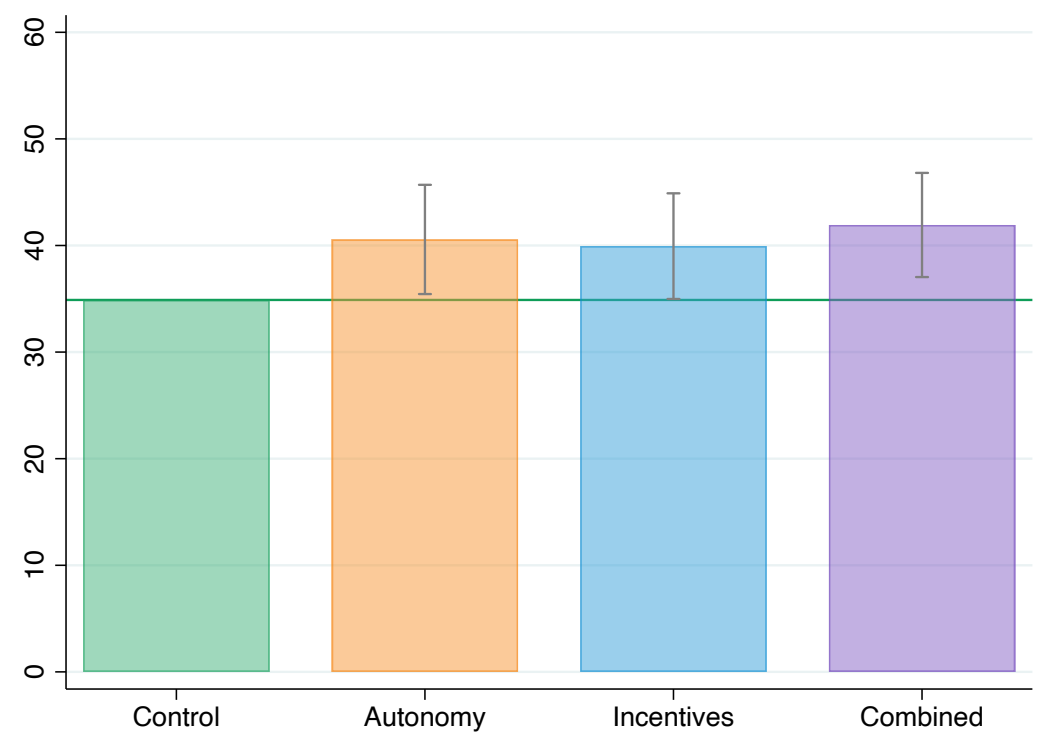

Notes: The figure shows our analysis of the effects of the experiment on the time bureaucrats allocate to procurement. Our endline survey asks bureaucrats to allocate months of the year to "very busy", "somewhat busy" and "not busy" months for procurement. The next question asks bureaucrats to specify the fraction of their time in each type of month they spend on procurement. We first combine these into a measure of the total amount of time in the year spent on procurement by averaging the answers to the latter question, weighting by the former. We find a $14 \%$ increase in the total amount of time spent on procurement in the incentives treatment, a 16\% increase in the autonomy group, and a $20 \%$ increase in the combined group. We cannot reject the hypothesis that the increase is the same in all three groups $(p=0.70)$. 


\section{Figure 11: QUANTILE TREATMENT EFFECTS}

Panel A: Autonomy

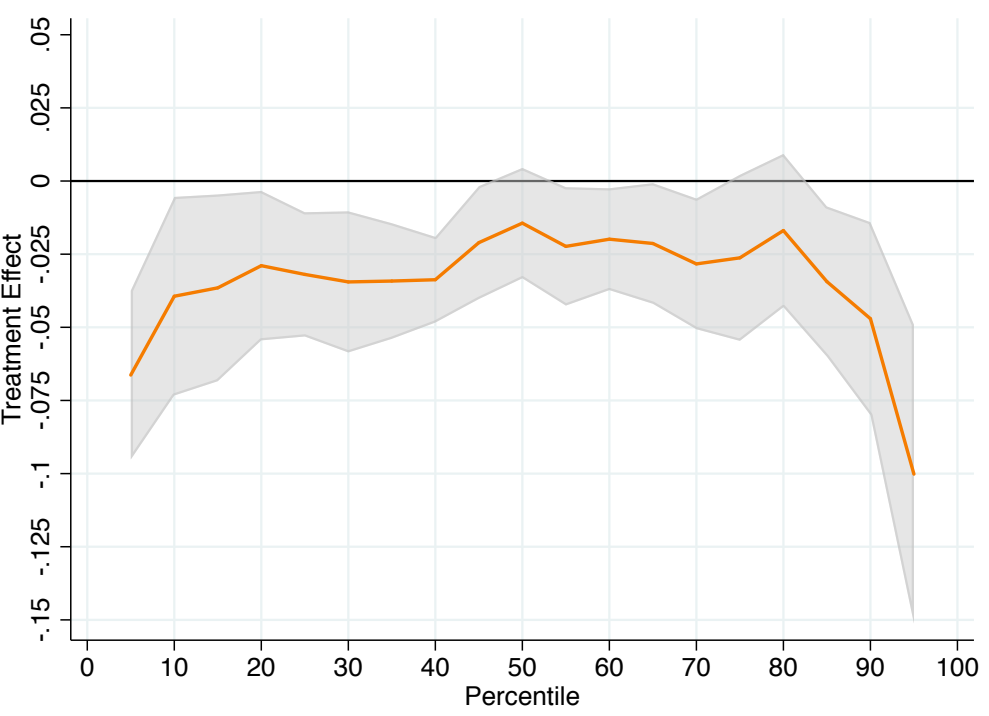

Panel C: Combined

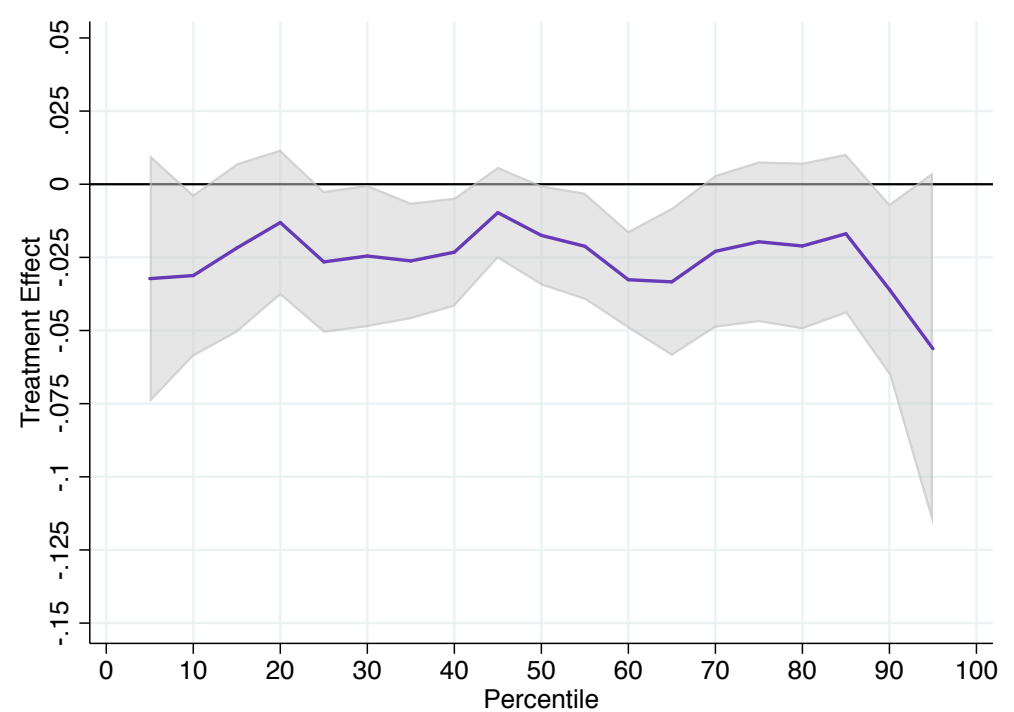

Panel B: Incentives

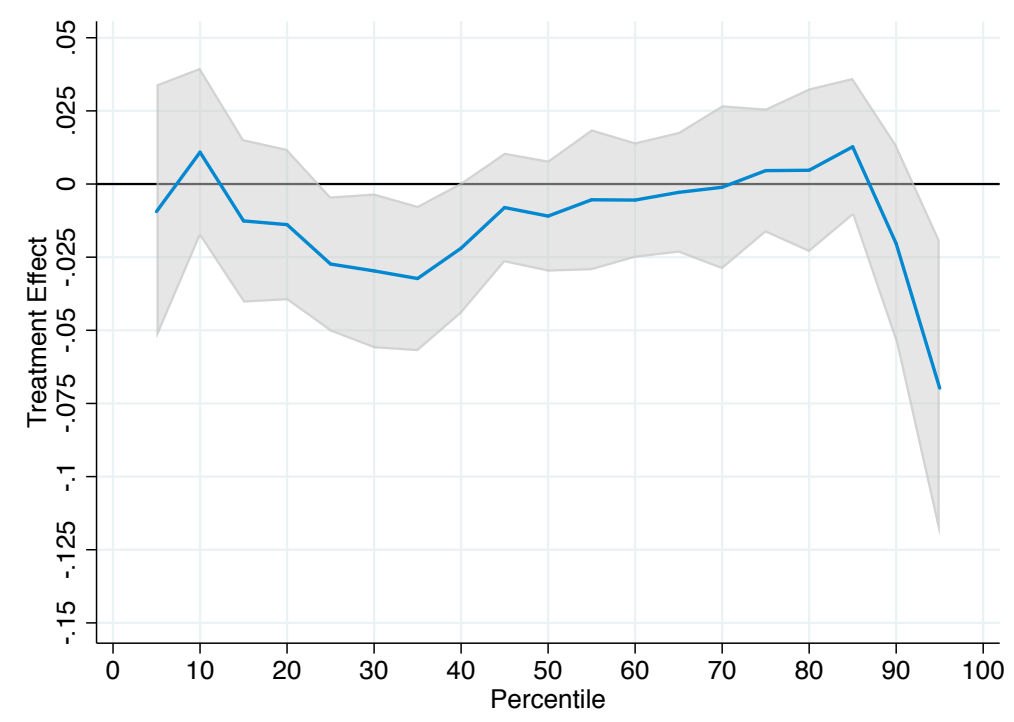

scalar measure of item variety. We estimate treatment effects from the 5th to the 95th percentile, in increments of 5. 
Table 1: Balance Across Treatment Arms

\begin{tabular}{|c|c|c|c|c|c|}
\hline & \multirow{2}{*}{$\begin{array}{l}\text { Control } \\
\text { mean/sd }\end{array}$} & \multicolumn{3}{|c|}{ Regression Coefficients } & \multirow{2}{*}{$\begin{array}{r}\text { Joint Test } \\
\text { All }=0\end{array}$} \\
\hline & & Incentives & Autonomy & Both & \\
\hline \multicolumn{6}{|l|}{ Office Characteristics } \\
\hline Number of Public Bodies & $\begin{array}{c}1.01 \\
\{0.086\}\end{array}$ & $\begin{array}{l}-0.007 \\
(0.007) \\
{[0.346]}\end{array}$ & $\begin{array}{c}0.033 \\
(0.024) \\
{[0.210]}\end{array}$ & $\begin{array}{c}0.012 \\
(0.013) \\
{[0.460]}\end{array}$ & $\begin{array}{c}2.360 \\
{[0.071]^{*}} \\
{[0.265]}\end{array}$ \\
\hline Number of Accounting Entities & $\begin{array}{c}1.26 \\
\{0.635\}\end{array}$ & $\begin{array}{c}0.069 \\
(0.086) \\
{[0.407]}\end{array}$ & $\begin{array}{c}0.222 \\
(0.100)^{* *} \\
{[0.028]^{* *}}\end{array}$ & $\begin{array}{c}0.186 \\
(0.087)^{* *} \\
{[0.038]^{* *}}\end{array}$ & $\begin{array}{c}2.427 \\
{[0.065]^{*}} \\
{[0.076]^{*}}\end{array}$ \\
\hline Share of June Approvals & $\begin{array}{c}0.39 \\
\{0.205\}\end{array}$ & $\begin{array}{l}-0.022 \\
(0.024) \\
{[0.363]}\end{array}$ & $\begin{array}{l}-0.009 \\
(0.024) \\
{[0.693]}\end{array}$ & $\begin{array}{l}-0.011 \\
(0.024) \\
{[0.649]}\end{array}$ & $\begin{array}{c}0.287 \\
{[0.835]} \\
{[0.828]}\end{array}$ \\
\hline \# POs During Experiment & $\begin{array}{c}1.13 \\
\{0.403\}\end{array}$ & $\begin{array}{c}0.003 \\
(0.047) \\
{[0.940]}\end{array}$ & $\begin{array}{c}0.027 \\
(0.051) \\
{[0.616]}\end{array}$ & $\begin{array}{c}0.077 \\
(0.050) \\
{[0.134]}\end{array}$ & $\begin{array}{c}1.089 \\
{[0.353]} \\
{[0.364]}\end{array}$ \\
\hline District ( $\chi^{2} \mathrm{p}$-val $)$ & & {$[0.856]$} & [ 0.972] & [ 0.897] & {$[0.351]$} \\
\hline Department ( $\chi^{2}$ p-val) & & [ 0.168$]$ & [ 0.958] & [ 0.858$]$ & [ 0.639] \\
\hline Procurement Officer Characteristics & & & & & \\
\hline Age & $\begin{array}{c}52.03 \\
\{6.883\}\end{array}$ & $\begin{array}{l}-1.263 \\
(0.938) \\
{[0.186]}\end{array}$ & $\begin{array}{l}-0.493 \\
(0.952) \\
{[0.622]}\end{array}$ & $\begin{array}{c}0.345 \\
(0.875) \\
{[0.700]}\end{array}$ & $\begin{array}{c}1.109 \\
{[0.345]} \\
{[0.392]}\end{array}$ \\
\hline Male & $\begin{array}{c}0.70 \\
\{0.460\}\end{array}$ & $\begin{array}{c}0.024 \\
(0.056) \\
{[0.683]}\end{array}$ & $\begin{array}{l}-0.011 \\
(0.058) \\
{[0.841]}\end{array}$ & $\begin{array}{c}0.007 \\
(0.056) \\
{[0.897]}\end{array}$ & $\begin{array}{c}0.137 \\
{[0.938]} \\
{[0.945]}\end{array}$ \\
\hline Bachelors Degree & $\begin{array}{c}0.09 \\
\{0.281\}\end{array}$ & $\begin{array}{c}0.025 \\
(0.037) \\
{[0.522]}\end{array}$ & $\begin{array}{c}0.043 \\
(0.040) \\
{[0.280]}\end{array}$ & $\begin{array}{c}0.070 \\
(0.041)^{*} \\
{[0.072]^{*}}\end{array}$ & $\begin{array}{c}1.062 \\
{[0.365]} \\
{[0.354]}\end{array}$ \\
\hline Masters Degree & $\begin{array}{c}0.76 \\
\{0.429\}\end{array}$ & $\begin{array}{c}0.004 \\
(0.054) \\
{[0.928]}\end{array}$ & $\begin{array}{l}-0.033 \\
(0.056) \\
{[0.555]}\end{array}$ & $\begin{array}{l}-0.013 \\
(0.055) \\
{[0.813]}\end{array}$ & $\begin{array}{c}0.179 \\
{[0.910]} \\
{[0.914]}\end{array}$ \\
\hline Ph.D Degree & $\begin{array}{c}0.15 \\
\{0.362\}\end{array}$ & $\begin{array}{l}-0.029 \\
(0.044) \\
{[0.530]}\end{array}$ & $\begin{array}{l}-0.010 \\
(0.046) \\
{[0.822]}\end{array}$ & $\begin{array}{l}-0.058 \\
(0.042) \\
{[0.172]}\end{array}$ & $\begin{array}{c}0.791 \\
{[0.499]} \\
{[0.507]}\end{array}$ \\
\hline Pay Grade $\leq 18$ & $\begin{array}{c}0.52 \\
\{0.502\}\end{array}$ & $\begin{array}{c}0.028 \\
(0.064) \\
{[0.660]}\end{array}$ & $\begin{array}{l}-0.083 \\
(0.065) \\
{[0.192]}\end{array}$ & $\begin{array}{l}-0.014 \\
(0.065) \\
{[0.822]}\end{array}$ & $\begin{array}{c}1.111 \\
{[0.344]} \\
{[0.320]}\end{array}$ \\
\hline
\end{tabular}


Table 1 - Continued from previous page

\begin{tabular}{|c|c|c|c|c|c|}
\hline & \multirow{2}{*}{$\begin{array}{l}\text { Control } \\
\text { mean/sd }\end{array}$} & \multicolumn{3}{|c|}{ Regression Coefficients } & \multirow{2}{*}{$\begin{array}{c}\text { Joint Test } \\
\text { All }=0\end{array}$} \\
\hline & & Incentives & Autonomy & Both & \\
\hline Pay Grade 19 & $\begin{array}{c}0.33 \\
\{0.472\}\end{array}$ & $\begin{array}{l}-0.017 \\
(0.060) \\
{[0.790]}\end{array}$ & $\begin{array}{c}0.060 \\
(0.062) \\
{[0.324]}\end{array}$ & $\begin{array}{c}0.011 \\
(0.061) \\
{[0.852]}\end{array}$ & $\begin{array}{c}0.590 \\
{[0.621]} \\
{[0.617]}\end{array}$ \\
\hline Pay Grade $\geq 20$ & $\begin{array}{c}0.15 \\
\{0.356\}\end{array}$ & $\begin{array}{l}-0.010 \\
(0.045) \\
{[0.804]}\end{array}$ & $\begin{array}{c}0.023 \\
(0.048) \\
{[0.612]}\end{array}$ & $\begin{array}{c}0.003 \\
(0.046) \\
{[0.940]}\end{array}$ & $\begin{array}{c}0.182 \\
{[0.908]} \\
{[0.908]}\end{array}$ \\
\hline Year-1 Budget Shares & & & & & \\
\hline Operating Expenses & $\begin{array}{c}0.80 \\
\{0.223\}\end{array}$ & $\begin{array}{c}0.024 \\
(0.024) \\
{[0.328]}\end{array}$ & $\begin{array}{l}-0.004 \\
(0.026) \\
{[0.875]}\end{array}$ & $\begin{array}{c}0.009 \\
(0.025) \\
{[0.708]}\end{array}$ & $\begin{array}{c}0.594 \\
{[0.619]} \\
{[0.611]}\end{array}$ \\
\hline Physical Assets & $\begin{array}{c}0.03 \\
\{0.115\}\end{array}$ & $\begin{array}{l}-0.005 \\
(0.012) \\
{[0.664]}\end{array}$ & $\begin{array}{l}-0.004 \\
(0.013) \\
{[0.769]}\end{array}$ & $\begin{array}{l}-0.008 \\
(0.013) \\
{[0.546]}\end{array}$ & $\begin{array}{c}0.142 \\
{[0.935]} \\
{[0.944]}\end{array}$ \\
\hline Repairs \& Maintenance & $\begin{array}{c}0.05 \\
\{0.098\}\end{array}$ & $\begin{array}{c}0.005 \\
(0.010) \\
{[0.625]}\end{array}$ & $\begin{array}{l}-0.001 \\
(0.010) \\
{[0.904]}\end{array}$ & $\begin{array}{l}-0.003 \\
(0.010) \\
{[0.784]}\end{array}$ & $\begin{array}{c}0.394 \\
{[0.757]} \\
{[0.783]}\end{array}$ \\
\hline POPS Universe & $\begin{array}{c}0.53 \\
\{0.327\}\end{array}$ & $\begin{array}{c}0.021 \\
(0.037) \\
{[0.579]}\end{array}$ & $\begin{array}{l}-0.001 \\
(0.038) \\
{[0.971]}\end{array}$ & $\begin{array}{l}-0.038 \\
(0.039) \\
{[0.352]}\end{array}$ & $\begin{array}{c}0.895 \\
{[0.444]} \\
{[0.467]}\end{array}$ \\
\hline Analysis Sample & $\begin{array}{c}0.15 \\
\{0.173\}\end{array}$ & $\begin{array}{c}0.027 \\
(0.020) \\
{[0.194]}\end{array}$ & $\begin{array}{c}0.025 \\
(0.021) \\
{[0.229]}\end{array}$ & $\begin{array}{l}-0.002 \\
(0.018) \\
{[0.886]}\end{array}$ & $\begin{array}{c}1.547 \\
{[0.201]} \\
{[0.197]}\end{array}$ \\
\hline Year-2 Budget Shares & & & & & \\
\hline Operating Expenses & $\begin{array}{c}0.78 \\
\{0.240\}\end{array}$ & $\begin{array}{l}-0.008 \\
(0.027) \\
{[0.761]}\end{array}$ & $\begin{array}{c}0.003 \\
(0.028) \\
{[0.911]}\end{array}$ & $\begin{array}{c}0.026 \\
(0.027) \\
{[0.354]}\end{array}$ & $\begin{array}{c}0.712 \\
{[0.545]} \\
{[0.585]}\end{array}$ \\
\hline Physical Assets & $\begin{array}{c}0.04 \\
\{0.131\}\end{array}$ & $\begin{array}{c}0.001 \\
(0.015) \\
{[0.971]}\end{array}$ & $\begin{array}{l}-0.019 \\
(0.013) \\
{[0.140]}\end{array}$ & $\begin{array}{l}-0.013 \\
(0.014) \\
{[0.368]}\end{array}$ & $\begin{array}{c}1.302 \\
{[0.273]} \\
{[0.302]}\end{array}$ \\
\hline Repairs \& Maintenance & $\begin{array}{c}0.05 \\
\{0.097\}\end{array}$ & $\begin{array}{c}0.001 \\
(0.010) \\
{[0.901]}\end{array}$ & $\begin{array}{c}0.000 \\
(0.010) \\
{[0.988]}\end{array}$ & $\begin{array}{l}-0.011 \\
(0.009) \\
{[0.222]}\end{array}$ & $\begin{array}{c}2.162 \\
{[0.091]^{*}} \\
{[0.112]}\end{array}$ \\
\hline POPS Universe & $\begin{array}{c}0.53 \\
\{0.311\}\end{array}$ & $\begin{array}{c}0.012 \\
(0.036) \\
{[0.716]}\end{array}$ & $\begin{array}{l}-0.001 \\
(0.036) \\
{[0.973]}\end{array}$ & $\begin{array}{l}-0.022 \\
(0.037) \\
{[0.529]}\end{array}$ & $\begin{array}{c}0.337 \\
{[0.799]} \\
{[0.790]}\end{array}$ \\
\hline
\end{tabular}


Table 1 - Continued from previous page

\begin{tabular}{ccccccc}
\hline & Control & \multicolumn{2}{c}{ Regression Coefficients } & \multirow{2}{*}{ Joint Test } \\
\cline { 3 - 5 } & mean/sd & Incentives & Autonomy & Both & All = 0 \\
\hline Analysis Sample & 0.16 & 0.011 & 0.007 & -0.018 & 1.029 \\
& $\{0.196\}$ & $\begin{array}{c}(0.023) \\
{[0.649]}\end{array}$ & $\begin{array}{c}(0.022) \\
{[0.725]}\end{array}$ & $\begin{array}{c}(0.020) \\
{[0.388]}\end{array}$ & {$[0.379]$} \\
\hline Number of Offices & & 150 & 148 & 153 & \\
\hline
\end{tabular}

Notes: The table shows balance of a range of covariates across the treatment arms. Each row of the table studies balance of a particular covariate. For continuous variables, the first column shows the mean and standard deviation (in curly brackets) of the variable in the control group. The next three columns show regression coefficients from a regression of the covariate on treatment indicators together with their robust standard errors in brackets, and the $\mathrm{p}$-value from randomization inference on null hypothesis of no difference between that group and the control group. The final column shows the F-statistic on the joint test that no treatment group differs from the control group. Beneath it, we display its asymptotic p-value and beneath that its randomization inference $p$-value. To test whether the offices are equally distributed across departments and districts, we present p-values from Pearson's $\chi^{2}$ tests for the equality of proportions. 


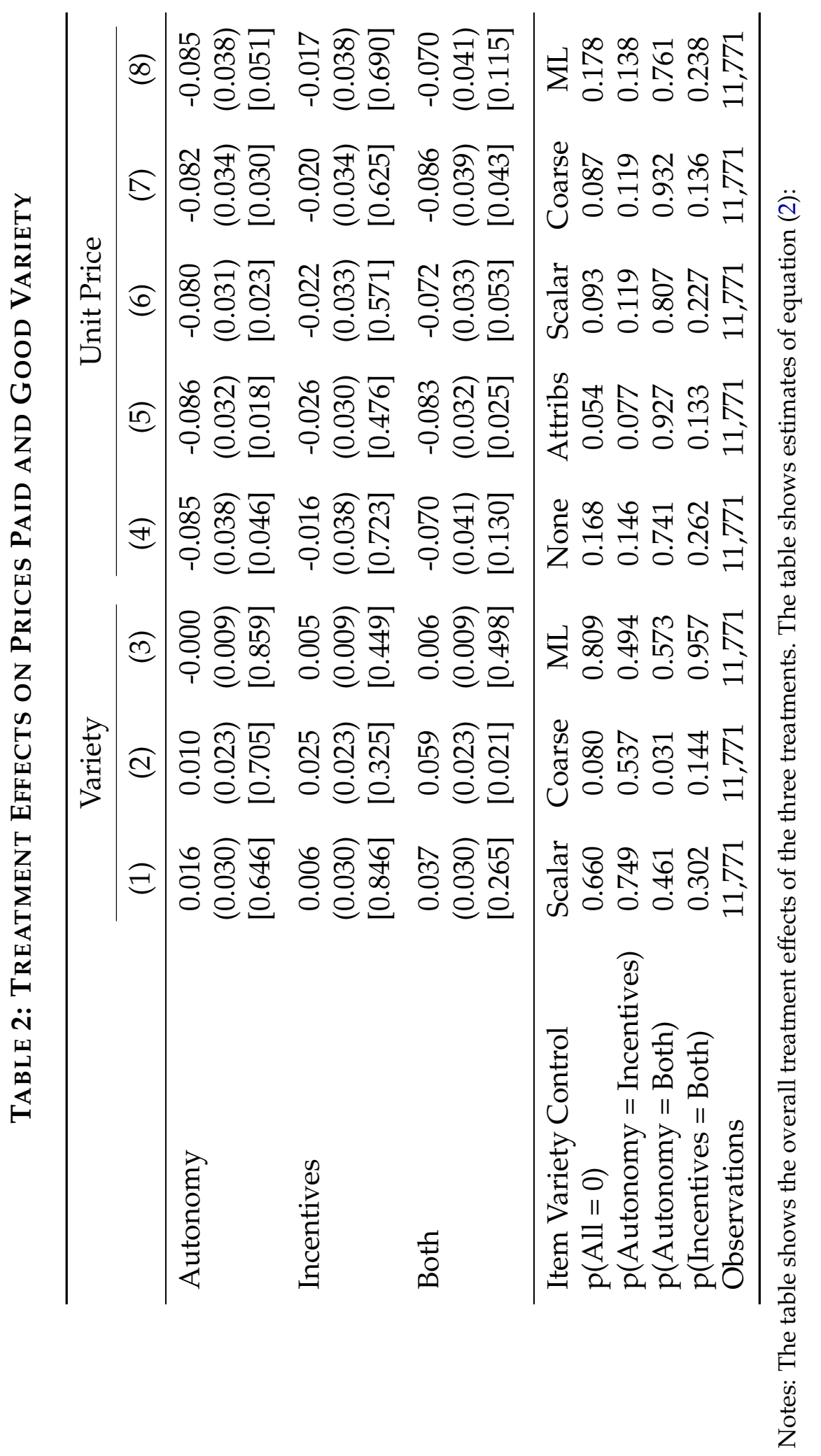

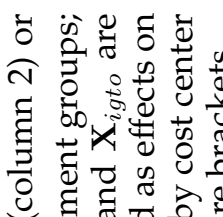

政

要 今

द्व

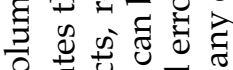

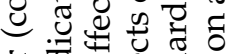

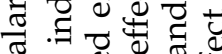

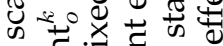

웜

î

$+\quad: 4 \omega^{\circ}$

$\therefore \quad$ I

$+\quad g$ ह

$\infty^{\infty}$ है औै

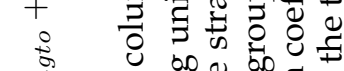

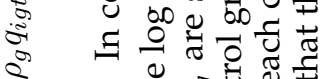

$\circ$ 요요

$\& .900$ 응

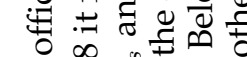
사요

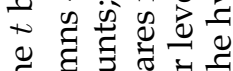

छ

- 5 o

क

0.9 .

$\approx \quad 0$ 잉

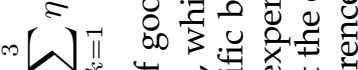

ठ

o .

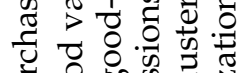

응

ㄴ

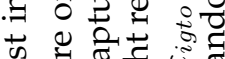

क

吉 弯

항

表

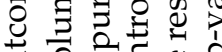

亏 过司记

ક

क ह ह 릉

웡

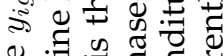

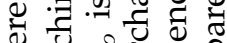

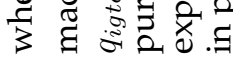




\section{TABle 3: TReATMent EFFects ON DeMAND For GoOdS}

\begin{tabular}{|c|c|c|c|c|}
\hline \multirow{2}{*}{ Item } & \multicolumn{3}{|c|}{ Treatment Effect } & \multirow{2}{*}{$\begin{array}{c}\text { Joint Test } \\
\text { All }=0\end{array}$} \\
\hline & Autonomy & Incentives & Both & \\
\hline Toner & $\begin{array}{c}14.2 \\
(290.62)\end{array}$ & $\begin{array}{c}103.1 \\
(294.41)\end{array}$ & $\begin{array}{c}32.6 \\
(292.44)\end{array}$ & $\begin{array}{c}0.05 \\
{[0.985]}\end{array}$ \\
\hline Ice Block & $\begin{array}{c}-6.3 \\
(21.16)\end{array}$ & $\begin{array}{l}-39.1^{*} \\
(21.43)\end{array}$ & $\begin{array}{c}-12.3 \\
(21.29)\end{array}$ & $\begin{array}{c}1.32 \\
{[0.266]}\end{array}$ \\
\hline Towel & $\begin{array}{c}-13.3 \\
(12.53)\end{array}$ & $\begin{array}{c}4.8 \\
(12.70)\end{array}$ & $\begin{array}{c}-15.1 \\
(12.61)\end{array}$ & $\begin{array}{c}1.25 \\
{[0.291]}\end{array}$ \\
\hline Soap/Detergent & $\begin{array}{c}-324.0 \\
(785.13)\end{array}$ & $\begin{array}{c}11.0 \\
(795.36)\end{array}$ & $\begin{array}{c}368.4 \\
(790.04)\end{array}$ & $\begin{array}{c}0.28 \\
{[0.843]}\end{array}$ \\
\hline Duster & $\begin{array}{l}-14.2 \\
(11.59)\end{array}$ & $\begin{array}{c}18.0 \\
(11.74)\end{array}$ & $\begin{array}{c}-16.8 \\
(11.66)\end{array}$ & $\begin{array}{c}3.91 \\
{[0.008]}\end{array}$ \\
\hline Wiper & $\begin{array}{c}-1.3 \\
(9.10)\end{array}$ & $\begin{array}{l}22.0^{* *} \\
(9.22)\end{array}$ & $\begin{array}{c}-7.4 \\
(9.16)\end{array}$ & $\begin{array}{c}4.08 \\
{[0.007]}\end{array}$ \\
\hline Lock & $\begin{array}{c}6.1 \\
(20.10)\end{array}$ & $\begin{array}{c}10.4 \\
(20.36)\end{array}$ & $\begin{array}{c}-17.1 \\
(20.23)\end{array}$ & $\begin{array}{c}0.75 \\
{[0.519]}\end{array}$ \\
\hline Pen & $\begin{array}{c}54.8 \\
(54.41)\end{array}$ & $\begin{array}{c}75.8 \\
(55.12)\end{array}$ & $\begin{array}{c}19.3 \\
(54.76)\end{array}$ & $\begin{array}{c}0.78 \\
{[0.503]}\end{array}$ \\
\hline Envelope & $\begin{array}{c}14.7 \\
(11.18)\end{array}$ & $\begin{array}{c}-4.8 \\
(11.32)\end{array}$ & $\begin{array}{c}-7.6 \\
(11.25)\end{array}$ & $\begin{array}{c}1.66 \\
{[0.172]}\end{array}$ \\
\hline Printer Paper & $\begin{array}{c}157.1 \\
(187.33)\end{array}$ & $\begin{array}{c}254.9 \\
(189.77)\end{array}$ & $\begin{array}{c}-140.4 \\
(188.50)\end{array}$ & $\begin{array}{c}1.79 \\
{[0.147]}\end{array}$ \\
\hline Register & $\begin{array}{c}-212.7 \\
(357.08)\end{array}$ & $\begin{array}{c}-62.3 \\
(361.74)\end{array}$ & $\begin{array}{c}68.2 \\
(359.32)\end{array}$ & $\begin{array}{c}0.24 \\
{[0.870]}\end{array}$ \\
\hline Stapler & $\begin{array}{l}-11.8 \\
(7.91)\end{array}$ & $\begin{array}{c}-8.9 \\
(8.01)\end{array}$ & $\begin{array}{l}-13.2^{*} \\
(7.96)\end{array}$ & $\begin{array}{c}1.09 \\
{[0.353]}\end{array}$ \\
\hline Staples & $\begin{array}{c}-1.4 \\
(2.87)\end{array}$ & $\begin{array}{c}0.7 \\
(2.91)\end{array}$ & $\begin{array}{c}1.3 \\
(2.89)\end{array}$ & $\begin{array}{c}0.34 \\
{[0.800]}\end{array}$ \\
\hline Calculator & $\begin{array}{c}-9.8 \\
(8.01)\end{array}$ & $\begin{array}{l}-11.5 \\
(8.11)\end{array}$ & $\begin{array}{l}-12.9 \\
(8.06)\end{array}$ & $\begin{array}{c}1.03 \\
{[0.378]}\end{array}$ \\
\hline File Cover & $\begin{array}{c}27.7 \\
(25.39)\end{array}$ & $\begin{array}{c}-29.4 \\
(25.72)\end{array}$ & $\begin{array}{c}10.4 \\
(25.55)\end{array}$ & $\begin{array}{c}1.83 \\
{[0.139]}\end{array}$ \\
\hline Stamp Pad & $\begin{array}{c}5.7 \\
(4.25)\end{array}$ & $\begin{array}{c}5.6 \\
(4.30)\end{array}$ & $\begin{array}{c}-1.4 \\
(4.28)\end{array}$ & $\begin{array}{c}1.58 \\
{[0.193]}\end{array}$ \\
\hline Photocopying & $\begin{array}{c}22.5 \\
(50.18)\end{array}$ & $\begin{array}{c}55.6 \\
(50.84)\end{array}$ & $\begin{array}{c}69.8 \\
(50.50)\end{array}$ & $\begin{array}{c}0.79 \\
{[0.501]}\end{array}$ \\
\hline Broom & $\begin{array}{c}45.1 \\
(47.26)\end{array}$ & $\begin{array}{c}84.9^{*} \\
(47.87)\end{array}$ & $\begin{array}{c}32.8 \\
(47.55)\end{array}$ & $\begin{array}{c}1.08 \\
{[0.355]}\end{array}$ \\
\hline Coal & $\begin{array}{c}-26.5 \\
(58.50)\end{array}$ & $\begin{array}{c}63.8 \\
(59.26)\end{array}$ & $\begin{array}{c}67.4 \\
(58.87)\end{array}$ & $\begin{array}{c}1.33 \\
{[0.263]}\end{array}$ \\
\hline Newspaper & $\begin{array}{c}20.9 \\
(33.64)\end{array}$ & $\begin{array}{c}0.4 \\
(34.08)\end{array}$ & $\begin{array}{c}2.4 \\
(33.86)\end{array}$ & $\begin{array}{c}0.19 \\
{[0.905]}\end{array}$ \\
\hline Pipe & $\begin{array}{c}41.6 \\
(33.42)\end{array}$ & $\begin{array}{l}90.5^{* * *} \\
(33.85)\end{array}$ & $\begin{array}{c}16.1 \\
(33.63)\end{array}$ & $\begin{array}{c}2.79 \\
{[0.039]}\end{array}$ \\
\hline Light Bulb & $\begin{array}{c}66.6 \\
(94.17)\end{array}$ & $\begin{array}{c}-38.7 \\
(95.40)\end{array}$ & $\begin{array}{c}-2.6 \\
(94.76)\end{array}$ & $\begin{array}{c}0.45 \\
{[0.715]}\end{array}$ \\
\hline Pencil & $\begin{array}{c}6.4 \\
(4.36)\end{array}$ & $\begin{array}{c}-0.1 \\
(4.42)\end{array}$ & $\begin{array}{c}-2.8 \\
(4.39)\end{array}$ & $\begin{array}{c}1.69 \\
{[0.167]}\end{array}$ \\
\hline Floor Cleaner & $\begin{array}{c}-18.3 \\
(43.58)\end{array}$ & $\begin{array}{c}-3.0 \\
(44.15)\end{array}$ & $\begin{array}{c}14.7 \\
(43.86)\end{array}$ & $\begin{array}{c}0.20 \\
{[0.893]}\end{array}$ \\
\hline Sign Board/Banner & $\begin{array}{c}123.4 \\
(166.19)\end{array}$ & $\begin{array}{c}24.1 \\
(168.35)\end{array}$ & $\begin{array}{c}32.4 \\
(167.23)\end{array}$ & $\begin{array}{c}0.22 \\
{[0.883]}\end{array}$ \\
\hline Joint F-Test & $\begin{array}{c}0.83 \\
{[0.704]}\end{array}$ & $\begin{array}{c}1.23 \\
{[0.198]}\end{array}$ & $\begin{array}{c}0.65 \\
{[0.911]}\end{array}$ & $\begin{array}{c}1.08 \\
{[0.297]}\end{array}$ \\
\hline
\end{tabular}

Notes: The table shows the overall treatment effects of the three treatments on the demand for different goods. We value each purchase using the counterfactual prices we estimate each purchase would have been made at had it been made by an office in the control group-the scalar variety measure. That is, for each purchase, the counterfactual expenditure is $e_{\text {igto }}=\exp \left(v_{\text {igto }}+q_{\text {igto }}\right)$ where $v_{\text {igto }}$ is the scalar good variety measure, and $q_{\text {igto }}$ is the log number of units purchased. We then aggregate the data to the goodmonth-office level and estimate good-specific treatment effects by multivariate regression with the following specification for each item $e_{g t o}=\sum_{k=1}^{3} \eta_{k g}$ Treatment ${ }_{o}^{k}+\gamma_{s}+\xi_{t}+\varepsilon_{g t o}$ where $e_{g t o}$ is the quantity purchased of good $g$ in month $t$ by office $o$; the $\eta_{k g}$ are good-specific treatment effects; $\gamma_{s}$ and $\xi_{t}$ are stratum and month fixed effects respectively; and $\varepsilon_{\text {gto }}$ are residuals clustered by office. For each good, we display the estimated $\eta_{k g}$ coefficients and their standard errors clustered by office, as well as the F-statistic for the hypothesis that all three $\eta_{k g}$ s are equal to zero and its p-value in square brackets. In the final row, we display F-statistics for the hypothesis that each treatment has zero effect on any item, and the F-statistic on the hypothesis that none of the treatments affects any of the items. 
Table 4: Time Use and Procurement Performance

\begin{tabular}{|c|c|c|c|c|c|c|c|c|c|}
\hline \multicolumn{10}{|c|}{ Panel A: Autonomy } \\
\hline & \multicolumn{3}{|c|}{ Overall } & \multicolumn{3}{|c|}{ Good AG } & \multicolumn{3}{|c|}{ Bad AG } \\
\hline & (1) & (2) & (3) & $(4)$ & (5) & (6) & (7) & (8) & (9) \\
\hline & OLS & IV & 1st Stage & OLS & IV & 1st Stage & OLS & IV & 1st Stage \\
\hline Time Spent on Procurement & $\begin{array}{c}-0.001 \\
(0.001)\end{array}$ & $\begin{array}{l}-0.006 \\
(0.005) \\
{[0.022]}\end{array}$ & & $\begin{array}{c}-0.001 \\
(0.002)\end{array}$ & $\begin{array}{c}0.014 \\
(0.022) \\
{[0.304]}\end{array}$ & & $\begin{array}{c}-0.001 \\
(0.001)\end{array}$ & $\begin{array}{c}-0.012 \\
(0.006) \\
{[0.001]}\end{array}$ & \\
\hline Autonomy & & & $\begin{array}{c}5.856 \\
(2.490) \\
{[0.043]}\end{array}$ & & & $\begin{array}{c}3.785 \\
(4.930) \\
{[0.510]}\end{array}$ & & & $\begin{array}{c}6.975 \\
(2.867) \\
{[0.037]}\end{array}$ \\
\hline Observations & 9,727 & 9,727 & 9,727 & 3,454 & 3,454 & 3,454 & 6,273 & 6,273 & 6,273 \\
\hline \multicolumn{10}{|c|}{ Panel B: Incentives } \\
\hline & \multicolumn{3}{|c|}{ Overall } & \multicolumn{3}{|c|}{ Good AG } & \multicolumn{3}{|c|}{ Bad AG } \\
\hline & (1) & (2) & (3) & $(4)$ & (5) & (6) & (7) & (8) & (9) \\
\hline & OLS & IV & 1st Stage & OLS & IV & 1st Stage & OLS & IV & 1st Stage \\
\hline Time Spent on Procurement & $\begin{array}{c}0.001 \\
(0.001)\end{array}$ & $\begin{array}{l}-0.008 \\
(0.005) \\
{[0.011]}\end{array}$ & & $\begin{array}{c}0.001 \\
(0.001)\end{array}$ & $\begin{array}{l}-0.010 \\
(0.005) \\
{[0.001]}\end{array}$ & & $\begin{array}{l}-0.000 \\
(0.002)\end{array}$ & $\begin{array}{c}-0.161 \\
(2.053) \\
{[0.903]}\end{array}$ & \\
\hline Incentives & & & $\begin{array}{c}6.132 \\
(2.165) \\
{[0.013]}\end{array}$ & & & $\begin{array}{c}8.335 \\
(2.464) \\
{[0.004]}\end{array}$ & & & $\begin{array}{c}-0.330 \\
(4.338) \\
{[0.950]}\end{array}$ \\
\hline Observations & 8,556 & 8,556 & 8,556 & 6,355 & 6,355 & 6,355 & 2,201 & 2,201 & 2,201 \\
\hline \multicolumn{10}{|c|}{ Panel C: Combined } \\
\hline & \multicolumn{3}{|c|}{ Overall } & \multicolumn{3}{|c|}{ Good AG } & \multicolumn{3}{|c|}{ Bad AG } \\
\hline & $(1)$ & (2) & (3) & $(4)$ & (5) & (6) & (7) & (8) & (9) \\
\hline & OLS & IV & 1st Stage & OLS & IV & 1st Stage & OLS & IV & 1st Stage \\
\hline Time Spent on Procurement & $\begin{array}{c}0.002 \\
(0.001)\end{array}$ & $\begin{array}{l}-0.004 \\
(0.007) \\
{[0.667]}\end{array}$ & & $\begin{array}{c}0.002 \\
(0.001)\end{array}$ & $\begin{array}{c}0.004 \\
(0.005) \\
{[0.190]}\end{array}$ & & $\begin{array}{c}0.002 \\
(0.001)\end{array}$ & $\begin{array}{c}-0.013 \\
(0.015) \\
{[0.151]}\end{array}$ & \\
\hline Combined & & & $\begin{array}{c}4.849 \\
(1.860) \\
{[0.018]}\end{array}$ & & & $\begin{array}{c}8.100 \\
(2.826) \\
{[0.022]}\end{array}$ & & & $\begin{array}{c}3.415 \\
(2.374) \\
{[0.226]}\end{array}$ \\
\hline Observations & 8,903 & 8,903 & 8,903 & 2,924 & 2,924 & 2,924 & 5,979 & 5,979 & 5,979 \\
\hline
\end{tabular}

Notes: The table shows estimates of the effect of additional time spent working on procurement on offices' procurement performance. We leverage the increase in time spent working on procurement due to the experiment in an instrumental variables strategy, studying one treatment at a time. Panel A studies the autonomy treatment, panel $\mathrm{B}$ the incentives treatment, and panel $\mathrm{C}$ the combined treatment. Each panel is constructed in the same way. Columns 1-3 study overall effects; columns 4-6 study offices monitored by a relatively well aligned Accountant General (AG) (we use the share of June approvals measure discussed in section 6.1. A good AG has a June share of 0.22 or below in panels $A$ and $C$, and 0.48 or below in panel B); and columns 7-9 study offices monitored by misaligned AGs. In each set of columns, the first shows the coefficient on time spent in an OLS regression, the second column shows the coefficient using treatment assignment to instrument for time spent, and the third column shows the corresponding first stage regression. Standard errors clustered by office are in parentheses. p-values from randomization inference under the null hypothesis of no effect are in square brackets. 


\section{Web Appendix (Not For Publication)}

\section{A Supplementary Figures and Tables}

Figure A.1: Prices Paid Vary Wildly. Even for the SAMe Variety of Item

\section{Panel A: Pen Prices}

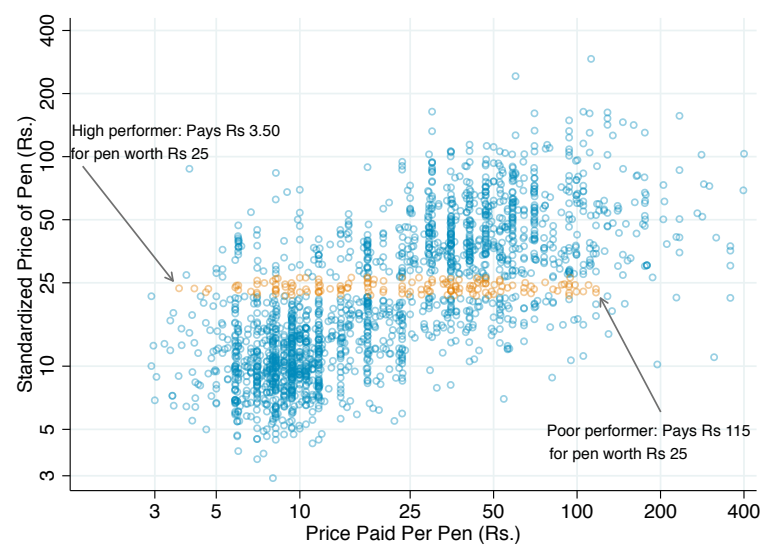

Panel C: Register Prices

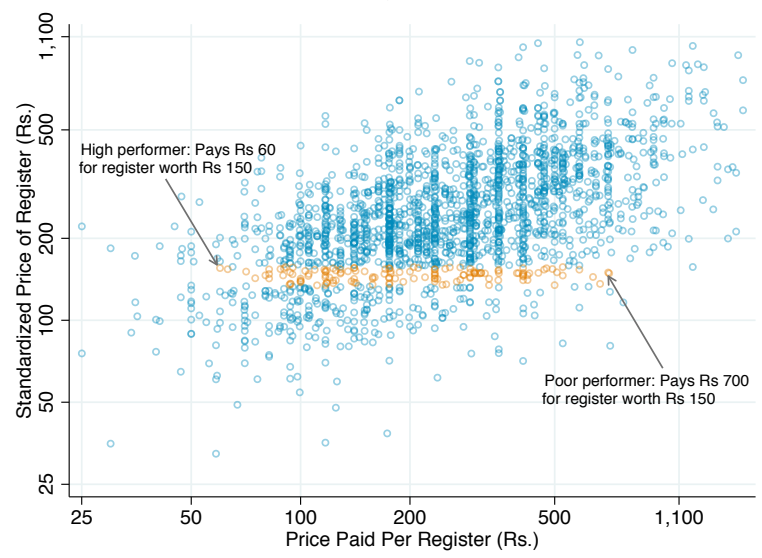

Panel B: Paper Prices

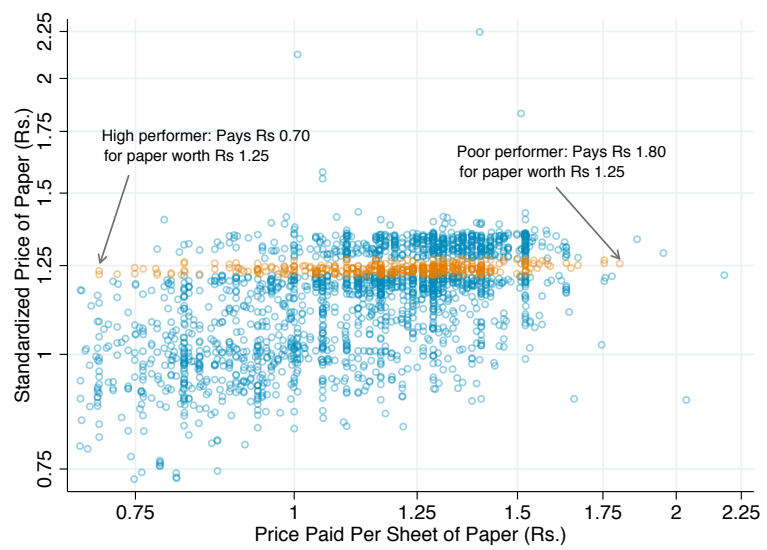

Panel D: Toner Prices

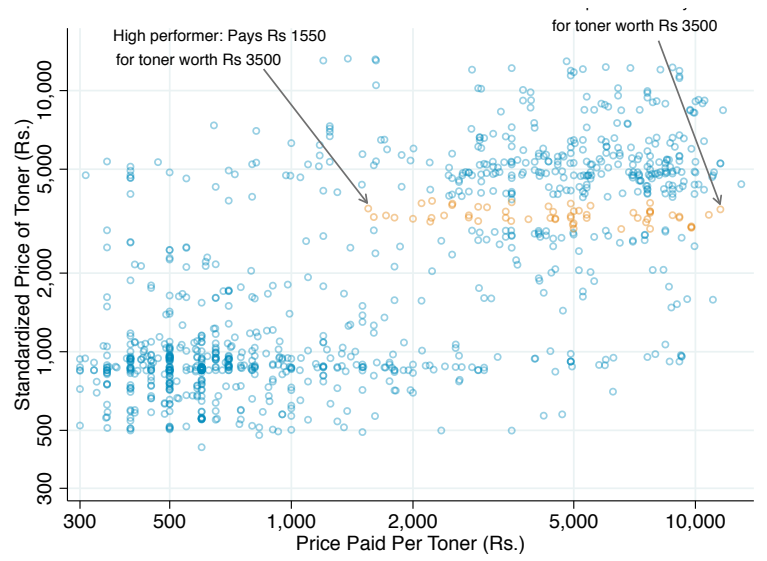

Notes: The figure shows the distribution of unit prices and standardized prices for four of the homogeneous items in our data. Each circle in the figures is a purchase. The horizontal axes display the actual price paid, while the vertical axes display the standardized prices using the scalar item variety measure described in section 5.1. Intuitively, this measure is our prediction of how much the item would have cost on average if it had been purchased in the control group, a standardized measure of the item's variety. The orange circles highlight a set of purchases with the same standardized value, illustrating the striking heterogeneity in prices even for the same item. 


\section{Figure A.2: How Poor Procurement Performance Can Damage Careers}

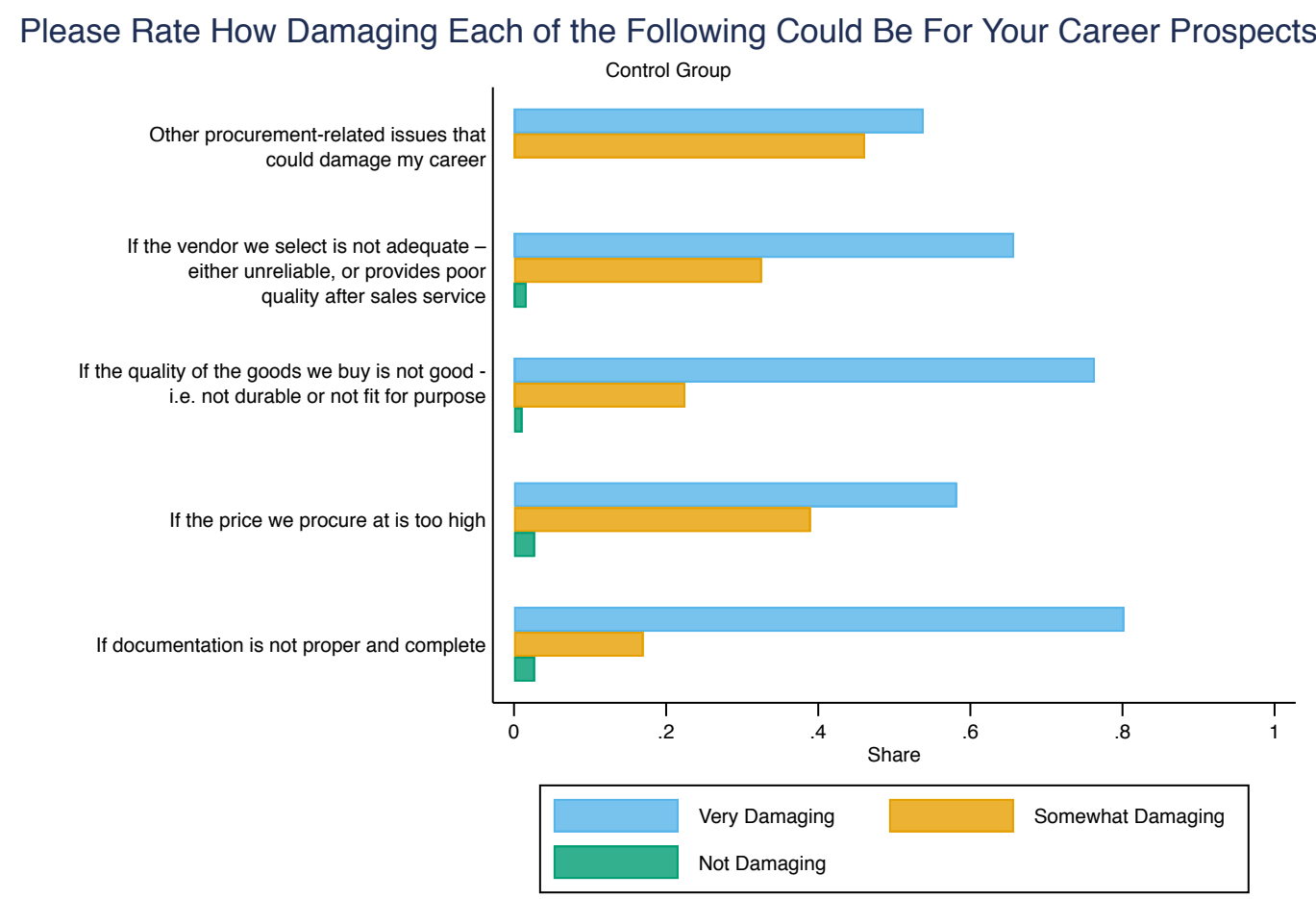

Notes: The figure shows responses among the control group in the endline survey to a question asking them about whether various types of poor performance in procurement could damage their careers. Each bar shows the share of respondents picking that option. 


\section{Figure A.3: Control Group Reasons for Low Value for Money}

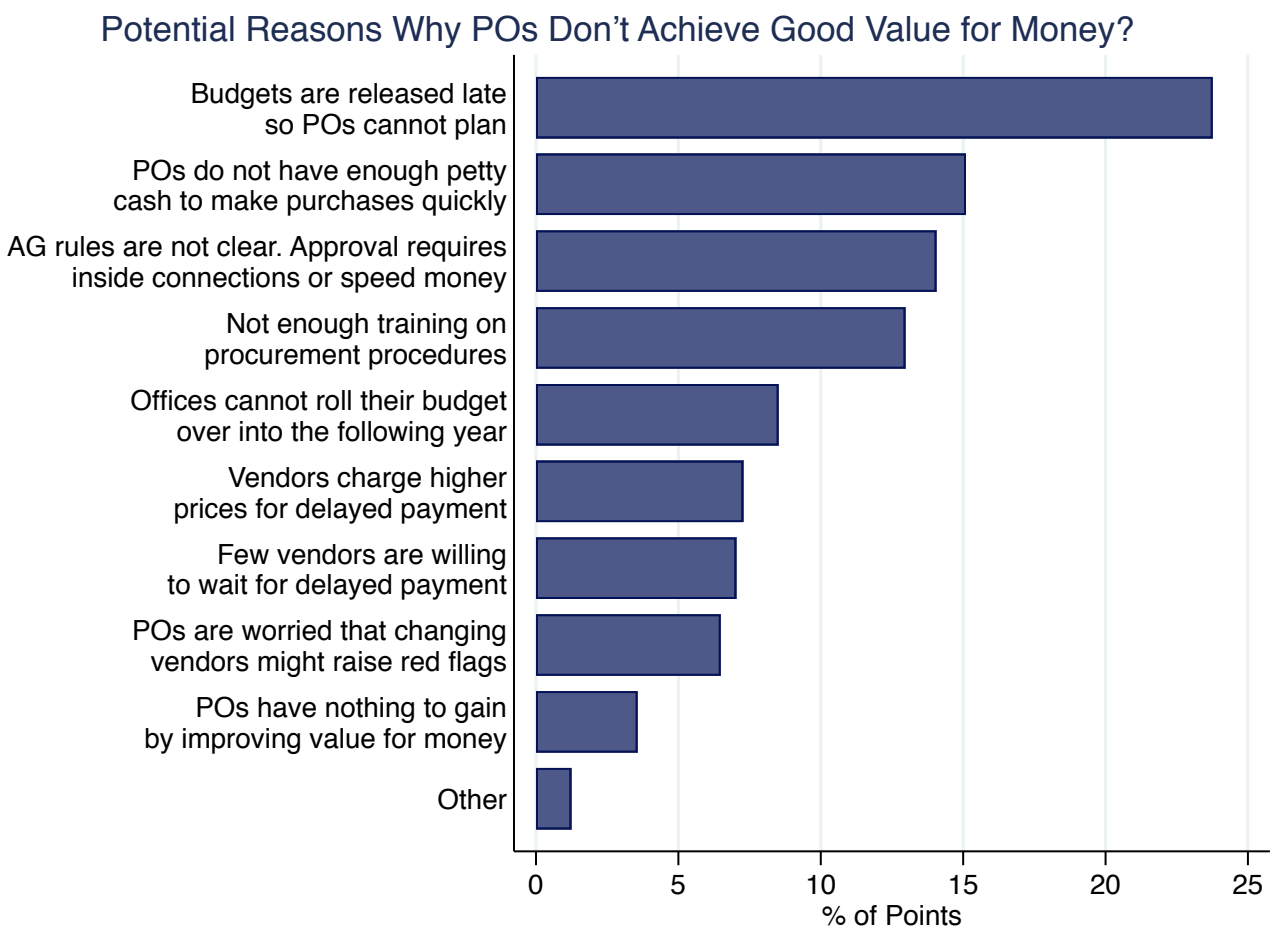

Notes: The figure shows responses among the control group in the endline survey to a question asking them about the reasons they felt that value for money was not being achieved in public procurement. Respondents were asked to allocate 100 points among the 10 options in proportion to how important they thought each option was. Each bar shows the mean number of points allocated to that option. 


\section{Figure A.4: Budget Release Timing UnAfFected}

\section{Panel A: Share of Budget Released Over Time}

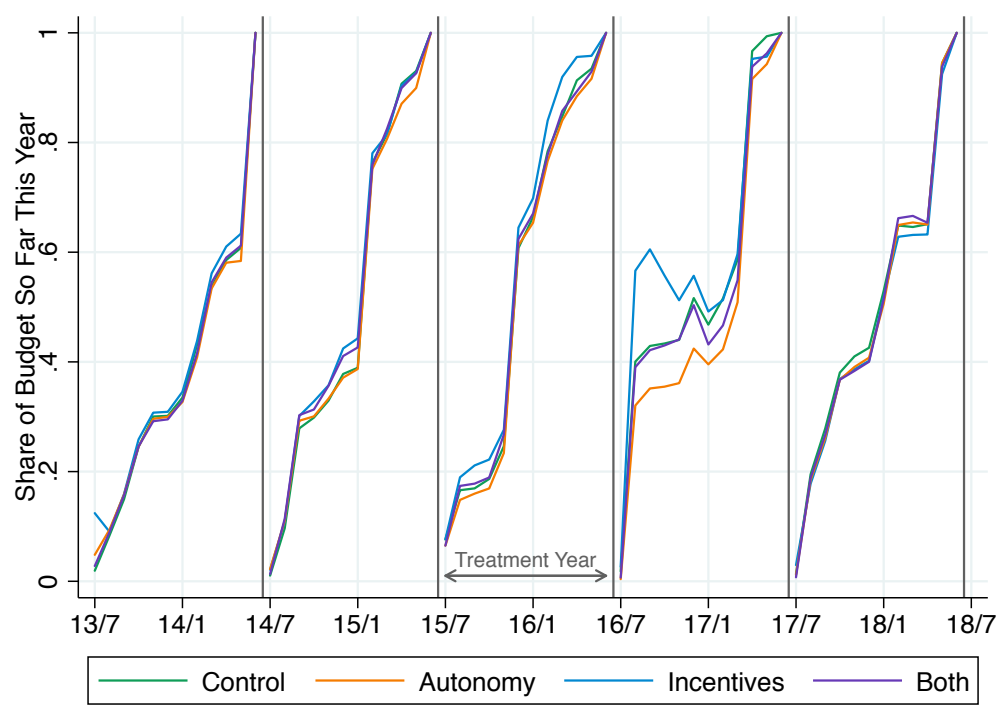

Panel B: Difference in Differences Estimates

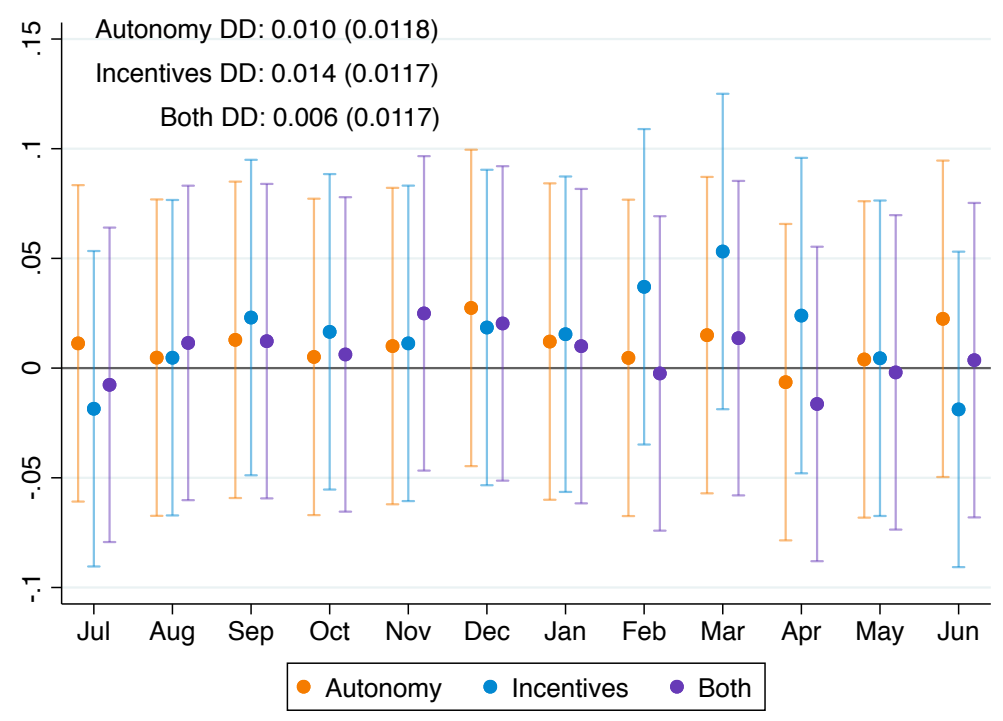

Notes: The figure shows that the timing of budget releases to the offices in the study was unaffected. A third component of the autonomy treatment attempted to improve the frequency and regularity of budget releases, but it was not possible to implement this. Panel A shows how the average share of offices' annual budget evolves over each year in each treatment group. The treatment year (July 2015-June 2016) does not look visibly different from the other years, and any slight differences from other years appear to have affected all four groups in the same way. Panel B shows estimates of the $\eta_{k m}$ coefficients from a differences in differences estimation of

$$
s_{o t}=\sum_{k=1}^{3} \sum_{m=J u l}^{J u n} \eta_{k m} \text { Treatment }_{o}^{k} \times \mathbf{1}\{\text { Month of year }=m\} \times \mathbf{1}\{\text { Fiscal Year 2015-16 }\}+\delta_{t}+\gamma_{o}+\varepsilon_{o t}
$$

where $s_{o t}$ is the share of office $o$ 's annual budget that has been released to it by month $t, \delta_{t}$ are month fixed effects, $\gamma_{o}$ are office fixed effects and $\varepsilon_{o t}$ are residuals. Overlaid on the figure are estimates of difference in difference coefficients of the average effect in the 2015-16 fiscal year in each treatment group. 


\section{FigURE A.5: LocATION OF SAMPLE OfFices}

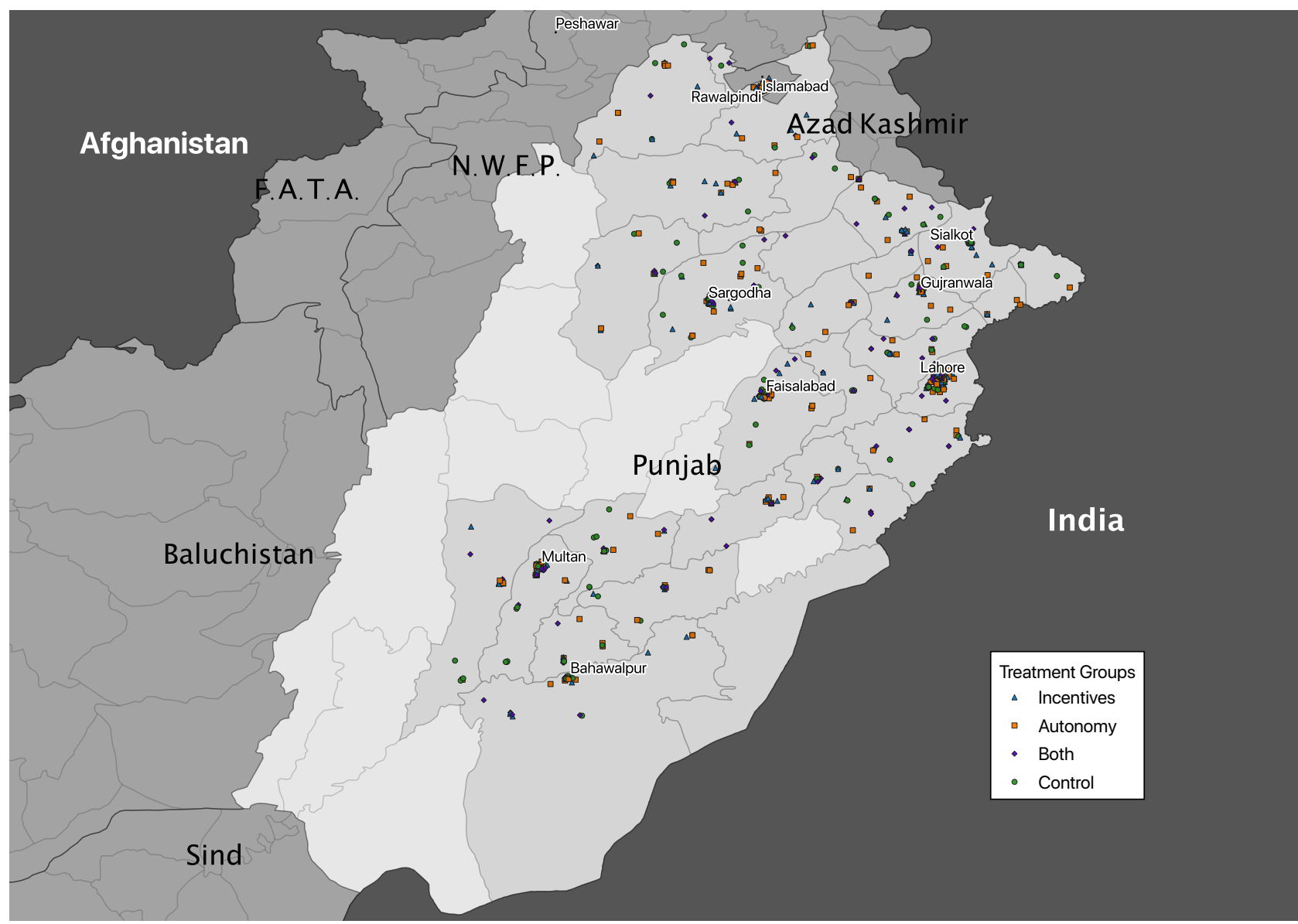

Notes: The figure shows the location of the offices in the study. The offices are located in 26 of the 36 districts in Punjab. Green dots denote control offices, orange dots the autonomy group, blue dots the performance pay group, and purple dots the combined treatment. 
Figure A.6: Sample Offices are a Small Share of the Offices Overseen by Users at THE AcCountant General's OfFice

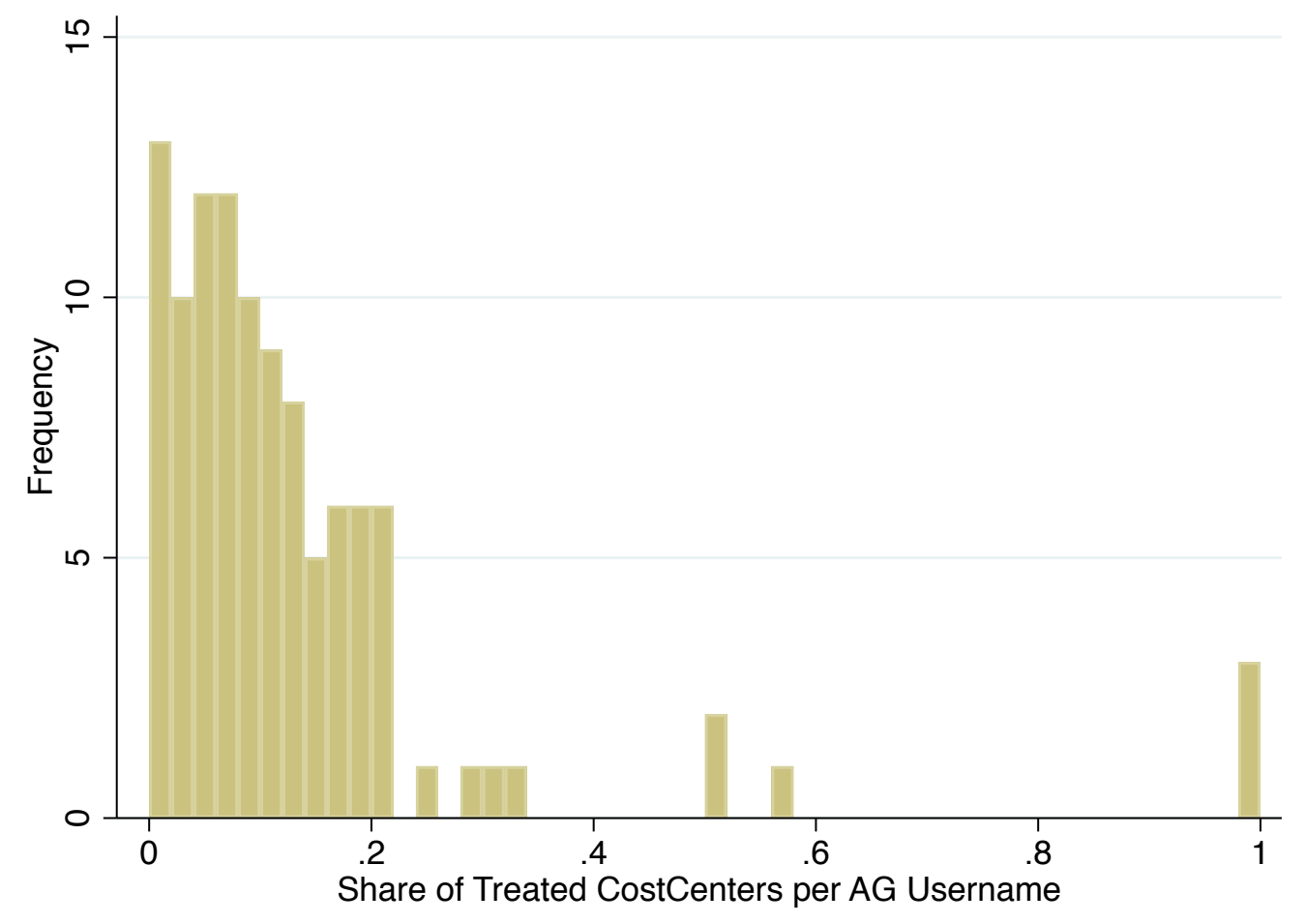

Notes:Each transaction approved by the accountant general's office is associated with a particular officer's username. The figure shows the share of cost centers associated with each username that are in the treated groups of our experiment. The figure shows that for the vast majority of users at the accountant general's office, fewer than $20 \%$ of their offices are treated. 


\section{Figure A.7: Price Changes in the Control Group are not Larger When More Offices Receive the Autonomy Treatment}

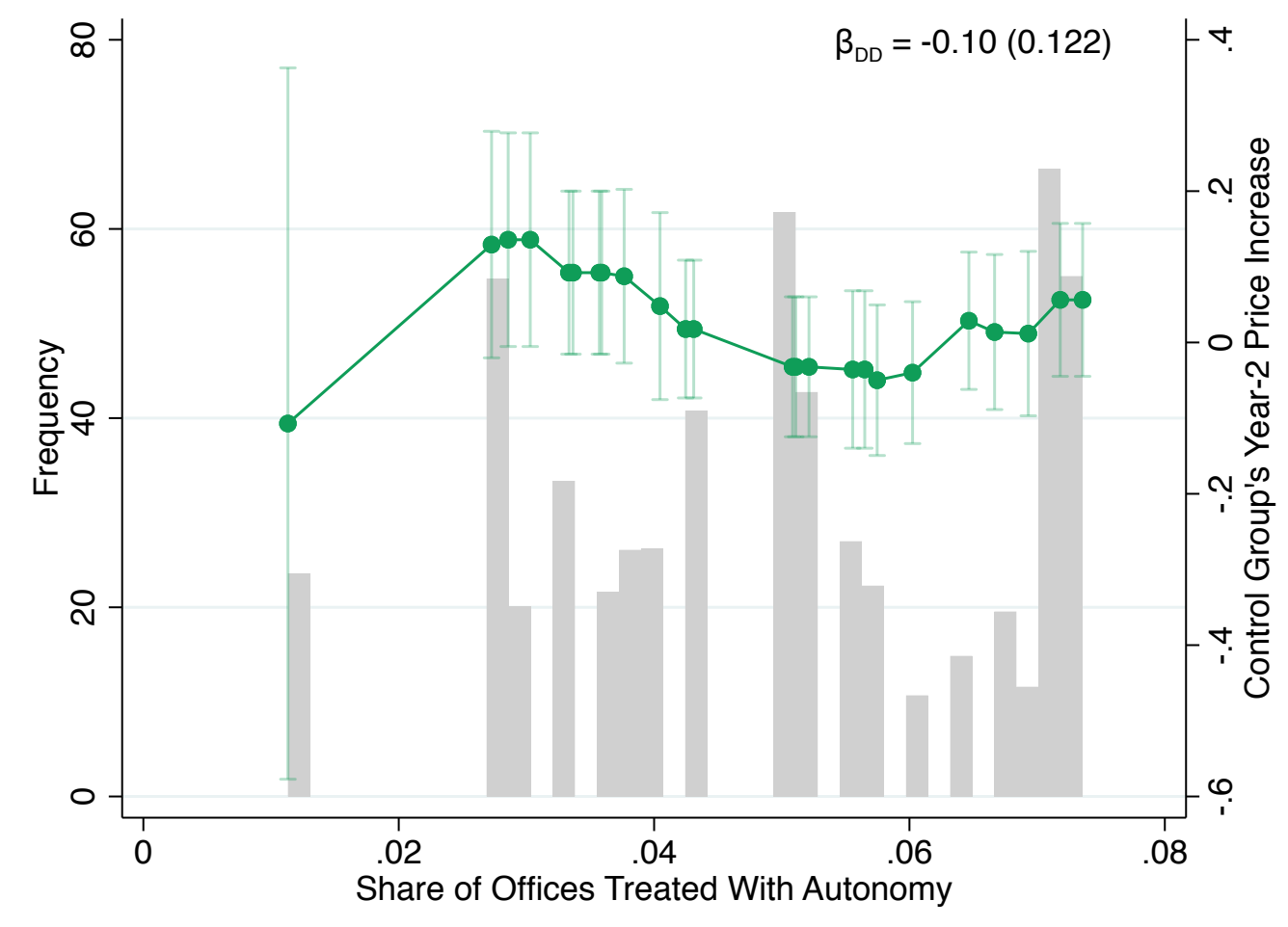

Notes: The figure shows how prices change between year 1 (before the rollout of the autonomy treatment) and year 2 (after the rollout) in offices in the control group as a function of the share of the offices monitored by an accountant general that receive the autonomy treatment. For each accountant general's office, we run the regression $p_{\text {igto }}=\alpha \hat{v}_{i g t o}^{\text {scalar }}+\beta_{Y 2}$ Year $2_{t}+\gamma_{g}+\rho_{g} q_{\text {igto }}+\varepsilon_{\text {igto }}$, where $\hat{v}_{i g t o}$ is the scalar measure of item variety, in a sample of control group procurement offices supervised by an accountant general with a share of offices in the autonomy group within 0.01 of the office in question. The figure presents these estimates with their $95 \%$ confidence intervals in green. We also overlay on the picture the difference in differences estimate of $\beta_{D D}$ in the following regression

$$
p_{\text {igto }}=\alpha \hat{v}_{\text {igto }}^{\text {scalar }}+\beta_{Y 2} \text { Year2 }_{t}+\beta_{D D} \text { Year2 }_{t} \times \text { AutonomyShare }_{o}+\gamma_{g}+\rho_{g} q_{\text {igto }}+\delta_{g} t+\varepsilon_{\text {igto }}
$$

where AutonomyShare ${ }_{o}$ is the share of procurement officers monitored by the same accountant general as officer $o$ who receive the autonomy treatment and the regression is run only amongst procurement officers in the control group. 


\section{Figure A.8: Balance of the Distribution of Attrition Rates Across Offices}

\section{Panel A. Year 1; POPS Reporting Rate}
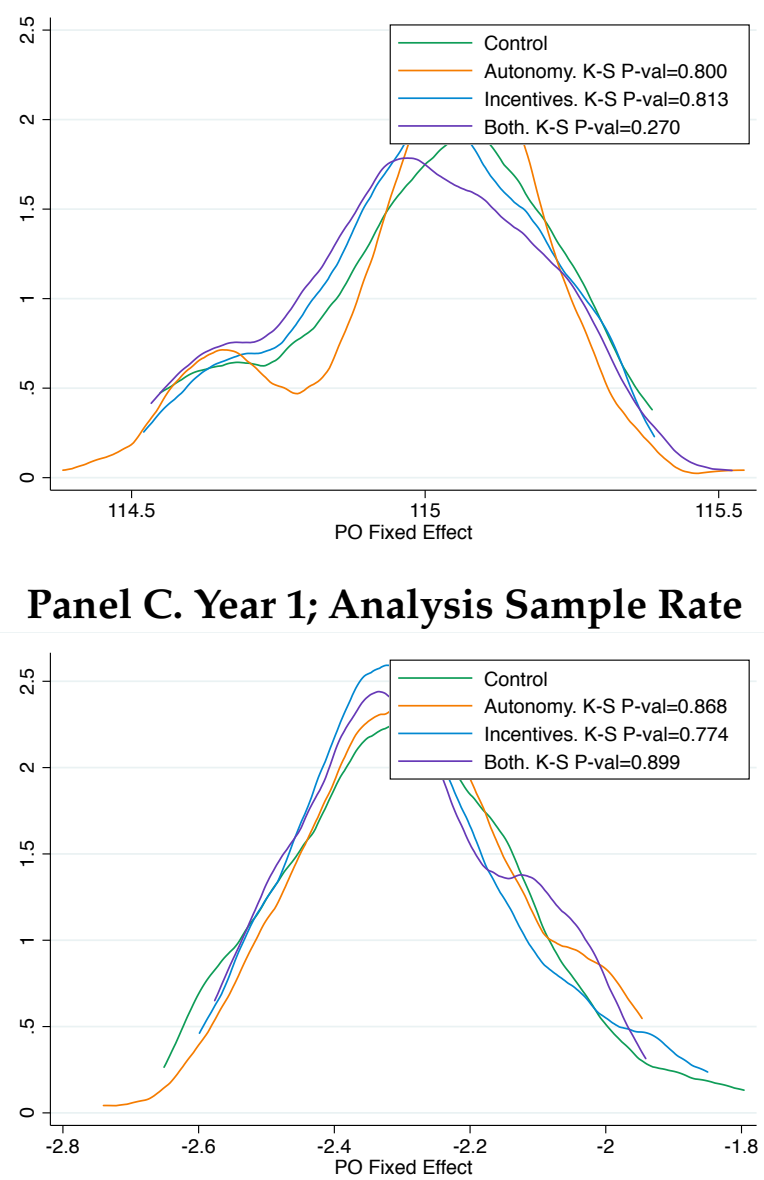

\section{Panel B. Year2; POPS Reporting Rate}

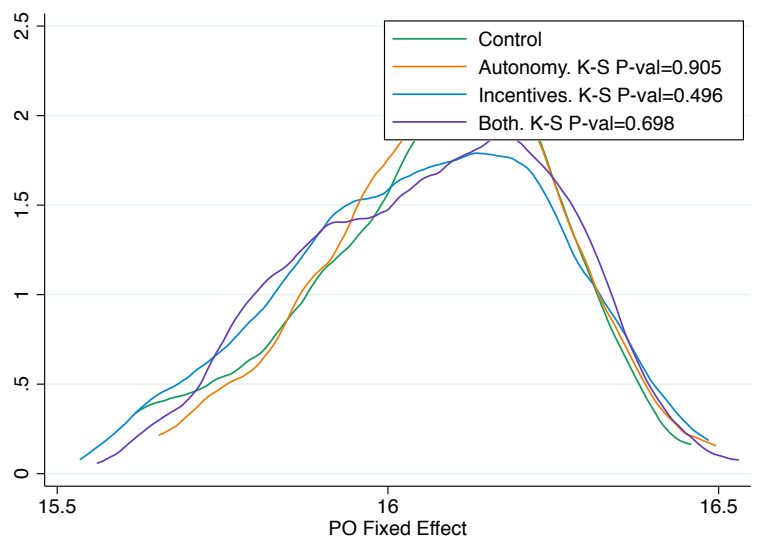

Panel D. Year2; Analysis Sample Rate

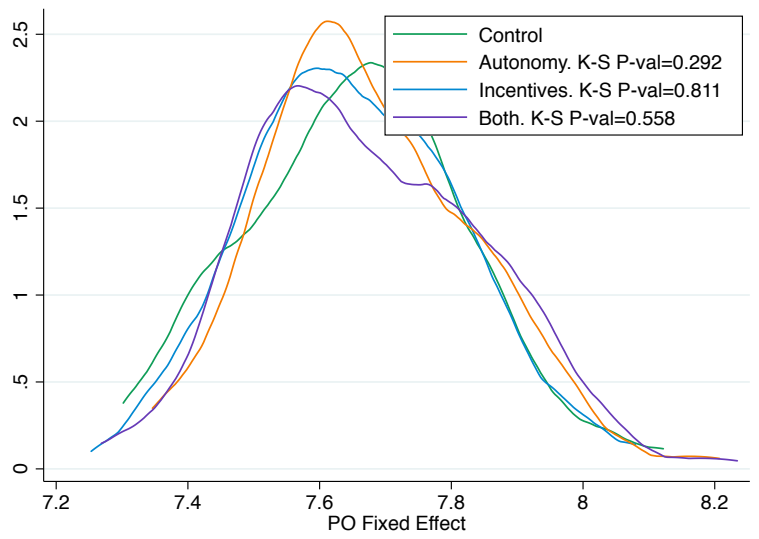

Notes: The figure shows the distribution of procurement office fixed effects $\delta_{o}$ in regressions of the form

$$
s_{b c o}=\mathbf{X}_{b c o} \beta+\gamma_{c}+\delta_{o}+\varepsilon_{b c o}
$$

where $s_{b c o}$ is the share of a transaction (bill) $b$ by office $c$ in an accounting code $o$ that is reported in POPS (panels A and B) or that is represented in our analysis sample (panels $\mathrm{C}$ and D); $\mathbf{X}_{b c o}$ are quadratic time and bill amount controls, $\gamma_{c}$ are accounting code fixed effect, $\delta_{o}$ are procurement office fixed effects, and $\varepsilon_{b c o}$ is an error term. Panels A and C use bills from year 1 of the experiment, while panels B and D analyze year 2. The panels show kernel density estimates of the distributions of the procurement office fixed effects in the 3 treatment groups and the control group. The panels also show exact P-values form Kolmogorov-Smirnov tests of the equality of each treatment group's distribution and the control group's. 


\section{Figure A.9: Decomposing Autonomy Effects on Approval Delays}

\section{Panel A: Delay Between Delivery and Document Submission}

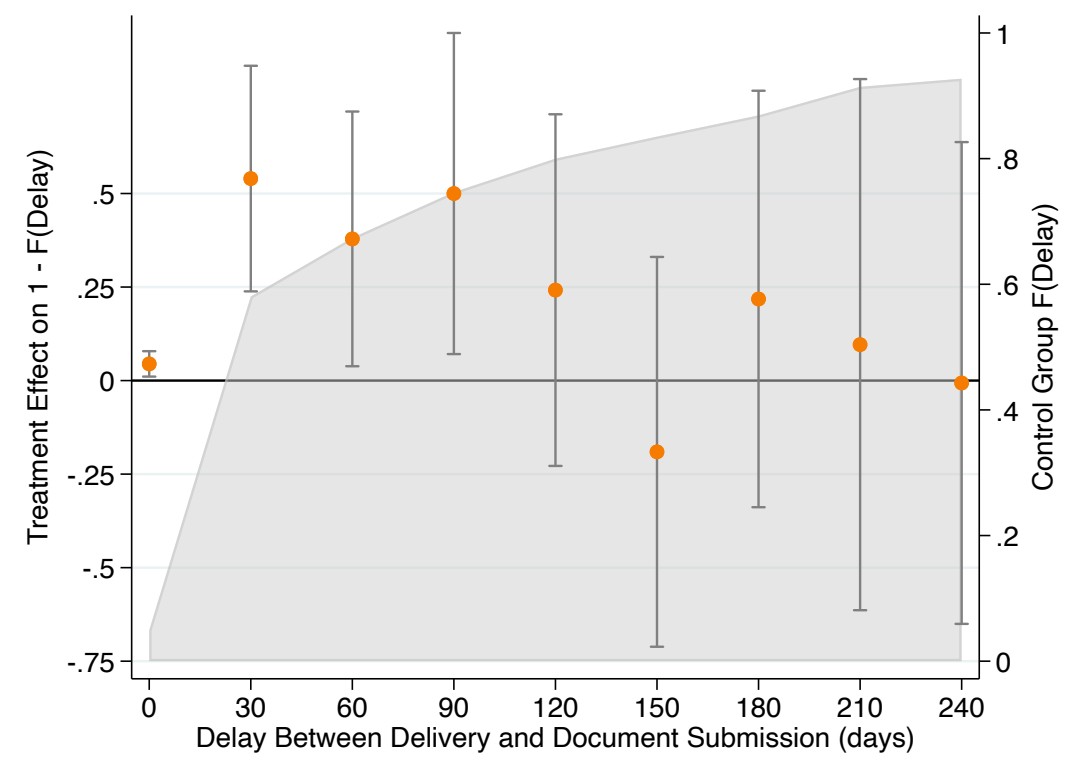

\section{Panel B: Delay Between Document Submission and Approval}

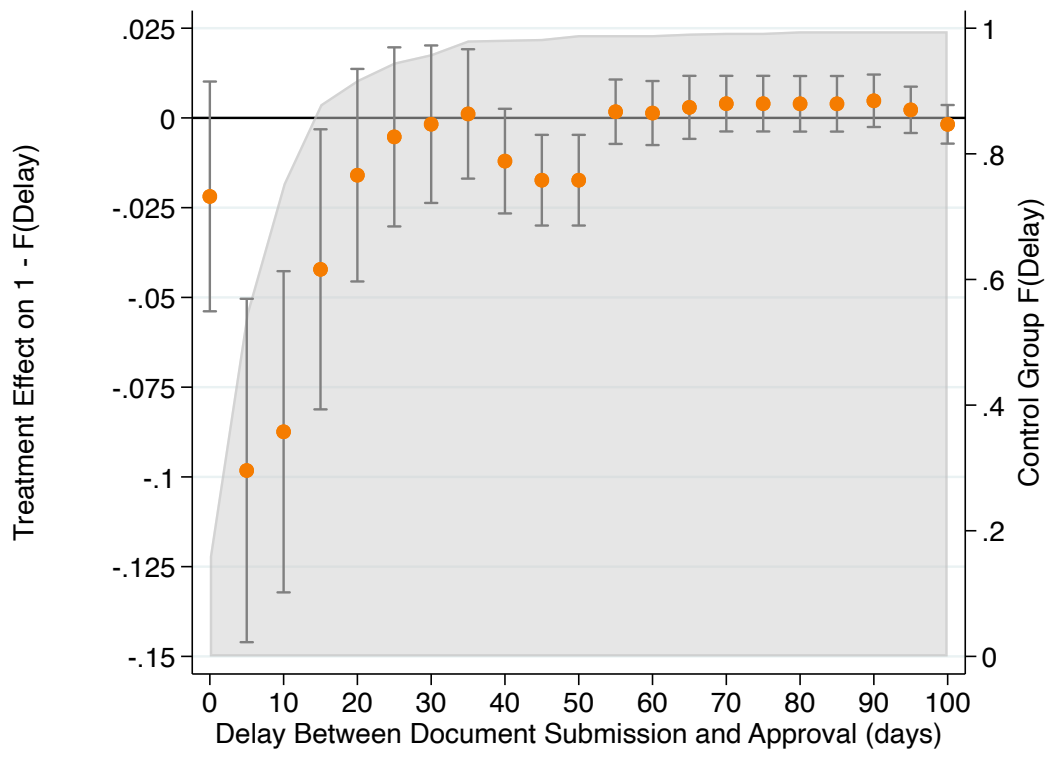

Notes: The figure decomposes the effects of the autonomy treatment on the delay between a purchased item's delivery and the approval of the purchase by the Accountant General (AG) into the delay between the item's delivery and the submission of the documents for approval (Panel A) and the delay between the document's submission and their approval by the AG (Panel B). The estimates come from a series of seemingly unrelated distributional regressions of the probability of delay of at least $j$ days in year 2 normalized by the probability of a delay of at least $j$ days in the control group in year 1 on treatment dummies, strata fixed effects $\gamma_{s}$ and good fixed effects $\gamma_{g}$ :

$$
\frac{1\left\{\text { delay }_{\text {igo }} \geq j\right\}}{\mathbb{P}(\text { delay } \geq j \mid \text { Control, Year } 1)}=\alpha+\sum_{k=1}^{3} \eta_{k} \text { Treatment }_{o}^{k}+\gamma_{s}+\gamma_{g}+\varepsilon_{i g o}
$$

the panel also shows the CDF of delays in the control group in year 1 for reference. 


\section{Figure A.10: Variation in JUne Approval Rates}

\section{Panel A: High and Low Approval Rate Districts}

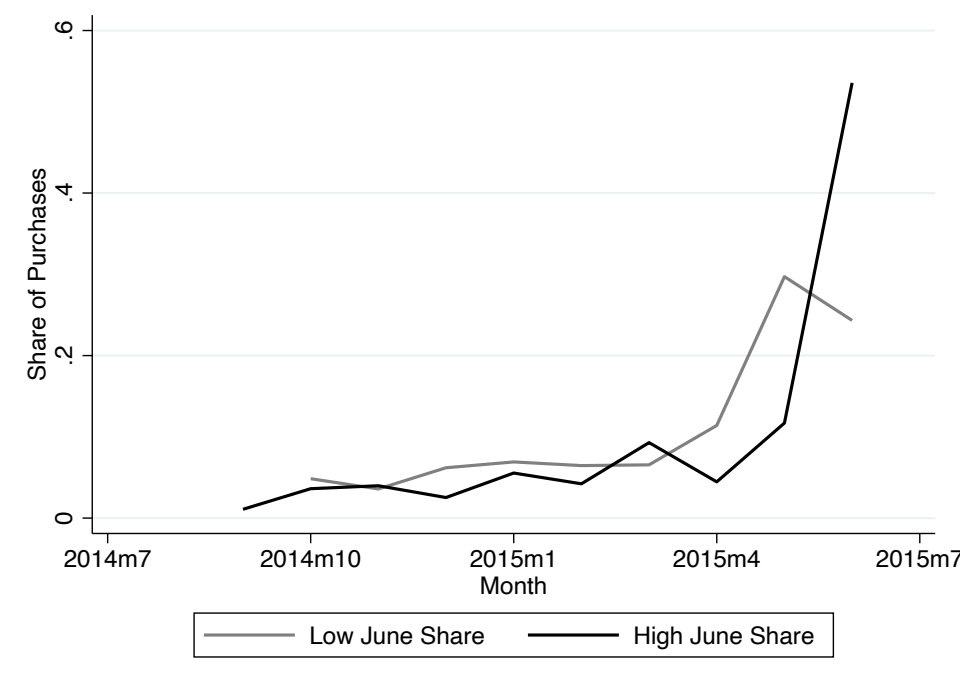

\section{Panel B: Sources of Variation in June Approval Rates}

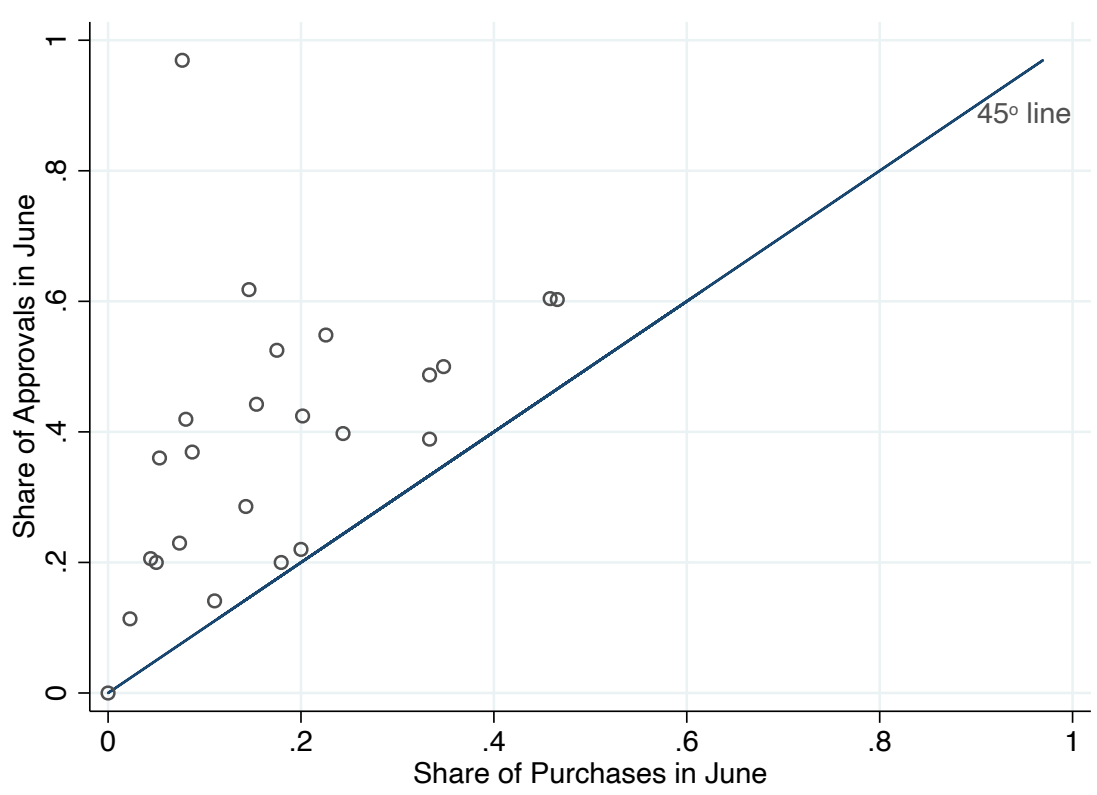

Notes: The figure shows the variation in our proxy for AG type, the share of approvals done in June. Panel A compares the approval rates in districts with high (above median) and low (below median) shares of transactions approved in June. Panel B shows the variation across districts' AG offices in the share of transactions made in June (the last month of the fiscal year) and the share of transactions approved in June (our proxy for the misalignment of the AG). Both aggregates are calculated in the control group in year 1. 


\section{Figure A.11: Heterogeneity by AG Type: Difference in Differences}

\section{Panel A: Autonomy}

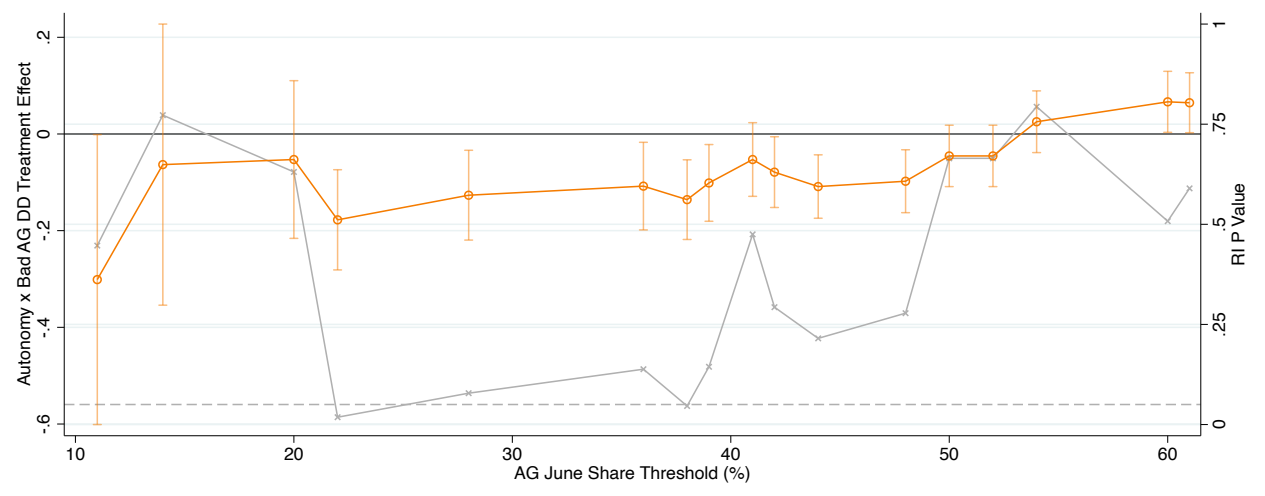

Panel B: Incentives

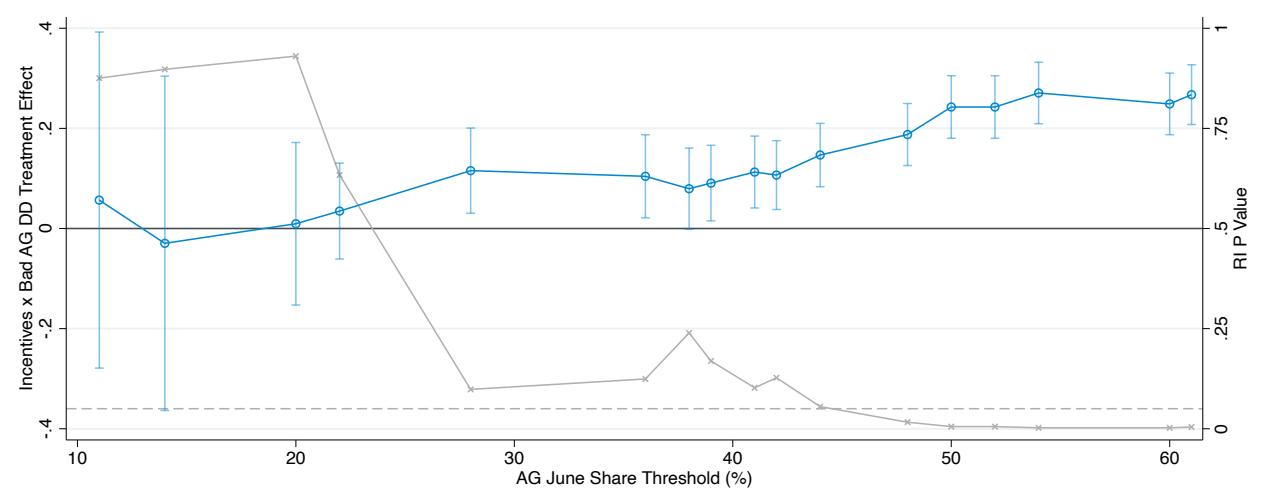

Panel C: Combined

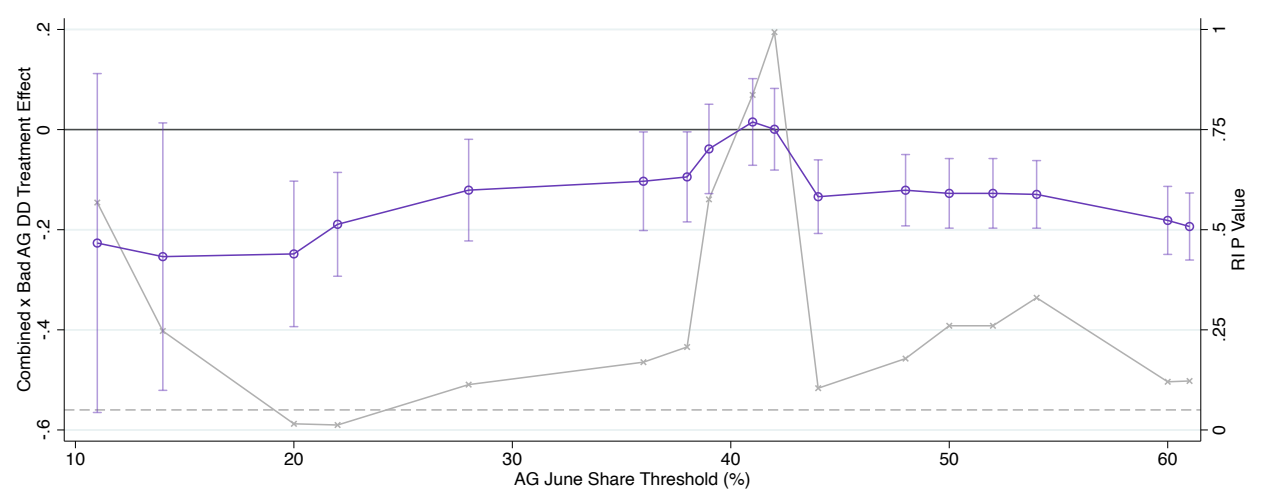

Notes: The figure shows how difference in difference estimates of the heterogeneity of treatment effects by monitor type change as the definition of a "bad" AG is changed. As discussed in section 6.1 our proxy for the degree of misalignment of the AG is the degree to which purchase approvals are bunched at the end of the fiscal year in June 2015 (year 1 of the project). Studying one treatment at a time, we estimate treatment effect heterogeneity by interacting a dummy for facing a "bad" AG with treatment dummies $p_{\text {igto }}=\alpha+\eta$ Treatment $_{o}+\zeta$ Treatment $_{o} \times$ BadAG $_{o}+\mathbf{X}_{\text {igto }} \beta+\rho_{g} q_{\text {igto }}+\delta_{s}+\gamma_{g}+\varepsilon_{\text {igto }}$ where all terms are as defined above, and we control for the scalar measure of item variety in $\mathbf{X}_{i g t o}$. Panel A studies the autonomy treatment, panel B the incentives treatment, and panel C the combined treatment. Each panel is constructed in the same way. The horizontal axis shows the threshold percentage of approvals in June 2015 above which an AG is considered "bad". The points show the point estimates of $\zeta$ and the bars their 95\% confidence interval using standard errors clustered by office. The gray crosses show the randomization inference $\mathrm{p}$ value for the hypothesis that the effect is zero. We pick our definition of a bad AG as the threshold at which the p-value falls below 0.05: 0.22 in panels A and C, and 0.48 in panel B. 
Figure A.12: Dice Scores as a Proxy for PO Type do not Predict Year 1 PRICES

Panel A: Distribution of Dice Scores

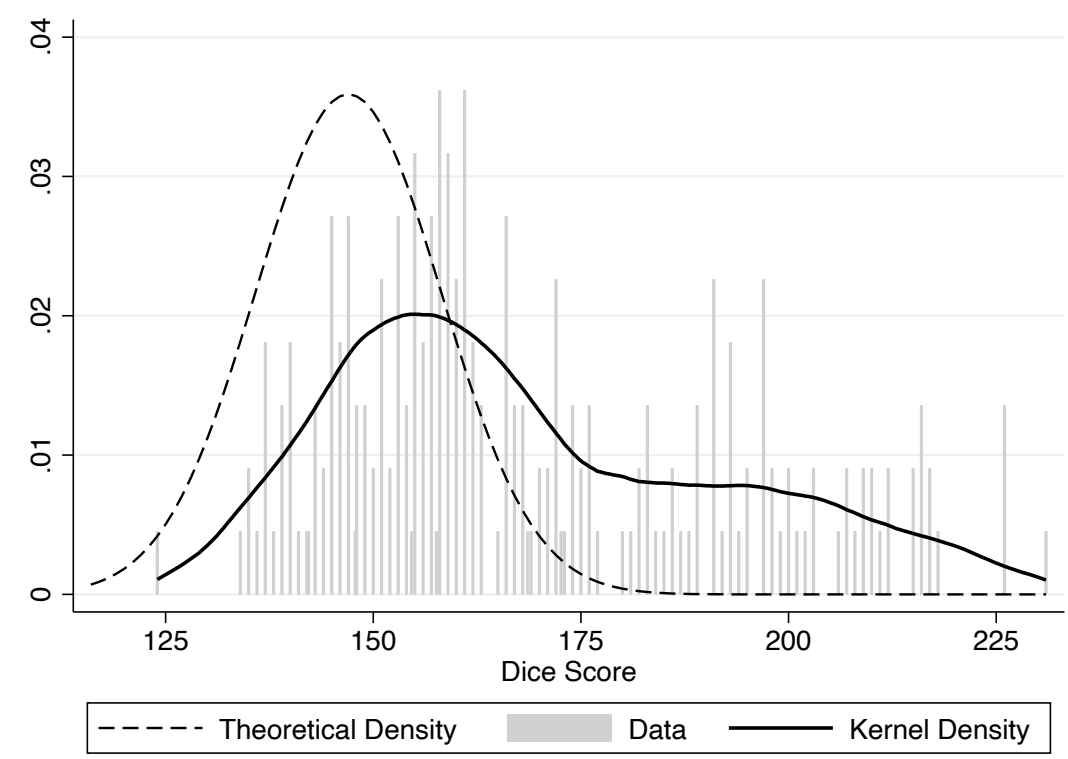

Panel B: Dice Scores do not Predict Year 1 Prices

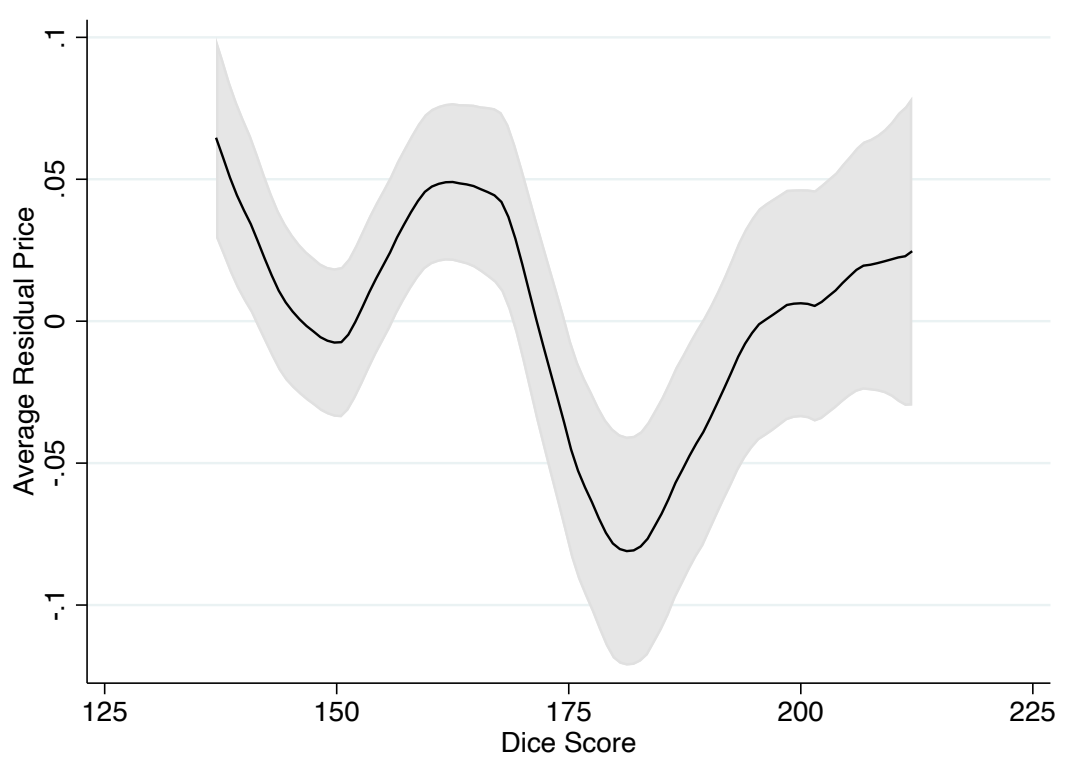

Notes: The figure shows that the dice scores in the lab in the field measure of dishonesty studied in Fischbacher \& Föllmi-Heusi (2013) and Hanna \& Wang (2017) are a poor proxy for PO type in our setting. The dice scores come from a game in which subjects privately roll a die 42 times and report each roll. In each roll they are free to report the number either on the top or the bottom of the die. Subjects play against each other and those achieving the highest scores win prizes. The dashed line in panel A shows the theoretical distribution of the total scores if a fair die is rolled 42 times. The histogram and the solid line (kernel density) show the totals achieved by our subjects. Panel B shows a semi-parametric regression of log unit prices in year 1 in the control group and the autonomy group on controls and the dice scores, showing that the dice scores do not predict prices in year 1. Together, the findings in panel A and B suggest that while there is significant variation in the dice scores in our sample, it is not predictive of procurement performance and hence is a poor proxy for PO type in our setting. 


\title{
Figure A.13: Time Allocation Across Procurement Tasks
}

\author{
Panel A: Reducing Amount Paid for Goods
}

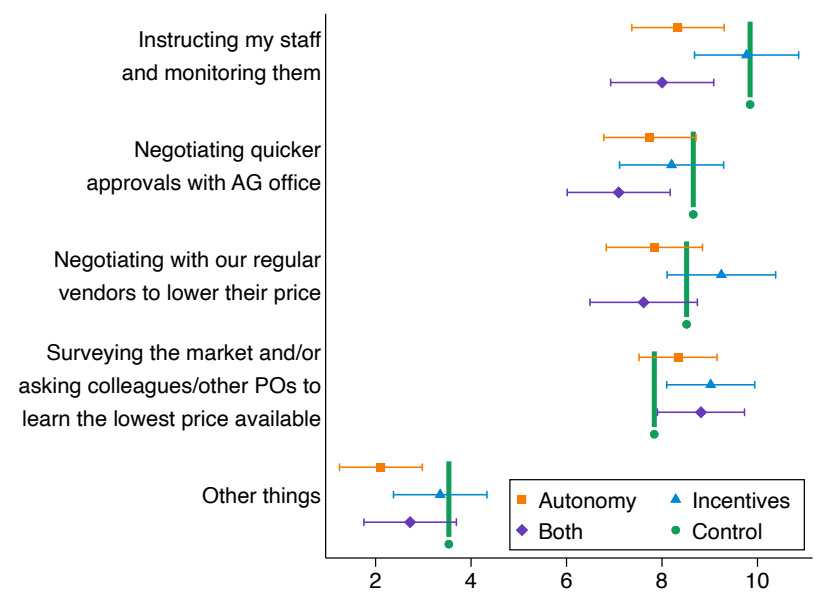

Panel B: Choosing Vendors

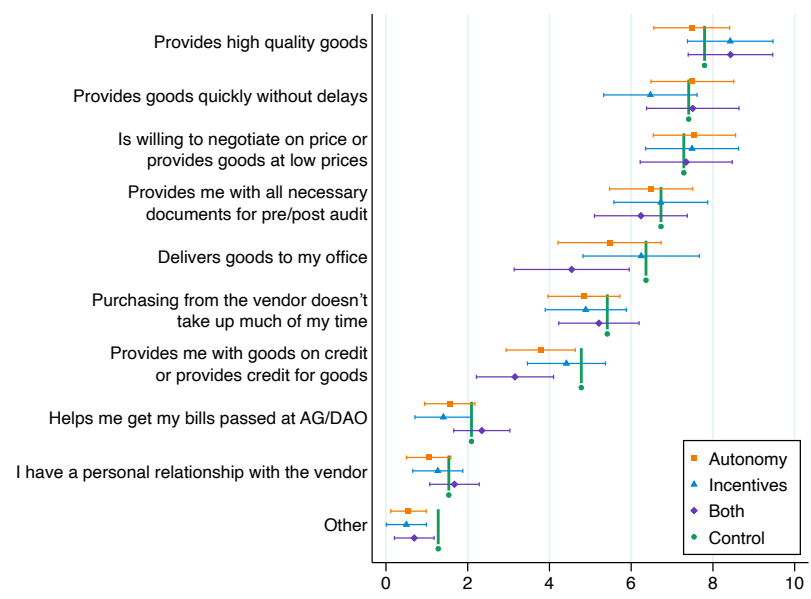

Notes: The figure shows analysis of the responses to our endline survey questions on mechanisms. The panels show differences (and their 95\% confidence intervals) in mean responses across the 4 treatment arms, weighting offices by the number of purchases they make. The control group mean is in green, autonomy in orange, incentives in blue, and combined in purple. Panel A shows responses to the question "Of all the time you spend trying to reduce the total amount your cost center pays (including hidden costs) for the goods you want, what percentage of your time do you and your staff spend on each of the tasks below?" Panel B shows responses to "Please think about the vendors you currently make contingent purchases from, and the vendors you could potentially make contingent purchases from. Which of the following characteristics of vendors are important to you in deciding which vendor(s) to buy from?" The possible responses are shortened to fit in the figures. The full text of the responses is in the questionnaire in the Social Science Registry at https://www.socialscienceregistry.org/trials/610. Answers may not sum to 100 since respondents seem in many cases to have interpreted the questions to mean percentage of total time rather than percentage of time spent on procurement. 
Table A.1: Universe of Generic Goods Accounting Codes

\begin{tabular}{lll}
\hline Code & Category & Description \\
\hline A03004 & Other & Panel A03 Operating Expenses \\
A03070 & Furnace Oil - Non Operational \\
\hline A03170 & Fees & Others \\
\hline A03204 & Others \\
A03205 & Communication & Electronic Communication \\
A03206 & Courier And Pilot Service \\
A03270 & Photography Charges \\
\hline A03304 & Others \\
A03305 & Utilities & Hot And Cold Weather \\
A03370 & POL For Generator \\
\hline A03401 & Others \\
A03405 & Charges \\
A03408 & Occupancy Costs & Rent Other Than Building \\
A03410 & Rent Of Machine \& Equipment \\
A03470 & Security \\
\hline A03501 & Others \\
A03502 & Machinery And Equipment \\
A03503 & Operating Leases & Buildings \\
A03504 & Motor Vehicles \\
A03506 & Computers \\
A03570 & Medical Machinery And Technical Equipment \\
\hline A03901 & Others \\
A03902 & Stationery \\
A03904 & Printing And Publication \\
A03905 & Hire Of Vehicles \\
A03907 & Newspapers Periodicals And Books \\
\hline & Advertising \& Publicity \\
\hline & Payments To Others For Service Rendered \\
\hline & Unforeseen Exp. For Disaster Preparedness \\
\hline &
\end{tabular}

General

Continued on next page 
Table A.1 - Continued from previous page

\begin{tabular}{|c|c|c|}
\hline Code & Category & Description \\
\hline A03927 & & Purchase Of Drug And Medicines \\
\hline A03933 & & Service Charges \\
\hline A03940 & & Unforeseen Expenditure \\
\hline A03942 & & Cost Of Other Stores \\
\hline A03955 & & Computer Stationary \\
\hline A03970 & & Others \\
\hline A03971 & & Cost Of State Trading Medicines \\
\hline A03972 & & Expenditure On Diet For Patient \\
\hline A03978 & & Free Text Books \\
\hline
\end{tabular}

\section{Panel B: A09 Physical Assets}

\begin{tabular}{lll}
\hline A09105 & & Transport \\
A09107 & Purchase of Physical Assets & Furniture And Fixtures \\
A09108 & Livestock \\
A09170 & Others \\
\hline A09204 & Computer Accessories & License Fee For Software \\
\hline A09302 & Fertilizer \\
A09303 & Commodity Purchases & Coal \\
A09370 & Others \\
\hline A09401 & Medical Stores \\
A09402 & Newsprint \\
A09403 & Tractors \\
A09404 & Medical And Laboratory Equipment \\
A09405 & Workshop Equipment \\
A09406 & Storage And Carrying Receptacles \\
A09407 & Specific Consumables \\
A09408 & Other Stores and Stock & Generic Consumables \\
A09409 & Medical Stocks \\
A09410 & Life Saving Medical Supplies \\
A09411 & General Utility Chemicals \\
A09412 & Specific Utility Chemicals \\
A09413 & Drapery Fabrics Clothing And Allied Materials \\
\hline &
\end{tabular}


Table A.1 - Continued from previous page

\begin{tabular}{|c|c|c|}
\hline Code & Category & Description \\
\hline A09414 & & Insecticides \\
\hline A09470 & & Others \\
\hline A09501 & \multirow{3}{*}{ Transport } & Transport \\
\hline A09502 & & Diplomatic Cars \\
\hline A09503 & & Others \\
\hline A09601 & \multirow{4}{*}{ Plant \& Machinery } & Plant And Machinery \\
\hline A09602 & & Cold Storage Equipment \\
\hline A09603 & & Signalling System \\
\hline A09604 & & Railways Rolling Stock \\
\hline A09701 & \multirow{2}{*}{ Furniture \& Fixtures } & Furniture And Fixtures \\
\hline A09702 & & Unkempt Furnishings \\
\hline A09801 & \multirow{4}{*}{ Livestock } & Livestock \\
\hline A09802 & & Purchase Of Other Assets - Others \\
\hline A09803 & & Meters \& Services Cables \\
\hline A09899 & & Others \\
\hline \multicolumn{3}{|c|}{ Panel C: A13 Repairs and Maintenance } \\
\hline A13101 & \multirow{2}{*}{ Machinery \& Equipment } & Machinery And Equipment \\
\hline A13199 & & Others \\
\hline A13201 & Furniture \& Fixture & Furniture And Fixture \\
\hline A13370 & Buildings \& Structure & Others \\
\hline A13470 & Irrigation & Others \\
\hline A13570 & Embankment \& Drainage & Others \\
\hline A13701 & \multirow{3}{*}{ Computer Equipment } & Hardware \\
\hline A13702 & & Software \\
\hline A13703 & & I.T. Equipment \\
\hline A13920 & Telecommunication & Others \\
\hline
\end{tabular}




\section{Table A.2: Project Timeline}

Year 1: July 2014 - June 2015

06/14 Cost Centers allocated to treatment arms

07-08/14 Trainings on POPS and treatment brochures

08-09/14 Follow-up trainings on POPS

02/15 Performance Evaluation Committee midline meeting

05-06/15 AG checklist rolled out

Year 2: July 2015 - June 2016

07-10/15 Refresher trainings on treatments and POPS

10/15 Higher cash balance rolled out

04/16 Performance Evaluation Committee midline meeting

06/16 Experiment ends

\section{Post-Experiment}

08-09/16 Endline survey part 1 \& Missing data collection

02/17 Performance Evaluation Committee endline meeting

02-03/17 Endline survey part 2 
TAble A.3: Order Sizes ARe UnAFFected

\begin{tabular}{|c|c|c|c|c|c|c|c|}
\hline & \multicolumn{5}{|c|}{ Quantity } & \multicolumn{2}{|c|}{ CF Value } \\
\hline & (1) & (2) & (3) & (4) & (5) & (6) & (7) \\
\hline Autonomy & $\begin{array}{l}-0.044 \\
(0.068) \\
{[0.537]}\end{array}$ & $\begin{array}{l}-0.004 \\
(0.060) \\
{[0.948]}\end{array}$ & $\begin{array}{l}-0.026 \\
(0.053) \\
{[0.629]}\end{array}$ & $\begin{array}{l}-0.045 \\
(0.068) \\
{[0.524]}\end{array}$ & $\begin{array}{l}-0.042 \\
(0.064) \\
{[0.559]}\end{array}$ & $\begin{array}{l}-0.028 \\
(0.054) \\
{[0.612]}\end{array}$ & $\begin{array}{l}-0.042 \\
(0.065) \\
{[0.557]}\end{array}$ \\
\hline Incentives & $\begin{array}{c}0.029 \\
(0.070) \\
{[0.702]}\end{array}$ & $\begin{array}{c}0.079 \\
(0.064) \\
{[0.250]}\end{array}$ & $\begin{array}{c}0.036 \\
(0.056) \\
{[0.544]}\end{array}$ & $\begin{array}{c}0.039 \\
(0.070) \\
{[0.614]}\end{array}$ & $\begin{array}{c}0.042 \\
(0.064) \\
{[0.563]}\end{array}$ & $\begin{array}{c}0.035 \\
(0.057) \\
{[0.555]}\end{array}$ & $\begin{array}{c}0.039 \\
(0.065) \\
{[0.595]}\end{array}$ \\
\hline Both & $\begin{array}{l}-0.096 \\
(0.071) \\
{[0.207]}\end{array}$ & $\begin{array}{l}-0.059 \\
(0.066) \\
{[0.418]}\end{array}$ & $\begin{array}{l}-0.055 \\
(0.060) \\
{[0.415]}\end{array}$ & $\begin{array}{l}-0.091 \\
(0.070) \\
{[0.239]}\end{array}$ & $\begin{array}{l}-0.085 \\
(0.067) \\
{[0.226]}\end{array}$ & $\begin{array}{l}-0.060 \\
(0.060) \\
{[0.370]}\end{array}$ & $\begin{array}{l}-0.088 \\
(0.067) \\
{[0.217]}\end{array}$ \\
\hline $\begin{array}{l}\text { Item Variety Control } \\
\text { p(All = 0) } \\
\text { Observations }\end{array}$ & $\begin{array}{c}\text { None } \\
0.362 \\
11,771\end{array}$ & $\begin{array}{c}\text { Attribs } \\
0.306 \\
11,771\end{array}$ & $\begin{array}{c}\text { Scalar } \\
0.559 \\
11,771\end{array}$ & $\begin{array}{c}\text { Coarse } \\
0.365 \\
11,771\end{array}$ & $\begin{array}{c}\text { ML } \\
0.357 \\
11,771\end{array}$ & $\begin{array}{c}\text { Scalar } \\
0.535 \\
11,771\end{array}$ & $\begin{array}{c}\text { ML } \\
0.360 \\
11,771\end{array}$ \\
\hline
\end{tabular}

Notes: The table shows estimates of overall treatment effects of the three treatments on the log quantity purchased in each order. The table shows estimates of equation:

$$
q_{i g t o}=\alpha+\sum_{k=1}^{3} \eta_{k} \text { Treatment }_{o}^{k}+\mathbf{X}_{i g t o} \beta+\delta_{s}+\gamma_{g}+\varepsilon_{i g t o}
$$

where $q_{i g t o}$ is the log quantity in purchase $i$ of good $g$ at time $t$ by office $o$ in columns $1-5$, the log "value" of the order (log quantity plus log "price") priced using the scalar control in column (6), and the log value priced using the ML control in column (7). Treatment ${ }_{o}^{k}$ indicates the three treatment groups; $\delta_{s}$ and $\gamma_{g}$ are stratum and good fixed effects, respectively; and $\mathbf{X}_{i g t o}$ are purchase-specific controls. In column (2) these controls include all item attributes, in column (3) the scalar item variety measure, in column (4) the coarse item variety, and in column (5) the machine-learning item variety measure. We weight regressions by expenditure shares in the control group so that treatment effects can be interpreted as effects on expenditure, and the residual term $\varepsilon_{i g t o}$ is clustered at the cost center level. Below each coefficient we report standard errors clustered by cost center in parentheses, and p-values from randomization inference tests of the hypothesis that the treatment has no effect on any office in square brackets. 


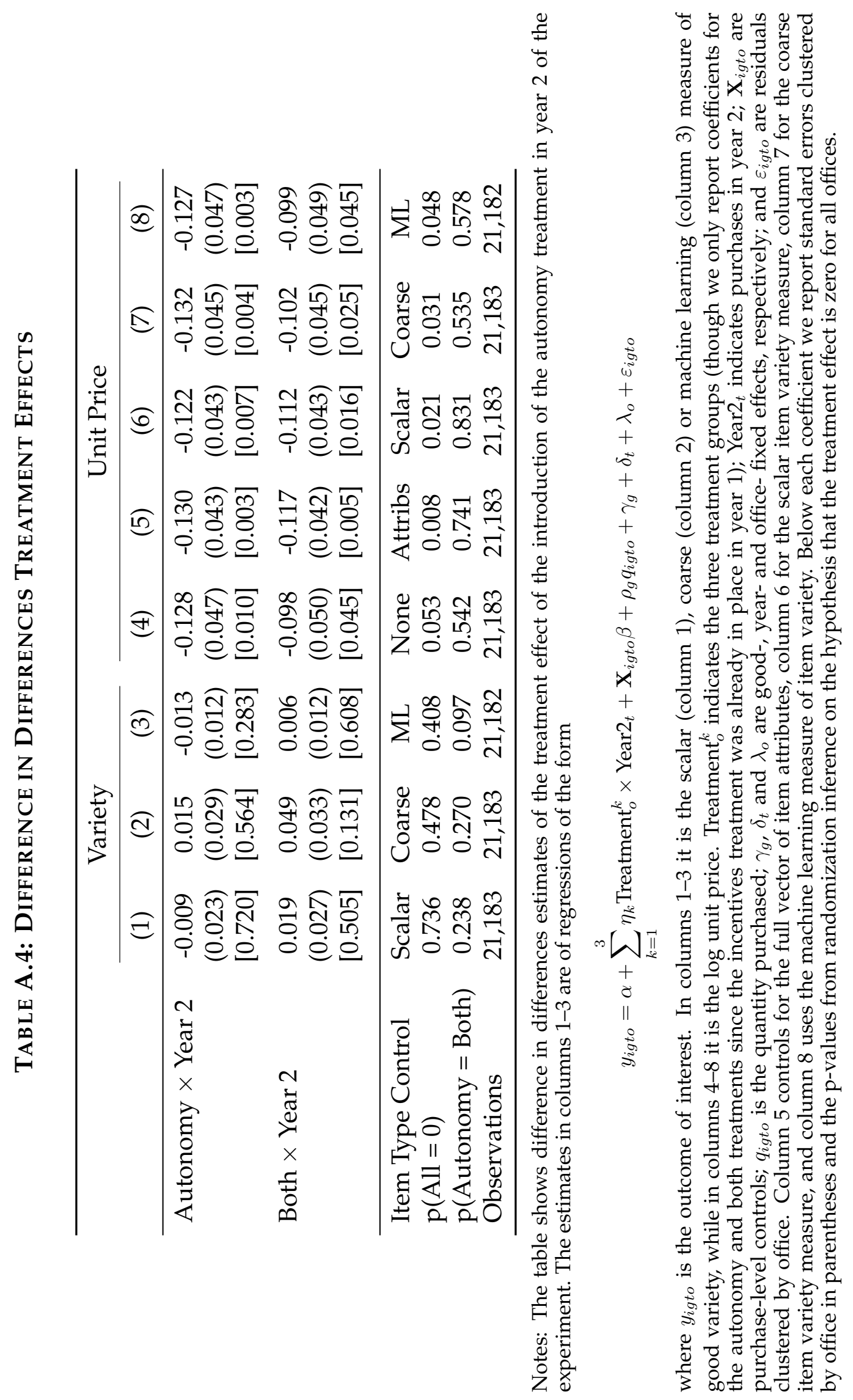




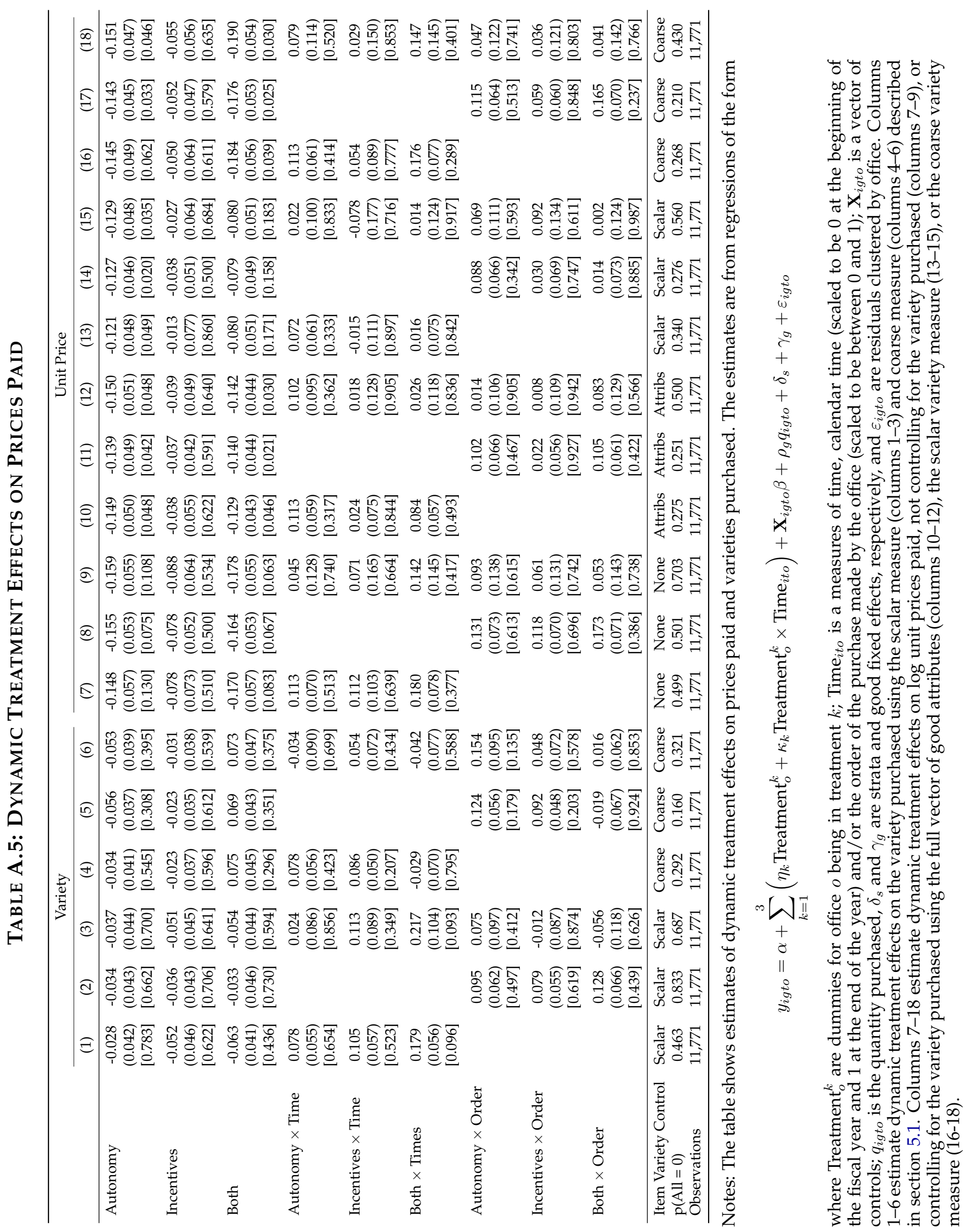




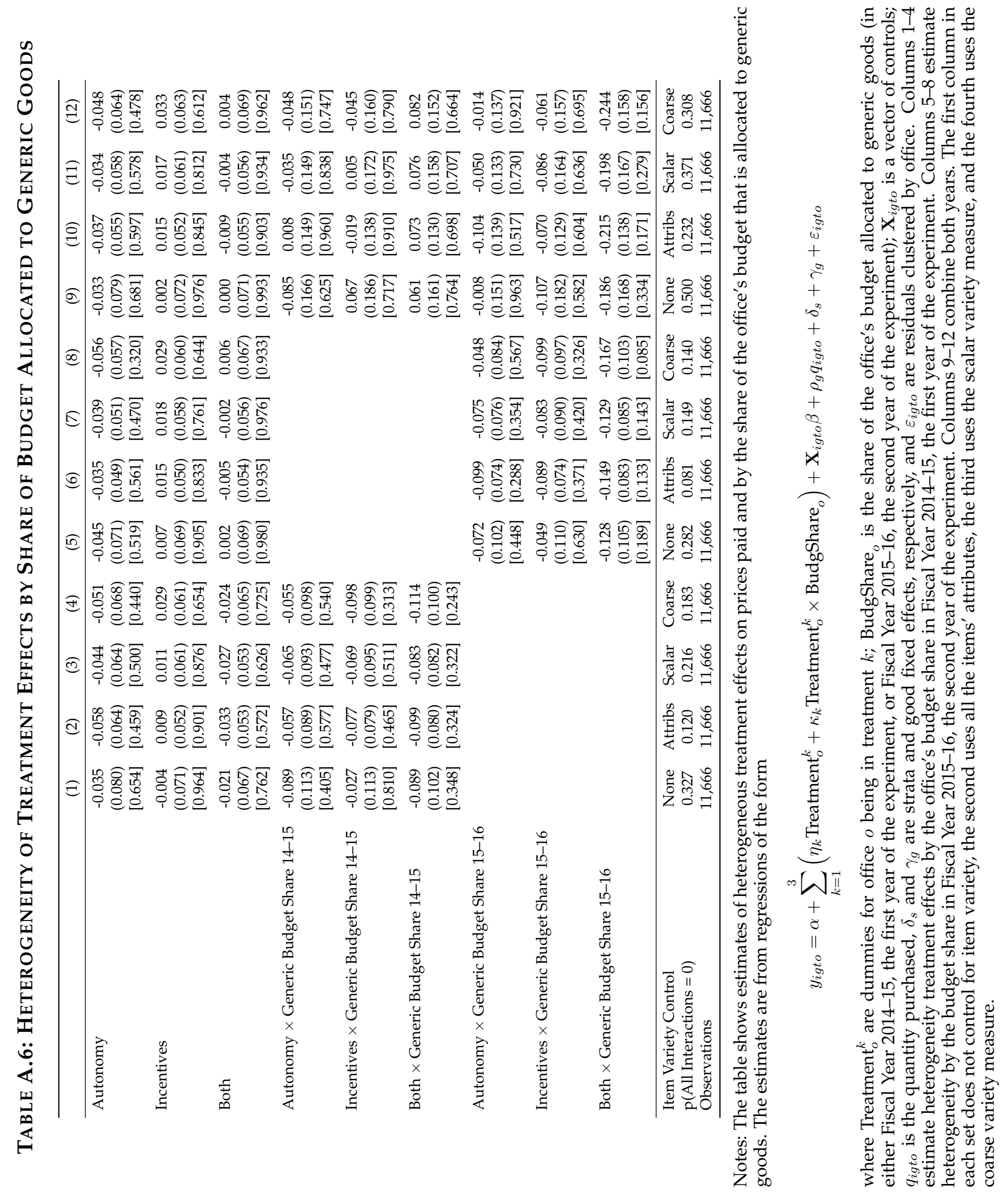


TABle A.7: BAlance of Attrition of Items

\begin{tabular}{|c|c|c|c|c|c|c|c|c|}
\hline & \multicolumn{4}{|c|}{ All Generics } & \multicolumn{4}{|c|}{ Analysis Objects } \\
\hline & (1) & (2) & (3) & (4) & (5) & (6) & (7) & (8) \\
\hline \multirow[t]{2}{*}{ Incentives } & 0.006 & 0.003 & -0.003 & 0.005 & 0.009 & 0.005 & -0.002 & 0.006 \\
\hline & $(0.015)$ & $(0.017)$ & $(0.013)$ & $(0.012)$ & $(0.018)$ & $(0.020)$ & $(0.015)$ & $(0.015)$ \\
\hline \multirow[t]{2}{*}{ Autonomy } & -0.011 & -0.009 & -0.009 & -0.003 & -0.010 & 0.000 & -0.008 & -0.001 \\
\hline & $(0.016)$ & $(0.016)$ & $(0.013)$ & $(0.012)$ & $(0.018)$ & $(0.019)$ & $(0.015)$ & $(0.015)$ \\
\hline \multirow[t]{2}{*}{ Both } & $-0.038^{*}$ & -0.013 & -0.017 & -0.001 & $-0.041^{*}$ & -0.013 & -0.020 & -0.002 \\
\hline & $(0.018)$ & $(0.018)$ & $(0.014)$ & $(0.013)$ & $(0.020)$ & $(0.020)$ & $(0.016)$ & $(0.017)$ \\
\hline \multirow[t]{2}{*}{ Assets: Fertilizer } & 0.000 & 0.000 & 0.000 & 0.000 & & & & \\
\hline & $()$. & $()$. & $()$. & $()$. & & & & \\
\hline \multirow[t]{2}{*}{ Assets: General Utility Chemicals } & -0.061 & $-0.108^{*}$ & 0.019 & -0.014 & & & & \\
\hline & $(0.053)$ & $(0.053)$ & $(0.022)$ & $(0.019)$ & & & & \\
\hline \multirow[t]{2}{*}{ Assets: Insecticides } & 0.111 & $-0.174^{* * *}$ & $-0.019^{* *}$ & -0.011 & & & & \\
\hline & $(0.067)$ & $(0.049)$ & $(0.007)$ & $(0.006)$ & & & & \\
\hline \multirow[t]{2}{*}{ Assets: Lab Equipment } & $-0.263^{* * *}$ & $-0.422^{* * *}$ & $0.069^{* *}$ & $0.066^{*}$ & & & & \\
\hline & $(0.055)$ & $(0.046)$ & $(0.026)$ & $(0.029)$ & & & & \\
\hline \multirow[t]{2}{*}{ Assets: Other Commodity } & 0.073 & -0.053 & -0.019 & $-0.020^{*}$ & 0.000 & 0.000 & 0.000 & 0.000 \\
\hline & $(0.093)$ & $(0.068)$ & $(0.012)$ & $(0.009)$ & $()$. & $()$. & $()$. & $()$. \\
\hline \multirow[t]{2}{*}{ Assets: Other Stocks and Stores } & -0.068 & -0.188 & 0.044 & 0.009 & & & & \\
\hline & $(0.138)$ & $(0.150)$ & $(0.036)$ & $(0.015)$ & & & & \\
\hline \multirow[t]{2}{*}{ Assets: Purchase of Furniture \& Fixture } & -0.108 & $-0.248^{* * *}$ & $0.047^{*}$ & $0.104^{* * *}$ & -0.167 & -0.132 & $0.081^{* * *}$ & $0.168^{* * *}$ \\
\hline & $(0.067)$ & $(0.066)$ & $(0.019)$ & $(0.021)$ & $(0.114)$ & $(0.097)$ & $(0.020)$ & $(0.031)$ \\
\hline Assets: Purchase of Plant \& Machinery & $-0.273^{* * *}$ & $-0.420^{* * *}$ & $0.079 * * *$ & 0.039 & $-0.301^{* *}$ & $-0.341^{* * *}$ & $0.122^{* * *}$ & $0.078^{* *}$ \\
\hline
\end{tabular}




\begin{tabular}{|c|c|c|c|c|c|c|c|c|}
\hline & $(0.071)$ & $(0.079)$ & $(0.021)$ & $(0.025)$ & $(0.111)$ & $(0.094)$ & $(0.022)$ & $(0.027)$ \\
\hline Assets: Purchase of Transport & $\begin{array}{c}-0.288^{* * *} \\
(0.061)\end{array}$ & $\begin{array}{c}-0.442^{* * *} \\
(0.051)\end{array}$ & $\begin{array}{c}0.032 \\
(0.029)\end{array}$ & $\begin{array}{c}0.087^{* * *} \\
(0.020)\end{array}$ & & & & \\
\hline Assets: Specific Utility Chemicals & $\begin{array}{l}-0.055 \\
(0.084)\end{array}$ & $\begin{array}{c}-0.282^{* * *} \\
(0.073)\end{array}$ & $\begin{array}{c}0.008 \\
(0.010)\end{array}$ & $\begin{array}{l}0.037^{\text {** }} \\
(0.012)\end{array}$ & $\begin{array}{l}-0.120 \\
(0.123)\end{array}$ & $\begin{array}{l}-0.199^{*} \\
(0.092)\end{array}$ & $\begin{array}{c}0.031 \\
(0.017)\end{array}$ & $\begin{array}{l}0.077^{* *} \\
(0.024)\end{array}$ \\
\hline OpEx: Advertising & $\begin{array}{l}-0.124^{*} \\
(0.058)\end{array}$ & $\begin{array}{c}-0.314^{* * *} \\
(0.046)\end{array}$ & $\begin{array}{c}0.217^{* * *} \\
(0.023)\end{array}$ & $\begin{array}{c}0.238^{* * *} \\
(0.023)\end{array}$ & $\begin{array}{l}-0.203 \\
(0.105)\end{array}$ & $\begin{array}{c}-0.266^{* * *} \\
(0.073)\end{array}$ & $\begin{array}{c}0.232^{* * *} \\
(0.026)\end{array}$ & $\begin{array}{r}0.254^{* * *} \\
(0.025)\end{array}$ \\
\hline OpEx: Courier & $\begin{array}{c}-0.455^{* * *} \\
(0.090)\end{array}$ & $\begin{array}{c}-0.735^{* * *} \\
(0.062)\end{array}$ & $\begin{array}{l}-0.055 \\
(0.049)\end{array}$ & $\begin{array}{c}-0.139^{* *} \\
(0.042)\end{array}$ & & & & \\
\hline OpEx: Electricity & $\begin{array}{l}0.138^{*} \\
(0.061)\end{array}$ & $\begin{array}{c}-0.135^{* *} \\
(0.046)\end{array}$ & $\begin{array}{c}0.495^{* * *} \\
(0.027)\end{array}$ & $\begin{array}{c}0.437^{* * *} \\
(0.025)\end{array}$ & $\begin{array}{c}0.055 \\
(0.105)\end{array}$ & $\begin{array}{l}-0.090 \\
(0.073)\end{array}$ & $\begin{array}{c}0.506^{* * *} \\
(0.027)\end{array}$ & $\begin{array}{r}0.450^{\text {*** }} \\
(0.025)\end{array}$ \\
\hline OpEx: Elextronic Communication & $\begin{array}{c}-0.382^{* * *} \\
(0.092)\end{array}$ & $\begin{array}{c}-0.678^{* * *} \\
(0.101)\end{array}$ & $\begin{array}{l}-0.000 \\
(0.037)\end{array}$ & $\begin{array}{l}-0.088^{*} \\
(0.039)\end{array}$ & & & & \\
\hline OpEx: Medicines & $\begin{array}{c}-0.196^{* * *} \\
(0.055)\end{array}$ & $\begin{array}{c}-0.422^{* * *} \\
(0.045)\end{array}$ & $\begin{array}{c}0.134^{* * *} \\
(0.014)\end{array}$ & $\begin{array}{c}0.119^{* * *} \\
(0.015)\end{array}$ & & & & \\
\hline OpEx: Newspapers & $\begin{array}{l}0.147^{*} \\
(0.064)\end{array}$ & $\begin{array}{c}-0.156^{* * *} \\
(0.046)\end{array}$ & $\begin{array}{c}0.289^{* * *} \\
(0.022)\end{array}$ & $\begin{array}{c}0.309^{* * *} \\
(0.024)\end{array}$ & $\begin{array}{c}0.070 \\
(0.107)\end{array}$ & $\begin{array}{l}-0.107 \\
(0.073)\end{array}$ & $\begin{array}{c}0.301^{* * *} \\
(0.022)\end{array}$ & $\begin{array}{c}0.324^{* * *} \\
(0.024)\end{array}$ \\
\hline OpEx: Other & $\begin{array}{c}0.009 \\
(0.055)\end{array}$ & $\begin{array}{c}-0.256^{* * *} \\
(0.043)\end{array}$ & $\begin{array}{c}0.197^{* * *} \\
(0.015)\end{array}$ & $\begin{array}{c}0.177^{* * *} \\
(0.016)\end{array}$ & $\begin{array}{l}-0.065 \\
(0.105)\end{array}$ & $\begin{array}{c}-0.209^{* *} \\
(0.072)\end{array}$ & $\begin{array}{c}0.214^{* * *} \\
(0.018)\end{array}$ & $\begin{array}{c}0.194^{* * *} \\
(0.018)\end{array}$ \\
\hline OpEx: Other Stores & $\begin{array}{c}-0.148^{* *} \\
(0.055)\end{array}$ & $\begin{array}{c}-0.366^{* * *} \\
(0.043)\end{array}$ & $\begin{array}{c}0.070^{* * *} \\
(0.015)\end{array}$ & $\begin{array}{c}0.058^{* * *} \\
(0.013)\end{array}$ & $\begin{array}{l}-0.212^{*} \\
(0.104)\end{array}$ & $\begin{array}{c}-0.310^{* * *} \\
(0.072)\end{array}$ & $\begin{array}{c}0.093^{* * *} \\
(0.016)\end{array}$ & $\begin{array}{r}0.080^{* * *} \\
(0.015)\end{array}$ \\
\hline OpEx: Other Stores: Computer/Stationery & $\begin{array}{c}0.090 \\
(0.070)\end{array}$ & $\begin{array}{c}-0.167^{* *} \\
(0.061)\end{array}$ & $\begin{array}{c}0.367^{* * *} \\
(0.050)\end{array}$ & $\begin{array}{c}0.371^{* * *} \\
(0.048)\end{array}$ & $\begin{array}{c}0.014 \\
(0.112)\end{array}$ & $\begin{array}{l}-0.118 \\
(0.084)\end{array}$ & $\begin{array}{c}0.385^{* * *} \\
(0.049)\end{array}$ & $\begin{array}{c}0.388^{* * *} \\
(0.047)\end{array}$ \\
\hline OpEx: Other Utilities & $\begin{array}{c}-0.245^{* * *} \\
(0.058)\end{array}$ & $\begin{array}{c}-0.420^{* * *} \\
(0.103)\end{array}$ & $\begin{array}{l}0.071^{*} \\
(0.033)\end{array}$ & $\begin{array}{c}0.137 \\
(0.082)\end{array}$ & $\begin{array}{c}-0.339^{* *} \\
(0.104)\end{array}$ & $\begin{array}{c}0.123 \\
(0.110)\end{array}$ & $\begin{array}{l}0.066^{* *} \\
(0.025)\end{array}$ & $\begin{array}{c}0.590^{* * *} \\
(0.133)\end{array}$ \\
\hline
\end{tabular}




\begin{tabular}{|c|c|c|c|c|c|c|c|c|}
\hline OpEx: Payments for Services & $\begin{array}{c}-0.298^{* * *} \\
(0.054)\end{array}$ & $\begin{array}{c}-0.574^{* * *} \\
(0.043)\end{array}$ & $\begin{array}{c}0.058^{* * *} \\
(0.015)\end{array}$ & $\begin{array}{l}-0.009 \\
(0.015)\end{array}$ & & & & \\
\hline OpEx: Printing & $\begin{array}{l}-0.044 \\
(0.054)\end{array}$ & $\begin{array}{c}-0.270^{* * *} \\
(0.045)\end{array}$ & $\begin{array}{c}0.173^{* * *} \\
(0.016)\end{array}$ & $\begin{array}{c}0.125^{* * *} \\
(0.019)\end{array}$ & $\begin{array}{l}-0.120 \\
(0.104)\end{array}$ & $\begin{array}{c}-0.219^{* *} \\
(0.073)\end{array}$ & $\begin{array}{c}0.190^{* * *} \\
(0.019)\end{array}$ & $\begin{array}{c}0.143^{* * *} \\
(0.020)\end{array}$ \\
\hline OpEx: Rent not on Building & $\begin{array}{c}-0.437^{* * *} \\
(0.064)\end{array}$ & $\begin{array}{c}-0.604^{* * *} \\
(0.069)\end{array}$ & $\begin{array}{c}0.003 \\
(0.021)\end{array}$ & $\begin{array}{c}0.020 \\
(0.024)\end{array}$ & & & & \\
\hline OpEx: Rent of Machine & $\begin{array}{c}-0.443^{* * *} \\
(0.065)\end{array}$ & $\begin{array}{c}-0.625^{* * *} \\
(0.069)\end{array}$ & $\begin{array}{l}-0.007 \\
(0.021)\end{array}$ & $\begin{array}{c}0.023 \\
(0.023)\end{array}$ & & & & \\
\hline OpEx: Stationery & $\begin{array}{c}0.076 \\
(0.056)\end{array}$ & $\begin{array}{c}-0.138^{* *} \\
(0.042)\end{array}$ & $\begin{array}{c}0.352^{* * *} \\
(0.018)\end{array}$ & $\begin{array}{c}0.372^{* * *} \\
(0.015)\end{array}$ & $\begin{array}{c}0.002 \\
(0.104)\end{array}$ & $\begin{array}{l}-0.091 \\
(0.072)\end{array}$ & $\begin{array}{c}0.369^{* * *} \\
(0.019)\end{array}$ & $\begin{array}{c}0.389^{* * *} \\
(0.020)\end{array}$ \\
\hline Repairs: Computer Hardware & $\begin{array}{l}-0.155^{*} \\
(0.079)\end{array}$ & $\begin{array}{c}-0.304^{* * *} \\
(0.086)\end{array}$ & $\begin{array}{l}0.107^{* *} \\
(0.041)\end{array}$ & $\begin{array}{l}0.116^{* *} \\
(0.045)\end{array}$ & $\begin{array}{l}-0.237 \\
(0.121)\end{array}$ & $\begin{array}{l}-0.249^{*} \\
(0.100)\end{array}$ & $\begin{array}{l}0.124^{* *} \\
(0.041)\end{array}$ & $\begin{array}{c}0.136^{* *} \\
(0.045)\end{array}$ \\
\hline Repairs: Computer Software & $\begin{array}{c}-0.328^{* * *} \\
(0.058)\end{array}$ & $\begin{array}{c}-0.538^{* * *} \\
(0.088)\end{array}$ & $\begin{array}{c}0.042 \\
(0.021)\end{array}$ & $\begin{array}{l}-0.019 \\
(0.017)\end{array}$ & & & & \\
\hline Repairs: Furniture \& Fixtures & $\begin{array}{c}-0.380^{* * *} \\
(0.055)\end{array}$ & $\begin{array}{c}-0.651^{* * *} \\
(0.043)\end{array}$ & $\begin{array}{l}-0.006 \\
(0.015)\end{array}$ & $\begin{array}{c}-0.077^{* * *} \\
(0.015)\end{array}$ & $\begin{array}{c}-0.459^{* * *} \\
(0.103)\end{array}$ & $\begin{array}{c}-0.606^{* * *} \\
(0.072)\end{array}$ & $\begin{array}{c}0.009 \\
(0.015)\end{array}$ & $\begin{array}{c}-0.063^{* * *} \\
(0.016)\end{array}$ \\
\hline Repairs: IT Equipment & $\begin{array}{l}-0.220 \\
(0.123)\end{array}$ & $\begin{array}{l}-0.053 \\
(0.167)\end{array}$ & $\begin{array}{c}0.085 \\
(0.066)\end{array}$ & $\begin{array}{c}0.199^{* * *} \\
(0.040)\end{array}$ & $\begin{array}{l}-0.290 \\
(0.153)\end{array}$ & $\begin{array}{c}0.018 \\
(0.170)\end{array}$ & $\begin{array}{c}0.103 \\
(0.068)\end{array}$ & $\begin{array}{c}0.230^{* * *} \\
(0.040)\end{array}$ \\
\hline Repairs: Machinery \& Equipment & $\begin{array}{c}-0.321^{* * *} \\
(0.055)\end{array}$ & $\begin{array}{c}-0.569^{* * *} \\
(0.044)\end{array}$ & $\begin{array}{c}0.020 \\
(0.016)\end{array}$ & $\begin{array}{l}-0.026 \\
(0.015)\end{array}$ & $\begin{array}{c}-0.399^{* * *} \\
(0.104)\end{array}$ & $\begin{array}{c}-0.521^{* * *} \\
(0.072)\end{array}$ & $\begin{array}{c}0.035^{*} \\
(0.016)\end{array}$ & $\begin{array}{c}-0.009 \\
(0.016)\end{array}$ \\
\hline Repairs: Other Building & $\begin{array}{c}-0.142^{* *} \\
(0.053)\end{array}$ & $\begin{array}{c}-0.485^{* * *} \\
(0.052)\end{array}$ & $\begin{array}{c}0.150^{* * *} \\
(0.012)\end{array}$ & $\begin{array}{c}0.058^{*} \\
(0.026)\end{array}$ & & & & \\
\hline Date & $\begin{array}{l}-0.007 \\
(0.006)\end{array}$ & $\begin{array}{c}-0.001^{* * *} \\
(0.000)\end{array}$ & $\begin{array}{c}0.004 \\
(0.006)\end{array}$ & $\begin{array}{c}-0.000^{* * *} \\
(0.000)\end{array}$ & $\begin{array}{l}-0.005 \\
(0.007)\end{array}$ & $\begin{array}{c}-0.001^{* * *} \\
(0.000)\end{array}$ & $\begin{array}{c}0.006 \\
(0.007)\end{array}$ & $\begin{array}{c}-0.000^{* * *} \\
(0.000)\end{array}$ \\
\hline Date $^{2}$ & 0.000 & $0.000^{* * *}$ & -0.000 & $0.000^{* * *}$ & 0.000 & $0.000^{* * *}$ & -0.000 & $0.000^{* * *}$ \\
\hline
\end{tabular}




\begin{tabular}{|c|c|c|c|c|c|c|c|c|}
\hline & $(0.000)$ & $(0.000)$ & $(0.000)$ & $(0.000)$ & $(0.000)$ & $(0.000)$ & $(0.000)$ & $(0.000)$ \\
\hline $\log$ Amount & $\begin{array}{c}-0.121^{* * *} \\
(0.028)\end{array}$ & $\begin{array}{c}-0.132^{* * *} \\
(0.020)\end{array}$ & $\begin{array}{c}-0.108^{* * *} \\
(0.023)\end{array}$ & $\begin{array}{c}-0.144^{* * *} \\
(0.024)\end{array}$ & $\begin{array}{c}-0.082^{* *} \\
(0.027)\end{array}$ & $\begin{array}{c}-0.095^{* *} \\
(0.032)\end{array}$ & $\begin{array}{c}-0.101^{* * *} \\
(0.025)\end{array}$ & $\begin{array}{c}-0.128^{* * *} \\
(0.031)\end{array}$ \\
\hline $\log (\text { Amount })^{2}$ & $\begin{array}{c}0.004^{* * *} \\
(0.001)\end{array}$ & $\begin{array}{c}0.005^{* * *} \\
(0.001)\end{array}$ & $\begin{array}{c}0.004^{* * *} \\
(0.001)\end{array}$ & $\begin{array}{c}0.005^{* * *} \\
(0.001)\end{array}$ & $\begin{array}{c}0.002 \\
(0.001)\end{array}$ & $\begin{array}{c}0.002 \\
(0.002)\end{array}$ & $\begin{array}{l}0.004^{* *} \\
(0.001)\end{array}$ & $\begin{array}{l}0.004^{* *} \\
(0.002)\end{array}$ \\
\hline Assets: Generic Consumables & & $\begin{array}{c}-0.400^{* * *} \\
(0.051)\end{array}$ & & $\begin{array}{c}0.131^{* * *} \\
(0.019)\end{array}$ & & & & \\
\hline Constant & $\begin{array}{c}69.447 \\
(61.980)\end{array}$ & $\begin{array}{c}13.868^{* * *} \\
(1.333)\end{array}$ & $\begin{array}{l}-41.798 \\
(63.492)\end{array}$ & $\begin{array}{c}6.610^{* * *} \\
(0.944)\end{array}$ & $\begin{array}{c}47.408 \\
(69.733)\end{array}$ & $\begin{array}{c}15.965^{* * *} \\
(1.531)\end{array}$ & $\begin{array}{l}-60.546 \\
(66.118)\end{array}$ & $\begin{array}{c}7.598^{* * *} \\
(1.075)\end{array}$ \\
\hline Observations & 23,423 & 22,498 & 23,423 & 22,498 & 17,361 & 16,553 & 17,361 & 16,553 \\
\hline$R^{2}$ & 0.33 & 0.33 & 0.28 & 0.32 & 0.25 & 0.24 & 0.24 & 0.27 \\
\hline Year & Year 1 & Year 2 & Year 1 & Year 2 & Year 1 & Year 2 & Year 1 & Year 2 \\
\hline Reporting Share & POPS & POPS & Analysis & Analysis & POPS & POPS & Analysis & Analysis \\
\hline
\end{tabular}




\section{Table A.8: Robustness of Price Effects to Including POPS Observations With INSUfFicient ATtRibutes}

\begin{tabular}{|c|c|c|c|c|}
\hline & $\begin{array}{l}(1) \\
\mathrm{DiD}\end{array}$ & $\begin{array}{l}(2) \\
\text { DiD }\end{array}$ & $\begin{array}{c}(3) \\
\text { Year } 2\end{array}$ & $\begin{array}{c}(4) \\
\text { Year } 2\end{array}$ \\
\hline Autonomy & & & $\begin{array}{l}-0.063 \\
(0.044) \\
{[0.209]}\end{array}$ & $\begin{array}{c}-0.050 \\
(0.031) \\
{[0.165]}\end{array}$ \\
\hline Incentives & & & $\begin{array}{l}-0.000 \\
(0.042) \\
{[0.993]}\end{array}$ & $\begin{array}{c}0.004 \\
(0.029) \\
{[0.909]}\end{array}$ \\
\hline Both & & & $\begin{array}{c}-0.036 \\
(0.042) \\
{[0.466]}\end{array}$ & $\begin{array}{l}-0.047 \\
(0.031) \\
{[0.193]}\end{array}$ \\
\hline Autonomy $\times$ Year 2 & $\begin{array}{c}-0.078 \\
(0.050) \\
{[0.102]}\end{array}$ & $\begin{array}{c}-0.071 \\
(0.040) \\
{[0.046]}\end{array}$ & & \\
\hline Both $\times$ Year 2 & $\begin{array}{c}-0.082 \\
(0.051) \\
{[0.075]}\end{array}$ & $\begin{array}{c}-0.084 \\
(0.041) \\
{[0.028]}\end{array}$ & & \\
\hline Year 2 & $\begin{array}{l}-0.001 \\
(0.042)\end{array}$ & $\begin{array}{c}0.019 \\
(0.032)\end{array}$ & & \\
\hline Item Variety Control & None & Attribs & None & Attribs \\
\hline $\begin{array}{l}\mathrm{p}(\text { All }=0) \\
\mathrm{p} \text { (Autonomy }=\text { Incentives) }\end{array}$ & 0.095 & 0.038 & $\begin{array}{l}0.545 \\
0.212\end{array}$ & $\begin{array}{l}0.262 \\
0.112\end{array}$ \\
\hline $\begin{array}{l}\mathrm{p} \text { (Autonomy }=\text { Both) } \\
\mathrm{p}(\text { Incentives }=\text { Both) }\end{array}$ & 0.101 & 0.747 & $\begin{array}{l}0.605 \\
0.441\end{array}$ & $\begin{array}{l}0.921 \\
0.133\end{array}$ \\
\hline Observations & 25,254 & 25,254 & 12,933 & 12,933 \\
\hline
\end{tabular}

Notes: The table shows estimates of the treatment effects of the experiments on log unit prices. The sample used extends our main analysis sample to also include observations from POPS that were dropped because they contained insufficient detail on the attributes of the items being purchased. Column 1 presents results from running our difference in difference specification to estimate the impacts of the autonomy and combined treatments. These results are comparable to those in column 1 of table A.4. Column 2 presents results from our baseline specification using only data from year 2 of the experiment. These results are comparable to those in column 3 of table 2. 
Table A.9: Heterogeneity by Monitor Type

\begin{tabular}{|c|c|c|c|c|c|}
\hline \multicolumn{6}{|c|}{ Panel A: Autonomy } \\
\hline & (1) & (2) & (3) & (4) & (5) \\
\hline Autonomy & $\begin{array}{c}0.072 \\
(0.072) \\
{[0.502]}\end{array}$ & $\begin{array}{c}0.019 \\
(0.054) \\
{[0.769]}\end{array}$ & $\begin{array}{c}0.042 \\
(0.053) \\
{[0.502]}\end{array}$ & $\begin{array}{c}0.056 \\
(0.063) \\
{[0.449]}\end{array}$ & $\begin{array}{l}0.068 \\
(0.072) \\
{[0.416]}\end{array}$ \\
\hline Autonomy $\times$ Bad AG & $\begin{array}{l}-0.231 \\
(0.083) \\
{[0.018]}\end{array}$ & $\begin{array}{l}-0.183 \\
(0.061) \\
{[0.016]}\end{array}$ & $\begin{array}{l}-0.178 \\
(0.063) \\
{[0.018]}\end{array}$ & $\begin{array}{l}-0.210 \\
(0.073) \\
{[0.013]}\end{array}$ & $\begin{array}{l}-0.226 \\
(0.083) \\
{[0.019]}\end{array}$ \\
\hline $\begin{array}{l}\text { Item Variety Control } \\
p(A l l=0) \\
\text { Observations }\end{array}$ & $\begin{array}{l}\text { None } \\
0.006 \\
5,798 \\
\end{array}$ & $\begin{array}{c}\text { Attribs } \\
0.002 \\
5,798 \\
\end{array}$ & $\begin{array}{c}\text { Scalar } \\
0.006 \\
5,798 \\
\end{array}$ & $\begin{array}{c}\text { Coarse } \\
0.003 \\
5,798 \\
\end{array}$ & $\begin{array}{c}\text { ML } \\
0.004 \\
5,798 \\
\end{array}$ \\
\hline \multicolumn{6}{|c|}{ Panel B: Incentives } \\
\hline & (1) & $(2)$ & (3) & (4) & (5) \\
\hline Incentives & $\begin{array}{l}-0.102 \\
(0.037) \\
{[0.004]}\end{array}$ & $\begin{array}{l}-0.111 \\
(0.031) \\
{[0.004]}\end{array}$ & $\begin{array}{l}-0.116 \\
(0.032) \\
{[0.004]}\end{array}$ & $\begin{array}{l}-0.094 \\
(0.034) \\
{[0.014]}\end{array}$ & $\begin{array}{l}-0.103 \\
(0.037) \\
{[0.012]}\end{array}$ \\
\hline Incentives $\times$ Bad AG & $\begin{array}{c}0.125 \\
(0.076) \\
{[0.016]}\end{array}$ & $\begin{array}{c}0.165 \\
(0.075) \\
{[0.077]}\end{array}$ & $\begin{array}{c}0.188 \\
(0.064) \\
{[0.016]}\end{array}$ & $\begin{array}{c}0.115 \\
(0.071) \\
{[0.199]}\end{array}$ & $\begin{array}{c}0.125 \\
(0.076) \\
{[0.173]}\end{array}$ \\
\hline $\begin{array}{l}\text { Item Variety Control } \\
\text { p(All = 0) } \\
\text { Observations }\end{array}$ & $\begin{array}{l}\text { None } \\
0.006 \\
5,413\end{array}$ & $\begin{array}{c}\text { Attribs } \\
0.011 \\
5,413\end{array}$ & $\begin{array}{c}\text { Scalar } \\
0.006 \\
5,413\end{array}$ & $\begin{array}{c}\text { Coarse } \\
0.075 \\
5,413 \\
\end{array}$ & $\begin{array}{c}\text { ML } \\
0.072 \\
5,413\end{array}$ \\
\hline \multicolumn{6}{|c|}{ Panel C: Combined } \\
\hline & $(1)$ & $(2)$ & (3) & (4) & (5) \\
\hline Combined & $\begin{array}{c}0.090 \\
(0.059) \\
{[0.336]}\end{array}$ & $\begin{array}{c}0.044 \\
(0.057) \\
{[0.559]}\end{array}$ & $\begin{array}{c}0.060 \\
(0.053) \\
{[0.336]}\end{array}$ & $\begin{array}{c}0.079 \\
(0.057) \\
{[0.235]}\end{array}$ & $\begin{array}{c}0.088 \\
(0.059) \\
{[0.194]}\end{array}$ \\
\hline Combined $\times$ Bad AG & $\begin{array}{l}-0.240 \\
(0.075) \\
{[0.012]}\end{array}$ & $\begin{array}{l}-0.181 \\
(0.069) \\
{[0.027]}\end{array}$ & $\begin{array}{l}-0.189 \\
(0.064) \\
{[0.012]}\end{array}$ & $\begin{array}{l}-0.222 \\
(0.071) \\
{[0.008]}\end{array}$ & $\begin{array}{l}-0.239 \\
(0.075) \\
{[0.007]}\end{array}$ \\
\hline $\begin{array}{l}\text { Item Variety Control } \\
\text { p(All = 0) } \\
\text { Observations }\end{array}$ & $\begin{array}{l}\text { None } \\
0.010 \\
5,546\end{array}$ & $\begin{array}{c}\text { Attribs } \\
0.017 \\
5,546\end{array}$ & $\begin{array}{c}\text { Scalar } \\
0.010 \\
5,546\end{array}$ & $\begin{array}{c}\text { Coarse } \\
0.013 \\
5,546\end{array}$ & $\begin{array}{c}\text { ML } \\
0.015 \\
5,546\end{array}$ \\
\hline
\end{tabular}

Notes: The table shows heterogeneity of treatment effects by the degree of misalignment of the district's accountant general. Panel A studies the autonomy treatment, panel B the incentives treatment, and panel $\mathrm{C}$ the combined treatment. As discussed in section 6.1 our proxy for the degree of misalignment of the AG is the degree to which purchase approvals are bunched at the end of the fiscal year in June 2015 (year 1 of the project). Studying one treatment at a time, we estimate treatment effect heterogeneity by interacting a dummy for facing a "bad" AG with treatment dummies $p_{\text {igto }}=\alpha+\eta$ Treatment $_{o}+\zeta$ Treatment $_{o} \times$ BadAG $_{o}+$ $\mathbf{X}_{\text {igto }} \beta+\rho_{g} q_{i g t o}+\delta_{s}+\gamma_{g}+\varepsilon_{i g t o}$. A "bad" AG is defined as a June Share above 0.22 in panels A and C, and 0.48 in panel B. Each panel is constructed in the same way, showing the $\eta_{k}$ and $\zeta_{k}$ coefficients together with standard errors clustered by office in parentheses and p-values from randomization inference under the null hypothesis of no effect in square brackets. Column 1 does not control for the variety of the item being purchased. Column 2 controls for the full vector of item attributes. Column 3 uses the scalar measure of item variety. Column 4 uses the coarse measure of item variety, and column 5 uses the machine learning measure of item variety. 


\section{Table A.10: Heterogeneity of Effects on Item Variety by Monitor Type}

\begin{tabular}{lccc}
\hline & $(1)$ & $(2)$ & $(3)$ \\
\hline Autonomy & 0.042 & 0.017 & 0.013 \\
& $(0.037)$ & $(0.039)$ & $(0.013)$ \\
& {$[0.298]$} & {$[0.666]$} & {$[0.362]$} \\
Incentives & 0.022 & 0.021 & 0.008 \\
& $(0.022)$ & $(0.026)$ & $(0.011)$ \\
Combined & {$[0.367]$} & {$[0.488]$} & {$[0.467]$} \\
& 0.047 & 0.111 & 0.004 \\
Autonomy $\times$ Bad AG & $-0.028)$ & $(0.038)$ & $(0.012)$ \\
& {$[0.134]$} & {$[0.005]$} & {$[0.732]$} \\
Incentives $\times$ Bad AG & -0.013 & -0.021 \\
& {$[0.042)$} & $(0.043)$ & $(0.016)$ \\
Combined $\times$ Bad AG & {$[0.772]$} & {$[0.244]$} \\
& -0.048 & 0.011 & -0.010 \\
& {$[0.038)$} & $(0.040)$ & $(0.018)$ \\
& -0.067 & -0.073 & 0.001 \\
Variety Measure & $(0.037)$ & $(0.043)$ & $(0.016)$ \\
p(All = 0) & {$[0.095]$} & {$[0.104]$} & {$[0.948]$} \\
Observations & Scalar & Coarse & ML \\
\hline
\end{tabular}

Notes: The table shows heterogeneity of the treatment effects on the variety of the items purchased by the degree of misalignment of the district's accountant general. As discussed in section 6.1 our proxy for the degree of misalignment of the AG is the degree to which purchase approvals are bunched at the end of the fiscal year in June 2015 (year 1 of the project). We interact our treatment dummies with dummies for facing a "bad" AG in the following specification: $v_{i g t o}=\alpha+\sum_{k=1}^{3}\left(\eta_{k}\right.$ Treatment $_{o}^{k}+\zeta_{k}$ Treatment $_{o}^{k} \times$ BadAG $\left._{o}\right)+$ $\mathbf{X}_{\text {igto }} \beta+\rho_{g} q_{\text {igto }}+\delta_{s}+\gamma_{g}+\varepsilon_{\text {igto }}$. A "bad" AG is defined as a June Share above 0.22 for the autonomy and combined treatments, and 0.48 in the incentives treatment. We showing the $\eta_{k}$ and $\zeta_{k}$ coefficients together with standard errors clustered by office in parentheses and p-values from randomization inference under the null hypothesis of no effect in square brackets. The dependent variable in Column 1 is the scalar measure of item variety. In column 2 we study the coarse measure of item variety, and in column 3 we study the machine-learning (ML) measure of item variety. 
Table A.11: Heterogeneity of EfFects on Demand by Monitor Type

\begin{tabular}{|c|c|c|c|c|c|c|c|c|}
\hline \multirow{2}{*}{ Item } & \multicolumn{3}{|c|}{ Linear Term } & \multicolumn{3}{|c|}{ Bad AG Interaction } & \multirow{2}{*}{$\begin{array}{l}\text { Linear } \\
\text { All }=0\end{array}$} & \multirow{2}{*}{$\begin{array}{c}\text { Interaction } \\
\text { All }=0\end{array}$} \\
\hline & Autonomy & Incentives & Both & Autonomy & Incentives & Both & & \\
\hline Toner & $\begin{array}{c}119.1 \\
(489.98)\end{array}$ & $\begin{array}{c}252.5 \\
(335.64)\end{array}$ & $\begin{array}{c}-800.8 \\
(490.34)\end{array}$ & $\begin{array}{c}-140.6 \\
(559.01)\end{array}$ & $\begin{array}{c}-495.0 \\
(528.17)\end{array}$ & $\begin{array}{l}1172.9^{* *} \\
(559.61)\end{array}$ & $\begin{array}{c}1.73 \\
{[0.158]}\end{array}$ & $\begin{array}{c}2.43 \\
{[0.063]}\end{array}$ \\
\hline Ice Block & $\begin{array}{c}-24.5 \\
(35.68)\end{array}$ & $\begin{array}{l}-52.6^{* *} \\
(24.44)\end{array}$ & $\begin{array}{c}-12.1 \\
(35.71)\end{array}$ & $\begin{array}{c}26.0 \\
(40.71)\end{array}$ & $\begin{array}{c}44.5 \\
(38.46)\end{array}$ & $\begin{array}{c}0.3 \\
(40.75)\end{array}$ & $\begin{array}{c}1.61 \\
{[0.184]}\end{array}$ & $\begin{array}{c}0.56 \\
{[0.643]}\end{array}$ \\
\hline Towel & $\begin{array}{l}-17.0 \\
(21.14)\end{array}$ & $\begin{array}{c}-3.0 \\
(14.48)\end{array}$ & $\begin{array}{c}11.0 \\
(21.15)\end{array}$ & $\begin{array}{c}5.1 \\
(24.11)\end{array}$ & $\begin{array}{c}25.8 \\
(22.78)\end{array}$ & $\begin{array}{c}-36.6 \\
(24.14)\end{array}$ & $\begin{array}{c}0.52 \\
{[0.669]}\end{array}$ & $\begin{array}{c}1.65 \\
{[0.176]}\end{array}$ \\
\hline Soap/Detergent & $\begin{array}{c}143.4 \\
(1324.31)\end{array}$ & $\begin{array}{c}-37.7 \\
(907.16)\end{array}$ & $\begin{array}{c}-59.4 \\
(1325.28)\end{array}$ & $\begin{array}{c}-651.4 \\
(1510.88)\end{array}$ & $\begin{array}{c}142.4 \\
(1427.52)\end{array}$ & $\begin{array}{c}597.1 \\
(1512.52)\end{array}$ & $\begin{array}{c}0.01 \\
{[0.999]}\end{array}$ & $\begin{array}{c}0.19 \\
{[0.906]}\end{array}$ \\
\hline Duster & $\begin{array}{c}-15.3 \\
(19.55)\end{array}$ & $\begin{array}{c}13.1 \\
(13.39)\end{array}$ & $\begin{array}{c}-21.0 \\
(19.56)\end{array}$ & $\begin{array}{c}1.8 \\
(22.30)\end{array}$ & $\begin{array}{c}16.0 \\
(21.07)\end{array}$ & $\begin{array}{c}6.0 \\
(22.33)\end{array}$ & $\begin{array}{c}1.27 \\
{[0.284]}\end{array}$ & $\begin{array}{c}0.20 \\
{[0.896]}\end{array}$ \\
\hline Wiper & $\begin{array}{c}10.4 \\
(15.35)\end{array}$ & $\begin{array}{c}19.6^{*} \\
(10.52)\end{array}$ & $\begin{array}{l}-11.7 \\
(15.36)\end{array}$ & $\begin{array}{c}-16.2 \\
(17.52)\end{array}$ & $\begin{array}{c}7.6 \\
(16.55)\end{array}$ & $\begin{array}{c}5.9 \\
(17.53)\end{array}$ & $\begin{array}{c}2.04 \\
{[0.106]}\end{array}$ & $\begin{array}{c}0.58 \\
{[0.631]}\end{array}$ \\
\hline Lock & $\begin{array}{c}49.6 \\
(33.88)\end{array}$ & $\begin{array}{c}-16.3 \\
(23.21)\end{array}$ & $\begin{array}{c}-7.1 \\
(33.91)\end{array}$ & $\begin{array}{c}-60.7 \\
(38.65)\end{array}$ & $\begin{array}{l}86.0^{* *} \\
(36.52)\end{array}$ & $\begin{array}{c}-14.3 \\
(38.70)\end{array}$ & $\begin{array}{c}1.38 \\
{[0.246]}\end{array}$ & $\begin{array}{c}3.36 \\
{[0.018]}\end{array}$ \\
\hline Pen & $\begin{array}{c}34.8 \\
(91.78)\end{array}$ & $\begin{array}{c}64.9 \\
(62.87)\end{array}$ & $\begin{array}{l}-30.0 \\
(91.85)\end{array}$ & $\begin{array}{c}29.2 \\
(104.71)\end{array}$ & $\begin{array}{c}35.7 \\
(98.94)\end{array}$ & $\begin{array}{c}70.3 \\
(104.83)\end{array}$ & $\begin{array}{c}0.57 \\
{[0.637]}\end{array}$ & $\begin{array}{c}0.17 \\
{[0.919]}\end{array}$ \\
\hline Envelope & $\begin{array}{c}30.7 \\
(18.84)\end{array}$ & $\begin{array}{c}-12.9 \\
(12.90)\end{array}$ & $\begin{array}{c}-52.6^{* * *} \\
(18.85)\end{array}$ & $\begin{array}{c}-21.8 \\
(21.49)\end{array}$ & $\begin{array}{c}25.8 \\
(20.30)\end{array}$ & $\begin{array}{l}63.5^{* * *} \\
(21.51)\end{array}$ & $\begin{array}{c}5.92 \\
{[0.000]}\end{array}$ & $\begin{array}{c}4.96 \\
{[0.002]}\end{array}$ \\
\hline Printer Paper & $\begin{array}{c}477.2 \\
(315.71)\end{array}$ & $\begin{array}{c}-30.0 \\
(216.26)\end{array}$ & $\begin{array}{l}-544.3^{*} \\
(315.94)\end{array}$ & $\begin{array}{c}-437.2 \\
(360.18)\end{array}$ & $\begin{array}{l}917.4^{* * *} \\
(340.31)\end{array}$ & $\begin{array}{c}570.9 \\
(360.57)\end{array}$ & $\begin{array}{c}2.99 \\
{[0.030]}\end{array}$ & $\begin{array}{c}4.57 \\
{[0.003]}\end{array}$ \\
\hline Register & $\begin{array}{c}-10.6 \\
(602.28)\end{array}$ & $\begin{array}{c}-55.1 \\
(412.57)\end{array}$ & $\begin{array}{c}-293.1 \\
(602.72)\end{array}$ & $\begin{array}{l}-280.0 \\
(687.13)\end{array}$ & $\begin{array}{c}-31.6 \\
(649.22)\end{array}$ & $\begin{array}{c}506.8 \\
(687.88)\end{array}$ & $\begin{array}{c}0.09 \\
{[0.964]}\end{array}$ & $\begin{array}{c}0.37 \\
{[0.778]}\end{array}$ \\
\hline Stapler & $\begin{array}{c}-0.3 \\
(13.34)\end{array}$ & $\begin{array}{l}-13.5 \\
(9.14)\end{array}$ & $\begin{array}{c}6.8 \\
(13.35)\end{array}$ & $\begin{array}{c}-16.3 \\
(15.22)\end{array}$ & $\begin{array}{c}14.8 \\
(14.38)\end{array}$ & $\begin{array}{l}-28.4^{*} \\
(15.23)\end{array}$ & $\begin{array}{c}1.14 \\
{[0.330]}\end{array}$ & $\begin{array}{c}2.02 \\
{[0.109]}\end{array}$ \\
\hline Staples & $\begin{array}{c}3.4 \\
(4.84)\end{array}$ & $\begin{array}{c}-1.6 \\
(3.31)\end{array}$ & $\begin{array}{c}-2.0 \\
(4.84)\end{array}$ & $\begin{array}{c}-6.6 \\
(5.52)\end{array}$ & $\begin{array}{c}7.1 \\
(5.21)\end{array}$ & $\begin{array}{c}4.6 \\
(5.52)\end{array}$ & $\begin{array}{c}0.47 \\
{[0.702]}\end{array}$ & $\begin{array}{c}1.82 \\
{[0.142]}\end{array}$ \\
\hline Calculator & $\begin{array}{c}-12.9 \\
(13.51)\end{array}$ & $\begin{array}{c}-19.0^{* *} \\
(9.25)\end{array}$ & $\begin{array}{c}-15.3 \\
(13.52)\end{array}$ & $\begin{array}{c}4.6 \\
(15.41)\end{array}$ & $\begin{array}{c}24.5^{*} \\
(14.56)\end{array}$ & $\begin{array}{c}3.6 \\
(15.42)\end{array}$ & $\begin{array}{c}1.48 \\
{[0.219]}\end{array}$ & $\begin{array}{c}0.95 \\
{[0.416]}\end{array}$ \\
\hline File Cover & $\begin{array}{c}12.1 \\
(42.83)\end{array}$ & $\begin{array}{c}-8.3 \\
(29.34)\end{array}$ & $\begin{array}{c}17.1 \\
(42.86)\end{array}$ & $\begin{array}{c}21.2 \\
(48.86)\end{array}$ & $\begin{array}{c}-68.4 \\
(46.16)\end{array}$ & $\begin{array}{c}-9.7 \\
(48.91)\end{array}$ & $\begin{array}{c}0.14 \\
{[0.936]}\end{array}$ & $\begin{array}{c}0.94 \\
{[0.422]}\end{array}$ \\
\hline Stamp Pad & $\begin{array}{c}5.2 \\
(7.17)\end{array}$ & $\begin{array}{c}6.0 \\
(4.91)\end{array}$ & $\begin{array}{l}-11.4 \\
(7.17)\end{array}$ & $\begin{array}{c}0.9 \\
(8.17)\end{array}$ & $\begin{array}{l}-1.4 \\
(7.72)\end{array}$ & $\begin{array}{l}14.2^{*} \\
(8.18)\end{array}$ & $\begin{array}{c}2.48 \\
{[0.059]}\end{array}$ & $\begin{array}{c}1.20 \\
{[0.309]}\end{array}$ \\
\hline Photocopying & $\begin{array}{c}-98.8 \\
(84.61)\end{array}$ & $\begin{array}{c}66.5 \\
(57.96)\end{array}$ & $\begin{array}{l}144.2^{*} \\
(84.67)\end{array}$ & $\begin{array}{l}169.5^{*} \\
(96.53)\end{array}$ & $\begin{array}{l}-31.5 \\
(91.20)\end{array}$ & $\begin{array}{l}-103.2 \\
(96.63)\end{array}$ & $\begin{array}{c}2.78 \\
{[0.040]}\end{array}$ & $\begin{array}{c}2.25 \\
{[0.080]}\end{array}$ \\
\hline Broom & $\begin{array}{c}54.2 \\
(79.71)\end{array}$ & $\begin{array}{c}92.9^{*} \\
(54.60)\end{array}$ & $\begin{array}{c}0.4 \\
(79.77)\end{array}$ & $\begin{array}{c}-12.6 \\
(90.94)\end{array}$ & $\begin{array}{c}-26.5 \\
(85.92)\end{array}$ & $\begin{array}{c}45.5 \\
(91.04)\end{array}$ & $\begin{array}{c}1.14 \\
{[0.331]}\end{array}$ & $\begin{array}{c}0.17 \\
{[0.915]}\end{array}$ \\
\hline Coal & $\begin{array}{c}70.5 \\
(98.66)\end{array}$ & $\begin{array}{c}63.9 \\
(67.58)\end{array}$ & $\begin{array}{c}9.0 \\
(98.73)\end{array}$ & $\begin{array}{l}-135.9 \\
(112.56)\end{array}$ & $\begin{array}{c}-3.6 \\
(106.35)\end{array}$ & $\begin{array}{c}80.8 \\
(112.68)\end{array}$ & $\begin{array}{c}0.42 \\
{[0.742]}\end{array}$ & $\begin{array}{c}1.02 \\
{[0.385]}\end{array}$ \\
\hline Newspaper & $\begin{array}{c}63.7 \\
(56.75)\end{array}$ & $\begin{array}{c}-0.8 \\
(38.87)\end{array}$ & $\begin{array}{c}-13.3 \\
(56.79)\end{array}$ & $\begin{array}{c}-60.1 \\
(64.74)\end{array}$ & $\begin{array}{c}2.3 \\
(61.17)\end{array}$ & $\begin{array}{c}21.4 \\
(64.81)\end{array}$ & $\begin{array}{c}0.64 \\
{[0.590]}\end{array}$ & $\begin{array}{c}0.47 \\
{[0.703]}\end{array}$ \\
\hline Pipe & $\begin{array}{c}206.5^{* * *} \\
(56.31)\end{array}$ & $\begin{array}{c}135.5^{* * *} \\
(38.57)\end{array}$ & $\begin{array}{c}47.6 \\
(56.35)\end{array}$ & $\begin{array}{c}-234.1^{* * *} \\
(64.24)\end{array}$ & $\begin{array}{c}-151.9^{* *} \\
(60.70)\end{array}$ & $\begin{array}{c}-48.5 \\
(64.31)\end{array}$ & $\begin{array}{c}7.05 \\
{[0.000]}\end{array}$ & $\begin{array}{c}5.76 \\
{[0.001]}\end{array}$ \\
\hline Light Bulb & $\begin{array}{c}206.9 \\
(158.75)\end{array}$ & $\begin{array}{c}-103.1 \\
(108.74)\end{array}$ & $\begin{array}{l}-269.0^{*} \\
(158.87)\end{array}$ & $\begin{array}{c}-192.1 \\
(181.11)\end{array}$ & $\begin{array}{c}204.5 \\
(171.12)\end{array}$ & $\begin{array}{l}375.3^{* *} \\
(181.31)\end{array}$ & $\begin{array}{c}2.85 \\
{[0.036]}\end{array}$ & $\begin{array}{c}3.11 \\
{[0.025]}\end{array}$ \\
\hline Pencil & $\begin{array}{c}3.1 \\
(7.35)\end{array}$ & $\begin{array}{c}-0.3 \\
(5.04)\end{array}$ & $\begin{array}{c}-0.8 \\
(7.36)\end{array}$ & $\begin{array}{c}4.7 \\
(8.39)\end{array}$ & $\begin{array}{c}0.8 \\
(7.93)\end{array}$ & $\begin{array}{l}-2.7 \\
(8.40)\end{array}$ & $\begin{array}{c}0.10 \\
{[0.962]}\end{array}$ & $\begin{array}{c}0.21 \\
{[0.886]}\end{array}$ \\
\hline Floor Cleaner & $\begin{array}{c}-44.4 \\
(73.51)\end{array}$ & $\begin{array}{c}-11.1 \\
(50.35)\end{array}$ & $\begin{array}{c}-70.7 \\
(73.56)\end{array}$ & $\begin{array}{c}38.2 \\
(83.86)\end{array}$ & $\begin{array}{c}26.9 \\
(79.24)\end{array}$ & $\begin{array}{c}121.4 \\
(83.95)\end{array}$ & $\begin{array}{c}0.34 \\
{[0.799]}\end{array}$ & $\begin{array}{c}0.70 \\
{[0.552]}\end{array}$ \\
\hline Sign Board/Banner & $\begin{array}{c}352.4 \\
(280.28)\end{array}$ & $\begin{array}{c}-10.7 \\
(192.00)\end{array}$ & $\begin{array}{l}-114.0 \\
(280.49)\end{array}$ & $\begin{array}{c}-319.7 \\
(319.77)\end{array}$ & $\begin{array}{c}105.7 \\
(302.13)\end{array}$ & $\begin{array}{c}203.4 \\
(320.12)\end{array}$ & $\begin{array}{c}0.90 \\
{[0.440]}\end{array}$ & $\begin{array}{c}0.79 \\
{[0.502]}\end{array}$ \\
\hline Joint F-Test & $\begin{array}{c}1.19 \\
{[0.236]}\end{array}$ & $\begin{array}{c}1.52 \\
{[0.047]}\end{array}$ & $\begin{array}{c}1.04 \\
{[0.403]}\end{array}$ & $\begin{array}{c}1.16 \\
{[0.261]}\end{array}$ & $\begin{array}{c}1.35 \\
{[0.116]}\end{array}$ & $\begin{array}{c}1.45 \\
{[0.068]}\end{array}$ & $\begin{array}{c}1.42 \\
{[0.010]}\end{array}$ & $\begin{array}{c}1.50 \\
{[0.003]}\end{array}$ \\
\hline
\end{tabular}

Notes: The table shows the results of estimating an extended version of equation (4) by multivariate regression. Specifically, for each item, we estimate $e_{g t o}=\sum_{k=1}^{3}\left(\eta_{k}\right.$ Treatment $_{o}^{k}+\zeta_{k}$ Treatment $\left._{o}^{k} \times \hat{\omega}_{s}\right)+\gamma_{s}+\xi_{t}+\varepsilon_{\text {gto }}$ on data aggregated up to the office $\times$ month $\times$ good level. To aggregate the data, we weight each purchase by our scalar measure of item type, which can be interpreted as the price we predict the item would cost had it been bought in the control group in year 1 . For each purchase, demand is $e_{\text {igto }}=\exp \left(q_{\text {igto }}+h_{\text {igto }}\right)$, where $q_{\text {igto }}$ is the log number of units purchased in purchase $i$, and $h_{\text {igto }}$ is the scalar item type measure, and we sum over all purchases of good $g$ in month $t$ by office $o$ to create $e_{g t o}$. 
Table A.12: Alternative Measurement of Monitor Type

\begin{tabular}{lccccc}
\hline & $(1)$ & $(2)$ & $(3)$ & $(4)$ & $(5)$ \\
\hline Autonomy & 0.335 & 0.091 & 0.146 & 0.228 & 0.331 \\
& $(0.153)$ & $(0.114)$ & $(0.110)$ & $(0.142)$ & $(0.152)$ \\
& {$[0.089]$} & {$[0.507]$} & {$[0.277]$} & {$[0.186]$} & {$[0.073]$} \\
Incentives & -0.066 & -0.064 & -0.094 & -0.036 & -0.068 \\
& $(0.102)$ & $(0.097)$ & $(0.088)$ & $(0.096)$ & $(0.103)$ \\
& {$[0.631]$} & {$[0.588]$} & {$[0.378]$} & {$[0.780]$} & {$[0.601]$} \\
Combined & 0.055 & -0.019 & -0.001 & 0.036 & 0.054 \\
& $(0.091)$ & $(0.091)$ & $(0.087)$ & $(0.102)$ & $(0.091)$ \\
Autonomy $\times$ AG Blame & {$[0.623]$} & {$[0.875]$} & {$[0.992]$} & {$[0.772]$} & {$[0.634]$} \\
& -0.894 & -0.391 & -0.478 & -0.655 & -0.885 \\
Incentives $\times$ AG Blame & $(0.304)$ & $(0.222)$ & $(0.216)$ & $(0.280)$ & $(0.302)$ \\
& {$[0.023]$} & {$[0.129]$} & {$[0.067]$} & {$[0.051]$} & {$[0.022]$} \\
& 0.089 & 0.059 & 0.146 & 0.039 & 0.093 \\
Combined $\times$ AG Blame & $(0.209)$ & $(0.189)$ & $(0.177)$ & $(0.196)$ & $(0.210)$ \\
& {$[0.761]$} & {$[0.781]$} & {$[0.499]$} & {$[0.884]$} & {$[0.732]$} \\
& -0.291 & -0.163 & -0.174 & -0.271 & -0.291 \\
& $(0.192)$ & $(0.180)$ & $(0.172)$ & $(0.207)$ & $(0.192)$ \\
& {$[0.214]$} & {$[0.416]$} & {$[0.372]$} & {$[0.276]$} & {$[0.211]$} \\
\hline Item Variety Control & None & Attribs & Scalar & Coarse & ML \\
Observations & 0.072 & 0.067 & 0.040 & 0.083 & 0.043 \\
\hline O) & 10,172 & 10,172 & 10,172 & 10,172 & 10,172 \\
\hline
\end{tabular}

Notes: The table shows heterogeneity of treatment effects by the degree of misalignment of the district's accountant general using an alternative proxy for the monitor's type. The alternative measure is the median weight given by respondents in the control group to the autonomy-related responses "Only a limited number of vendors are willing to wait for delayed payment", "Vendors charge higher prices for delayed payment", "AG/DAO requirements are not clear and they do not clear bills without inside connections or payment of speed money" and "DDOs do not have enough petty cash to make purchases quickly" when asked "These are potential reasons for why DDOs don't achieve good value for money. In your experience how important is each of these?" in the endline survey. We estimate treatment effect heterogeneity by interacting treatment dummies with the weight measure $p_{\text {igto }}=\alpha+\sum_{k=1}^{3}\left(\eta_{k}\right.$ Treatment $_{o}^{k}+\zeta_{k}$ Treatment $_{o}^{k} \times$ Weight $\left._{o}\right)+\mathbf{X}_{\text {igto }} \beta+\rho_{g} q_{\text {igto }}+\delta_{s}+\gamma_{g}+\varepsilon_{\text {igto }}$. The table shows the $\eta_{k}$ and $\zeta_{k}$ coefficients together with standard errors clustered by office in parentheses and $\mathrm{p}$-values from randomization inference under the null hypothesis of no effect in square brackets. Column 1 does not control for the variety of the item being purchased. Column 2 controls for the full vector of item attributes. Column 3 uses the scalar measure of item variety. Column 4 uses the coarse measure of item variety, and column 5 uses the machine learning measure of item variety. 


\section{TAble A.13: Heterogeneity by Monitor Type: Robustness}

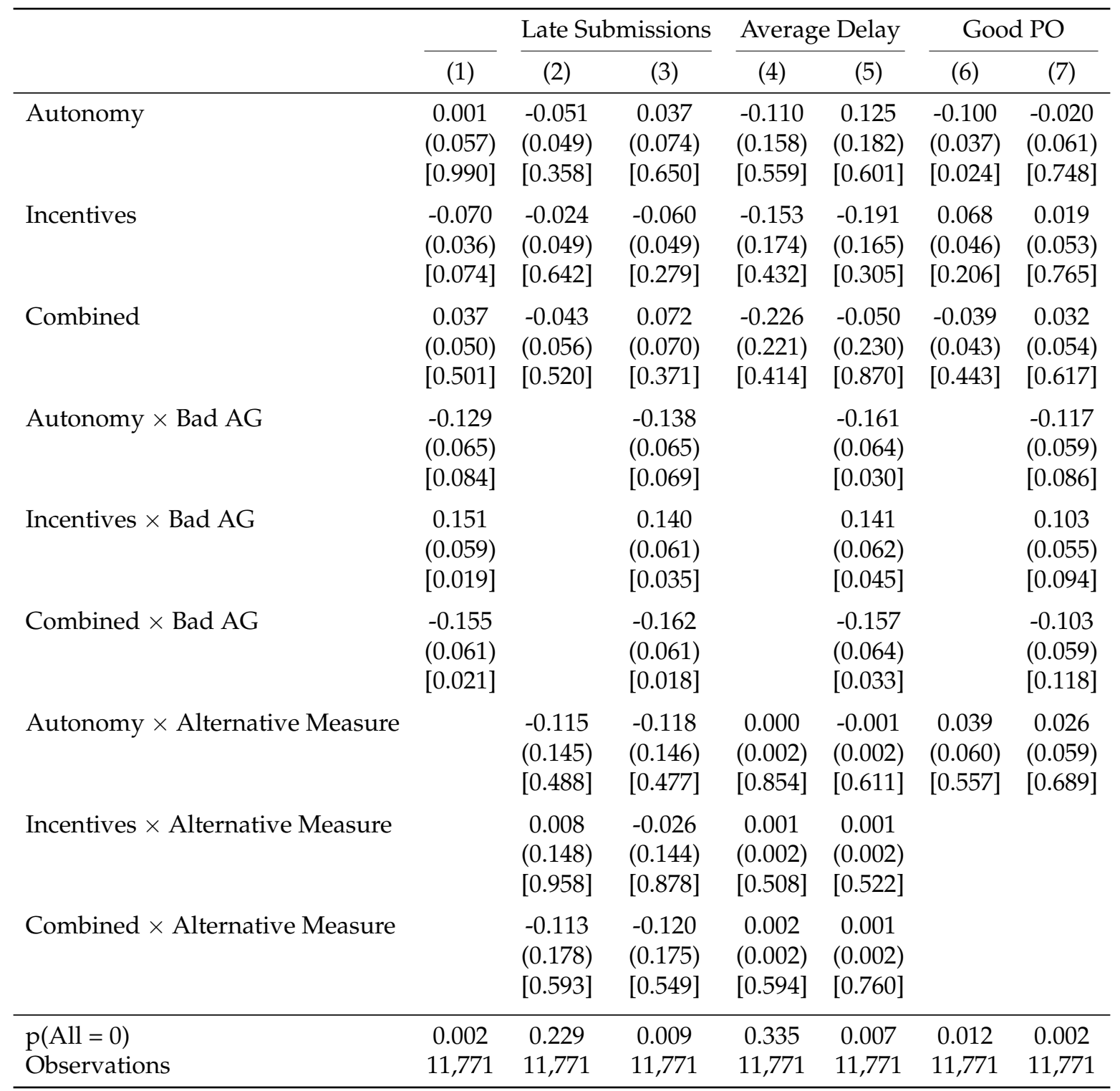

Notes: The table shows robustness of the heterogeneity of treatment effects by the degree of misalignment of the district's accountant general to the inclusion of alternative explanations. As discussed in section 6.1 our proxy for the degree of misalignment of the AG is the degree to which purchase approvals are bunched at the end of the fiscal year in June 2015 (year 1 of the project). We estimate treatment effect heterogeneity by interacting treatment dummies with a dummy for facing a "bad" AG and with alternative explanation measures $p_{\text {igto }}=\alpha+\sum_{k=1}^{3}\left(\eta_{k}\right.$ Treatment $_{o}^{k}+\zeta_{k}$ Treatment $_{o}^{k} \times$ BadAG $_{o}+\xi_{k}$ Treatment $_{o}^{k} \times$ AlternativeMeasure $\left._{o}\right)+$ $\mathbf{X}_{\text {igto }} \beta+\rho_{g} q_{\text {igto }}+\delta_{s}+\gamma_{g}+\varepsilon_{\text {igto }}$. A "bad" AG is defined as a June Share above 0.22 for the autonomy and combined treatments, and 0.48 for the incentive treatment. We show the $\eta_{k} \zeta_{k}$ and $\xi_{k}$ coefficients together with standard errors clustered by office in parentheses and p-values from randomization inference under the null hypothesis of no effect in square brackets. Column 1 does not include any alternative hypothesis. Columns 2 and 3 consider heterogeneity caused by transactions being submitted for approval late. The alternative measure is the share of transactions submitted for approval at the end of the year (May and June). Columns 4 and 5 consider heterogeneity caused by general delays in monitors approving purchases. The alternative measure is the average delay between submission and approval. Columns 6 and 7 consider heterogeneity caused by the effectiveness of the procurement officers (POs) rather than the monitors. We estimate PO fixed effects using the year-1 data and the alternative measure is a dummy for the fixed effect being negative (below average). Note that since the incentives treatment was in place in year 1 the coefficients for the incentives and combined groups cannot be interpreted as heterogeneity by PO type. 
Table A.14: Heterogeneity of Treatment Effects by Procurement Officer DICE SCORE

\begin{tabular}{lcccc}
\hline & $(1)$ & $(2)$ & $(3)$ & $(4)$ \\
\hline Autonomy & 0.2791 & 0.4386 & 0.3442 & 0.4123 \\
& $(0.2820)$ & $(0.2396)$ & $(0.2317)$ & $(0.2589)$ \\
& {$[0.396]$} & {$[0.134]$} & {$[0.213]$} & {$[0.180]$} \\
Incentives & -0.0413 & 0.2079 & 0.0963 & 0.1967 \\
& $(0.3089)$ & $(0.2457)$ & $(0.2574)$ & $(0.2774)$ \\
Both & {$[0.915]$} & {$[0.505]$} & {$[0.770]$} & {$[0.579]$} \\
& -0.0431 & 0.2665 & 0.1409 & 0.1225 \\
& $(0.4106)$ & $(0.3199)$ & $(0.3319)$ & $(0.3965)$ \\
Autonomy $\times$ Dice Score & {$[0.915]$} & {$[0.504]$} & {$[0.717]$} & {$[0.797]$} \\
& -0.0023 & -0.0033 & -0.0026 & -0.0030 \\
Incentives $\times$ Dice Score & {$[0.0017)$} & $(0.0015)$ & $(0.0014)$ & $(0.0016)$ \\
& {$[0.249]$} & {$[0.071]$} & {$[0.122]$} & {$[0.112]$} \\
Both $\times$ Dice Score & 0.0001 & -0.0015 & -0.0007 & -0.0013 \\
& {$[0.0019)$} & $(0.0015)$ & $(0.0016)$ & $(0.0017)$ \\
& $-0.954]$ & {$[0.426]$} & {$[0.698]$} & {$[0.541]$} \\
& $(0.0025)$ & -0.0022 & -0.0013 & -0.0013 \\
& {$[0.0019)$} & $(0.0020)$ & $(0.0024)$ \\
Item Variety Control & None & Attribs & Scalar & Coarse \\
p(All Interactions $=0)$ & 0.167 & 0.056 & 0.156 & 0.132 \\
Observations & 10,283 & 10,283 & 10,283 & 10,283 \\
\hline
\end{tabular}

Notes: The table shows heterogeneity of treatment effects by the degree of misalignment of the procurement officer, as measured by their score in the dice game measure of dishonesty studied in Fischbacher \& Föllmi-Heusi (2013) and Hanna \& Wang (2017) and summarized in appendix figure A.12. We estimate treatment effect heterogeneity by interacting our proxy for PO type $\hat{\mu}_{o}$ with treatment dummies $p_{\text {igto }}=\alpha+\eta$ Autonomy $_{o}+\zeta$ Autonomy $_{o} \times \hat{\mu}_{o}+\mathbf{X}_{\text {igto }} \beta+\rho_{g} q_{\text {igto }}+\delta_{s}+\gamma_{g}+\varepsilon_{\text {igto }}$. 


\section{B Proofs and Other Theory Material}

\section{Proof of Proposition 1}

By re-arranging $\Delta_{A}$, we can see that $\Delta_{A}>0$ if and only if

$$
\frac{\theta_{A G}}{1-\theta_{A G}}<\frac{\frac{\theta_{P O}}{1-\theta_{P O}}\left(p_{M}-p_{M A}\right)}{-\left(\frac{\theta_{P O}}{1-\theta_{P O}}\left(p_{M}-p_{M M}\right)+\left(c-p_{A M}\right)\right)}
$$

Both the numerator and the denominator are positive. Hence for any $\theta_{P O}$ there exists $\bar{\theta}_{A G}\left(\theta_{P O}\right)>0$ such that for all $\theta_{A G}>\bar{\theta}_{A G}\left(\theta_{P O}\right)$, the inequality holds. Note that $\bar{\theta}_{A G}\left(\theta_{P O}\right)$ is increasing in $\theta_{P O}$.

If the bandit competition effect is absent $\left(p_{M}=p_{M M}\right)$ and the bad-monitor effect is low with respect to the good-monitor effect $\left(\left(p_{A M}-c\right) /\left(p_{M}-p_{M A}\right)<1\right)$, then the inequality becomes

$$
\frac{\theta_{A G}}{1-\theta_{A G}}>\frac{\theta_{P O}}{1-\theta_{P O}} \frac{p_{M}-p_{M A}}{p_{A M}-c}>\frac{\theta_{P O}}{1-\theta_{P O}},
$$

and there exists $\bar{\theta}_{A G}\left(\theta_{P O}\right) \in(0,1)$ such that it holds as an equality.

\section{Proof of Corollary 1}

Autonomy treatment decreases price if

$$
\frac{\theta_{A G}}{1-\theta_{A G}}>\frac{\frac{\theta_{P O}}{1-\theta_{P O}}\left(p_{M}-p_{M A}\right)}{-\left(\frac{\theta_{P O}}{1-\theta_{P O}}\left(p_{M}-p_{M M}\right)+\left(c-p_{A M}\right)\right)},
$$

or

$$
\frac{\theta_{A G}}{1-\theta_{A G}}\left(-\left(\frac{\theta_{P O}}{1-\theta_{P O}}\left(p_{M}-p_{M M}\right)+\left(c-p_{A M}\right)\right)\right)>\frac{\theta_{P O}}{1-\theta_{P O}}\left(p_{M}-p_{M A}\right) .
$$

If $\theta_{A G}=\theta_{P O}$, the condition becomes:

$$
-\left(\frac{\theta_{P O}}{1-\theta_{P O}}\left(p_{M}-p_{M M}\right)+\left(c-p_{A M}\right)\right)>p_{M}-p_{M A} .
$$

As $p_{M}-p_{M M}<0$, the condition is satisfied a fortiori if

$$
p_{A M}-c>p_{M}-p_{M A}
$$

which can be re-written as

$$
p_{M}-p_{A M}<p_{M A}-c,
$$


which is always true because

$$
p_{M}-p_{A M}<p_{M M}-p_{A M} \leq p_{M A}-c,
$$

where the first inequality is because $p_{M}<p_{M M}$ and the second inequality is true because of Complementarity Between Agent Types.

\section{Proof of Proposition 2}

The effect of the incentive treatment on price is:

$$
\begin{aligned}
\Delta_{I} & =\theta_{A G} p_{A M}+\left(1-\theta_{A G}\right) c \\
& -\left(\theta_{P O} \theta_{A G} p_{M M}+\theta_{P O}\left(1-\theta_{A G}\right) p_{M A}+\left(1-\theta_{P O}\right) \theta_{A G} p_{A M}+\left(1-\theta_{P O}\right)\left(1-\theta_{A G}\right) c\right) \\
& =\theta_{P O} \theta_{A G}\left(p_{A M}-p_{M M}\right)+\theta_{P O}\left(1-\theta_{A G}\right)\left(c-p_{M A}\right)<0
\end{aligned}
$$

We also see that

$$
\lim _{\theta_{A G} \rightarrow 0, p_{M M} \rightarrow p_{A M}} \Delta_{I}=0
$$

\section{Statement and Proof of Proposition 3}

Proposition 3. (i) The price reduction generated by the combined autonomy and treatment effect is at least as large as the larger price reduction generated by Autonomy and Incentive as individual treatments.

(ii) There exist values of $\left(\theta_{P O}, \theta_{A G}\right)$ for which the weak inequality in (i) holds as a strict inequality.

Proof. The combined effect is

$$
\begin{aligned}
\Delta_{C} & =c-\left(\theta_{P O} \theta_{A G} p_{M M}+\theta_{P O}\left(1-\theta_{A G}\right) p_{M A}+\left(1-\theta_{P O}\right) \theta_{A G} p_{A M}+\left(1-\theta_{P O}\right)\left(1-\theta_{A G}\right) c\right) \\
& =\theta_{P O} \theta_{A G}\left(c-p_{M M}\right)+\theta_{P O}\left(1-\theta_{A G}\right)\left(c-p_{M A}\right)+\left(1-\theta_{P O}\right) \theta_{A G}\left(c-p_{A M}\right)
\end{aligned}
$$

Compare with

$$
\begin{aligned}
\Delta_{I} & =\theta_{A G} p_{A M}+\left(1-\theta_{A G}\right) c \\
& -\left(\theta_{P O} \theta_{A G} p_{M M}+\theta_{P O}\left(1-\theta_{A G}\right) p_{M A}+\left(1-\theta_{P O}\right) \theta_{A G} p_{A M}+\left(1-\theta_{P O}\right)\left(1-\theta_{A G}\right) c\right) \\
& =\theta_{P O} \theta_{A G}\left(p_{A M}-p_{M M}\right)+\theta_{P O}\left(1-\theta_{A G}\right)\left(c-p_{M A}\right)<0
\end{aligned}
$$


and

$$
\Delta_{A}=\theta_{P O} \theta_{A G}\left(p_{M}-p_{M M}\right)+\theta_{P O}\left(1-\theta_{A G}\right)\left(p_{M}-p_{M A}\right)+\left(1-\theta_{P O}\right) \theta_{A G}\left(c-p_{A M}\right)
$$

The comparison with the incentive treatment yields:

$$
\begin{aligned}
\Delta_{C}-\Delta_{I} & =\theta_{P O} \theta_{A G}\left(c-p_{M M}\right)+\left(1-\theta_{P O}\right) \theta_{A G}\left(c-p_{A M}\right)-\theta_{P O} \theta_{A G}\left(p_{A M}-p_{M M}\right) \\
& =\theta_{P O} \theta_{A G}\left(c-p_{A M}\right)+\left(1-\theta_{P O}\right) \theta_{A G}\left(c-p_{A M}\right)<0
\end{aligned}
$$

The comparison with the autonomy treatment yields:

$$
\begin{aligned}
\Delta_{C}-\Delta_{A} & =\theta_{P O} \theta_{A G}\left(c-p_{M M}\right)+\theta_{P O}\left(1-\theta_{A G}\right)\left(c-p_{M A}\right) \\
& -\left(\theta_{P O} \theta_{A G}\left(p_{M}-p_{M M}\right)+\theta_{P O}\left(1-\theta_{A G}\right)\left(p_{M}-p_{M A}\right)\right) \\
& =\theta_{P O} \theta_{A G}\left(c-p_{M}\right)+\theta_{P O}\left(1-\theta_{A G}\right)\left(c-p_{M}\right)<0
\end{aligned}
$$

For (ii), simply notice that for $\left(\theta_{P O}, \theta_{A G}\right) \in\{(0,0),(1,0),(0,1)\}$, either $\Delta_{C}=\Delta_{I}, \Delta_{C}=$ $\Delta_{A}$, or both. 


\section{Alternative, Micro-founded Model}

This appendix presents an alternative model of the setting we study and the effects we expect from the experimental treatments. The model is still stylized, but instead of the primitives of the model being prices, the model's primitives are the procurement officer and the monitor's utility functions. In addition, both the procurement officer and the monitor have a continuum of types, giving rise to a continuum of prices. Nevertheless, the model remains a parsimonious framework that delivers highly stylized predictions to guide the analysis.

\section{C.1 Set-up}

This simple model describes our context, where procurement decisions are taken by an officer and monitored by a monitor with veto power.

For each purchase, the officer selects a mark-up $x \geq 0$. The mark-up $x$ captures different forms of misalignment between the interests of the officer and her principal, the taxpayer. It can be interpreted as active waste (bribes), passive waste (inefficiency), or a combination of both. We will discuss both interpretations below.

The officer operates under a monitoring agency. The purchase is audited by the monitor with probability $1-a$ (where $a$ stands for autonomy - the probability that the officer is not audited). The purchase price is thus

$$
p=c+x+\omega(1-a),
$$

where $c$ is the cost of the good, $x$ is the officer's mark-up, and $\omega$ is an additional cost introduced by the monitor.

If a purchase is audited, the officer receives a punishment proportional to the markup $x$. Finally, the officer faces an incentive to spend less. Her utility is:

$$
u=\gamma \ln x-\mu(1-a) x-b x,
$$

where: the first term is the benefit the officer receives from the mark-up, which is scaled by $\gamma$, the weight the officer puts on her private utility; the second term is the cost the officer incurs if she is audited on the procured good, which depends on the effectiveness of the monitoring process, $\mu$; and $b$ in the third term represents the strength of a monetary incentive scheme whereby the officer is rewarded for spending less.

The model has two interpretations. In the active waste interpretation, the officer receives a bribe from the supplier in exchange for increasing the purchase price above 
the supply cost. The underlying assumption is that there is a bribing technology that transforms a mark-up $x$ into a benefit for the officer $\gamma \ln x$. In this interpretation a higher markup has three effects: it increases the price of the purchased good by $x$; it produces utility for the officer, who enjoys the bribe, given by $\gamma \ln x$, and it imposes a risk of sanction on the officer given by $\mu(1-a) x$.

In the passive waste interpretation, the officer is lazy and prefers not to exert effort to locate the cheapest supplier or wring the lowest price from the chosen supplier. The underlying assumption is that there is a search/bargaining technology that transforms a mark-up $x$ into a benefit for the officer $\gamma \ln x$ : less work leads to higher prices. In this interpretation a higher mark-up has three effects too: it increases the price of the purchased good by $x$; it produces utility for the officer, who enjoys the lower effort, given by $\gamma \ln x$, and it imposes a risk of sanction on the officer given by $\mu(1-a) x$. Of course, it is also possible to interpret the model as a mix of active and passive waste.

The role of the monitor can also be interpreted in two ways. In the active waste interpretation, the monitor also receives a bribe and that raises the purchase price by $\omega(1-a)$. The monitor also punishes the officer for accepting bribes through $\mu(1-a) x$. In the passive waste interpretation, the monitor too dislikes effort: if there is an audit he may add to the price of good by taking a long time to process the purchase (perhaps because suppliers predict that it will take them a long time to be paid). This too raises the purchase price by $\omega(1-a)$. The monitor also punishes the officer for engaging in passive waste through $\mu(1-a) x$.

In both interpretations the monitor has a positive effect and a negative effect. The positive effect consists in disciplining the officer through $\mu(1-a) x$. As we shall see shortly, this induces the officer to decrease her mark-up $x$. The negative effect instead operates through $\omega(1-a)$ : it is the additional passive or active waste that the monitor generates. The rest of the analysis will show that the overall effect of the monitor will depend on relative size of these two effects.

We now proceed with the analysis (normalizing $c$ to zero without loss of generality). The officer selects the optimal mark-up level given her preference parameters and the environment she faces:

$$
x=\frac{\gamma}{\mu(1-a)+b}
$$

and the price is

$$
p=\frac{\gamma}{\mu(1-a)+b}+\omega(1-a)
$$

The price formula embodies the autonomy tradeoff: the first term captures the monitor's disciplining effect on the officer, while the second represents the additional mark-up 
imposed by the monitor.

This simple model thus captures the trade-off at the heart of the allocation of authority: giving more autonomy to the officer (higher $a$ ) increases markups especially if the officer puts a large weight on her private benefits $\gamma$, but it reduces supervision costs at the same time.

\section{C.2 Treatment effects}

Our two experimental treatments involve an increase in autonomy (higher $a$ ) and an increase in the power of incentives (higher $b$ ). The effects of the two treatments on prices (in percentage terms) are as follows

Proposition 4. (i) An increase in autonomy decreases $p$ if and only if $\omega$ is sufficiently large relative to $\gamma$, and the decrease is larger when $\omega$ is large

(ii) An increase in incentive power always decreases $p$, but the decrease is larger when $\omega$ is small and tends to zero as $\omega \rightarrow \infty$.

Proof. For (i):

$$
\frac{\frac{\partial p}{\partial a}}{p}=\frac{\frac{\partial}{\partial a}\left(\frac{\gamma}{\mu(1-a)+b}+(1-a) \omega\right)}{p}=\frac{\frac{\gamma \mu}{(\mu(1-a)+b)^{2}}-\omega}{p}<0 \text { iff } \omega>\bar{\omega} \equiv \frac{\gamma \mu}{(\mu(1-a)+b)^{2}}
$$

Clearly $\frac{\frac{\partial p}{\partial a}}{p}$ is decreasing in $\omega$ and $\lim _{\omega \rightarrow \infty} \frac{\frac{\partial p}{\partial a}}{p}=-\frac{1}{1-a}$

For (ii):

$$
\begin{aligned}
\frac{\frac{\partial p}{\partial b}}{p} & =\frac{\frac{\partial}{\partial b}\left(\frac{\gamma}{\mu(1-a)+b}+(1-a) s\right)}{p}=-\frac{\frac{\gamma}{(\mu(1-a)+b)^{2}}}{\frac{\gamma}{\mu(1-a)+b}+(1-a) \omega} \\
& =-\frac{\gamma}{(\mu(1-a)+b)\left(\gamma+(1-a)^{2} \omega \mu+\mu(1-a) b\right)}
\end{aligned}
$$

hence $\frac{\frac{\partial p}{\partial b}}{p}$ is increasing in $\omega$ and $\lim _{\omega \rightarrow \infty} \frac{\partial p / \partial b}{p}=0$.

This simple framework makes precise that the effectiveness of the two policy levers depends on the efficiency of the monitor relative to the procurement officer. Because of this, offering the two jointly is either detrimental or inconsequential:

Proposition 5. A joint increase in autonomy and incentives:

(i) reduces prices by less than incentives alone when $\omega$ is low relative to $h$

(ii) converges to the effect of autonomy alone as $\omega \rightarrow \infty$. 
Proof. Consider the combined treatment that changes autonomy by $d a$ and incentives by $d b$. The effect of this is to change prices by

$$
\begin{aligned}
d p & =\frac{\partial p}{\partial a} d a+\frac{\partial p}{\partial b} d b+\frac{\partial^{2} p}{\partial a \partial b} d a d b \\
& =\left(\frac{\gamma \mu}{(\mu(1-a)+b)^{2}}-\omega\right) d a-\frac{\gamma}{(\mu(1-a)+b)^{2}} d b-\frac{2 \gamma \mu}{(\mu(1-a)+b)^{3}} d a d b
\end{aligned}
$$

To see (i) compare the price change from the combined treatment to the price change resulting from a treatment that changes incentives by the same amount $d b$ but leaves autonomy unchanged. It is

$$
\frac{d a}{(\mu(1-a)+b)^{3}}\left[\gamma \mu(\mu(1-a)+b)-\omega(\mu(1-a)+b)^{3}-2 \gamma \mu d b\right]
$$

which is negative as long as $\omega<\bar{\omega}-\frac{2 \gamma \mu}{(\mu(1-a)+b)^{3}} d b$ where $\bar{\omega}$ is as defined in the proof of proposition 4. (ii) follows from application of l'Hôpital's rule: $\lim _{\omega \rightarrow \infty} d p / p=1 /(1-a)$ which is the same as the limit of the autonomy treatment effect.

The predictions of the model for the treatment effects and how they vary with the misalignment of the monitor $\omega$ are summarized graphically in figure C.14. 


\section{Figure C.14: Model Predictions of Heterogeneity of Treatment Effects by MONITOR TYPE}

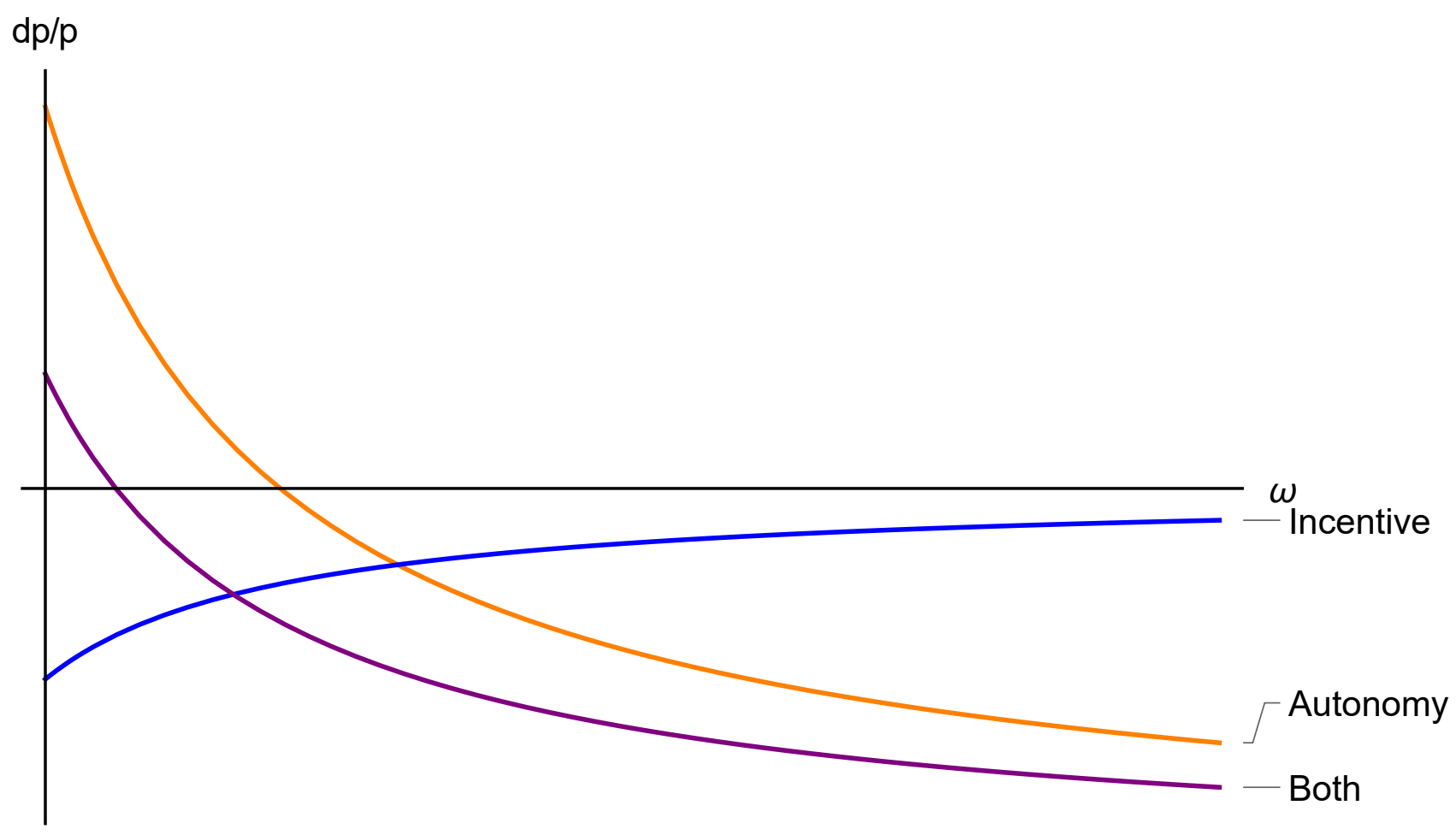

Notes: The figure shows the predictions our model in section $C$ makes about how the treatment effects of our experiment will vary with the degree of misalignment of the monitor $(\omega)$ as described in propositions 4 and 5 . 


\section{Construction of Item Variety Controls}

This appendix describes the methods we used to construct the item variety controls used throughout the empirical analysis. The idea behind the methods is to use data from the experiment's control group to construct measures in both treatment and control groups that allow us to hold constant all the features of the good that can affect its price in the control group. This poses two challenges. First, the set of attributes of each good may be large. Of these, only a subset is relevant for prices, and we want to avoid overfitting the data from the control group, so we want to reduce the dimensionality of the controls we use. Second, when using the control group data to construct measures of item variety in the treatment groups, the attributes used as inputs to these measures may not have common support. There may be attributes that occur in the treatment groups that never appear in the data from the control group. Our measures will predict how attributes that occur in the control group affect prices, but will not know how to deal with an attribute that only ever occurs in the treatment groups.

Our first three measures address these issues through manual grouping of attributes and using hedonic regressions to reduce the dimensionality of the measures. We begin by manually grouping attributes to ensure common support and avoid overfitting. Most of the attributes we use are categorical and so we group values. For values that occur less than three times in the control group or only in the treatment group, we either group them together with similar values (using contextual knowledge and extensive googling to find similar values) or if similar values are not available, set them to missing. Observations with all attributes missing after this cleaning are dropped. Ensuring that each group appears at least three times avoids overfitting, and ensuring that the groups are observed in both the control and treatment groups ensures common support. These groups then form the $\mathbf{X}_{\text {igto }}$ controls used in the hedonic regressions (1). Table D.15 illustrates the procedure. The first columns show the attributes in the raw data and the number of categories (for categorical variables) or the mean and standard deviation (for numerical variables) for each one. The second set of columns shows the same statistics for the data used for the hedonic regressions and the main analysis.

Our fourth, machine learning, measure develops a variant of a random forest algorithm to allow for non-linearities and interactions between attributes that the hedonic regression 1 rules out and also to perform the grouping of attributes' values in a datadriven way. For this we do much lighter cleaning of the data only harmonizing spellings. This can be seen in the third group of columns in table D.15, where the attributes tend to have a far greater number of categories. We then train a random forest algorithm for each 
item, averaging 500 trees to form predicted prices. The algorithm is trained only on the control group's data, so as in the case of the scalar and coarse measures of item variety, the predicted prices should be interpreted as a prediction of the price of the purchase had it been conducted by a PO in the control group.

After training each tree in the control group, the algorithm places each observation in the treatment groups into its corresponding leaf. It first places all treatment group observations that only have attributes that are sufficient to place it into a unique leaf in the tree. Then, for observations that have an attribute that prevents it from being placed into a leaf, the algorithm selects all leaves the observation could be placed into given the attributes that can be used, and then for each attribute that cannot be used, replaces that attribute with the category in the same treatment group with the closest average, but that does appear in the control group. Once every observation is placed into a leaf, the average price amongst control group observations in the leaf is then that tree's predicted price. Averaging the 500 trees gives us our machine learning measure of item variety. 
Table D.15: POPS Data Cleaning

\begin{tabular}{|c|c|c|c|c|c|c|c|}
\hline \multirow[b]{2}{*}{ Item } & \multirow[b]{2}{*}{ Attributes } & \multicolumn{2}{|c|}{ Raw Data } & \multicolumn{2}{|c|}{ Regression Data } & \multicolumn{2}{|c|}{ Machine Learning Data } \\
\hline & & $\begin{array}{c}\text { mean (s.d.) / } \\
\text { \#categories }\end{array}$ & \# missing & $\begin{array}{c}\text { mean (s.d.) / } \\
\text { \#categories }\end{array}$ & \# missing & $\begin{array}{c}\text { mean (s.d.) / } \\
\text { \#categories }\end{array}$ & \# missing \\
\hline \multirow{7}{*}{ Pencil } & Brand & 21 categories & 272 & 8 categories & 187 & 19 categories & 156 \\
\hline & Grade & 26 categories & 279 & 13 categories & 175 & 25 categories & 159 \\
\hline & Type & 8 categories & 156 & 5 categories & 54 & 5 categories & 46 \\
\hline & With Rubber? & 2 categories & 281 & 2 categories & 177 & 2 categories & 164 \\
\hline & Unit Price. mean (s.d.) & $10.81(14.91)$ & & $10.51(14.42)$ & & $9.80(11.31)$ & \\
\hline & \# Purchasing PBs & 311 & & 275 & & 253 & \\
\hline & \# Observations & 612 & & 476 & & 475 & \\
\hline \multirow{3}{*}{ Ice Block } & Unit Price. mean (s.d.) & $0.01(0.02)$ & & $0.01(0.01)$ & & $0.01(0.01)$ & \\
\hline & \# Purchasing PBs & \multicolumn{2}{|l|}{321} & \multicolumn{2}{|c|}{304} & \multicolumn{2}{|c|}{304} \\
\hline & \# Observations & \multicolumn{2}{|c|}{680} & \multicolumn{2}{|c|}{638} & \multicolumn{2}{|c|}{638} \\
\hline \multirow{8}{*}{ Wiper } & Brand & 13 categories & 388 & 4 categories & 173 & 12 categories & 152 \\
\hline & Country of Origin & 3 categories & 331 & 2 categories & 98 & 2 categories & 98 \\
\hline & Handle Length & 8 categories & 381 & 5 categories & 141 & 5 categories & 141 \\
\hline & Handle Material & 5 categories & 304 & 4 categories & 77 & 4 categories & 77 \\
\hline & Wiper Material & 7 categories & 314 & 3 categories & 88 & 3 categories & 87 \\
\hline & Unit Price. mean (s.d.) & $271.42(125.82)$ & & $264.13(115.92)$ & & $264.13(115.92)$ & \\
\hline & \# Purchasing PBs & 401 & & 296 & & 296 & \\
\hline & \# Observations & 753 & & 484 & & 484 & \\
\hline
\end{tabular}


TABle D.15: POPS Data Cleaning

\begin{tabular}{|c|c|c|c|c|c|c|c|}
\hline \multirow[b]{2}{*}{ Item } & \multirow[b]{2}{*}{ Attributes } & \multicolumn{2}{|c|}{ Raw Data } & \multicolumn{2}{|c|}{ Regression Data } & \multicolumn{2}{|c|}{ Machine Learning Data } \\
\hline & & $\begin{array}{c}\text { mean (s.d.) / } \\
\text { \#categories }\end{array}$ & \# missing & $\begin{array}{c}\text { mean (s.d.) / } \\
\text { \#categories }\end{array}$ & \# missing & $\begin{array}{c}\text { mean (s.d.) / } \\
\text { \#categories }\end{array}$ & \# missing \\
\hline \multirow{6}{*}{ Calculator } & Brand \& Model & 7 categories & 150 & 12 categories & 49 & 22 categories & 44 \\
\hline & Number of Digits & 6 categories & 205 & 4 categories & & 4 categories & \\
\hline & Type & 5 categories & 185 & 4 categories & 76 & 4 categories & 77 \\
\hline & Unit Price. mean (s.d.) & $271.42(125.82)$ & & $796.24(350.34)$ & & $795.93(350.05)$ & \\
\hline & \# Purchasing PBs & 401 & & 326 & & 326 & \\
\hline & \# Observations & 616 & & 486 & & 487 & \\
\hline \multirow{3}{*}{ Coal } & Unit Price. mean (s.d.) & $0.08(0.26)$ & & $0.06(0.02)$ & & $0.06(0.02)$ & \\
\hline & \# Purchasing PBs & 384 & & 362 & & 362 & \\
\hline & \# Observations & 685 & & 650 & & 650 & \\
\hline \multirow{5}{*}{ Staples } & Brand & 19 categories & 69 & 8 categories & 59 & 19 categories & 36 \\
\hline & Size & 27 categories & 60 & 6 categories & 26 & 5 categories & 26 \\
\hline & Unit Price. mean (s.d.) & $0.14(0.43)$ & & $0.11(0.20)$ & & $0.11(0.20)$ & \\
\hline & \# Purchasing PBs & 334 & & 288 & & 288 & \\
\hline & \# Observations & 551 & & 465 & & 465 & \\
\hline
\end{tabular}


Table D.15: POPS Data Cleaning

\begin{tabular}{|c|c|c|c|c|c|c|c|}
\hline \multirow[b]{2}{*}{ Item } & \multirow[b]{2}{*}{ Attributes } & \multicolumn{2}{|c|}{ Raw Data } & \multicolumn{2}{|c|}{ Regression Data } & \multicolumn{2}{|c|}{ Machine Learning Data } \\
\hline & & $\begin{array}{c}\text { mean (s.d.) / } \\
\text { \#categories }\end{array}$ & \# missing & $\begin{array}{c}\text { mean (s.d.) / } \\
\text { \#categories }\end{array}$ & \# missing & $\begin{array}{c}\text { mean (s.d.) / } \\
\text { \#categories }\end{array}$ & \# missing \\
\hline \multirow{10}{*}{ Lock } & Brand \& Model & 18 categories & 508 & 4 categories & 270 & 9 categories & 231 \\
\hline & Country of Origin & 5 categories & 384 & 2 categories & 117 & 2 categories & 119 \\
\hline & Digital? & 2 categories & 526 & 2 categories & 245 & 2 categories & 247 \\
\hline & Fitting Charges? & 2 categories & 514 & 2 categories & 235 & 2 categories & 237 \\
\hline & Size & 27 categories & 60 & 6 categories & 26 & 5 categories & 26 \\
\hline & Material & 8 categories & 512 & 4 categories & 233 & 4 categories & 235 \\
\hline & Type & 20 categories & 440 & 7 categories & 166 & 13 categories & 160 \\
\hline & Unit Price. mean (s.d.) & \multicolumn{2}{|l|}{$315.94(340.11)$} & \multicolumn{2}{|l|}{$282.89(235.49)$} & \multicolumn{2}{|l|}{$282.56(235.21)$} \\
\hline & \# Purchasing PBs & \multicolumn{2}{|l|}{404} & \multicolumn{2}{|l|}{318} & \multicolumn{2}{|l|}{319} \\
\hline & \# Observations & \multicolumn{2}{|c|}{965} & \multicolumn{2}{|c|}{652} & \multicolumn{2}{|l|}{654} \\
\hline \multirow{7}{*}{ Stamp Pad } & Brand & 19 categories & 262 & 10 categories & 77 & 18 categories & 64 \\
\hline & Color & 8 categories & 281 & 5 categories & 86 & 6 categories & 86 \\
\hline & Size & 22 categories & 317 & 8 categories & 125 & 8 categories & 125 \\
\hline & With Ink? & 3 categories & 266 & 2 categories & 81 & 2 categories & 81 \\
\hline & Unit Price. mean (s.d.) & $85.92(50.40)$ & & $82.72(44.05)$ & & $82.98(43.92)$ & \\
\hline & \# Purchasing PBs & 430 & & 352 & & 352 & \\
\hline & \# Observations & 771 & & 545 & & 543 & \\
\hline
\end{tabular}


Table D.15: POPS Data Cleaning

\begin{tabular}{|c|c|c|c|c|c|c|c|}
\hline \multirow[b]{2}{*}{ Item } & \multirow[b]{2}{*}{ Attributes } & \multicolumn{2}{|c|}{ Raw Data } & \multicolumn{2}{|c|}{ Regression Data } & \multicolumn{2}{|c|}{ Machine Learning Data } \\
\hline & & $\begin{array}{c}\text { mean (s.d.) / } \\
\text { \#categories }\end{array}$ & \# missing & $\begin{array}{c}\text { mean (s.d.) / } \\
\text { \#categories }\end{array}$ & \# missing & $\begin{array}{c}\text { mean (s.d.) / } \\
\text { \#categories }\end{array}$ & \# missing \\
\hline \multirow{7}{*}{ Duster } & Material & 9 categories & 261 & 6 categories & 37 & 7 categories & 37 \\
\hline & Size & 52 categories & 437 & 17 categories & 195 & 18 categories & 193 \\
\hline & Type & 9 categories & 343 & 4 categories & 116 & 4 categories & 116 \\
\hline & With Handle? & 2 categories & 435 & 2 categories & 196 & 2 categories & 196 \\
\hline & Unit Price. mean (s.d.) & $66.31(76.83)$ & & $65.13(71.31)$ & & $65.13(71.31)$ & \\
\hline & \# Purchasing PBs & \multicolumn{2}{|l|}{386} & \multicolumn{2}{|l|}{290} & \multicolumn{2}{|l|}{290} \\
\hline & \# Observations & \multicolumn{2}{|c|}{722} & \multicolumn{2}{|c|}{456} & \multicolumn{2}{|c|}{456} \\
\hline \multirow{9}{*}{ Floor Cleaner } & Acid Cleaner & 7 categories & 376 & 4 categories & 242 & 4 categories & 235 \\
\hline & Brand & 38 categories & 348 & 16 categories & 258 & 30 categories & 216 \\
\hline & Environmentally Friendly & 2 categories & 286 & 2 categories & 168 & 2 categories & 169 \\
\hline & Make & 6 categories & 307 & 4 categories & 180 & 6 categories & 177 \\
\hline & Scented & 2 categories & 230 & 2 categories & 116 & 2 categories & 117 \\
\hline & State & 8 categories & 225 & 3 categories & 103 & 3 categories & 104 \\
\hline & Unit Price. mean (s.d.) & $0.27(0.94)$ & & $0.19(0.30)$ & & $0.19(0.30)$ & \\
\hline & \# Purchasing PBs & \multicolumn{2}{|l|}{458} & \multicolumn{2}{|c|}{377} & \multicolumn{2}{|l|}{377} \\
\hline & \# Observations & \multicolumn{2}{|c|}{1162} & \multicolumn{2}{|c|}{945} & \multicolumn{2}{|l|}{946} \\
\hline
\end{tabular}


Table D.15: POPS Data Cleaning

\begin{tabular}{|c|c|c|c|c|c|c|c|}
\hline \multirow[b]{2}{*}{ Item } & \multirow[b]{2}{*}{ Attributes } & \multicolumn{2}{|c|}{ Raw Data } & \multicolumn{2}{|c|}{ Regression Data } & \multicolumn{2}{|c|}{ Machine Learning Data } \\
\hline & & $\begin{array}{c}\text { mean (s.d.) / } \\
\text { \#categories }\end{array}$ & \# missing & $\begin{array}{c}\text { mean (s.d.) / } \\
\text { \#categories }\end{array}$ & \# missing & $\begin{array}{c}\text { mean (s.d.) / } \\
\text { \#categories }\end{array}$ & \# missing \\
\hline \multirow{10}{*}{ File Cover } & Brand & 20 categories & 399 & 5 categories & 306 & 18 categories & 286 \\
\hline & With Clip & 2 categories & 662 & 2 categories & 258 & 2 categories & 259 \\
\hline & Country of Origin & 6 categories & 379 & 4 categories & 265 & 3 categories & 266 \\
\hline & Cover Material & 22 categories & 244 & 11 categories & 150 & 13 categories & 151 \\
\hline & Customized Printing & 5 categories & 328 & 4 categories & 228 & 3 categories & 229 \\
\hline & File Type & 28 categories & 138 & 14 categories & 61 & 22 categories & 58 \\
\hline & Size & 27 categories & 414 & 3 categories & 290 & 3 categories & 291 \\
\hline & Unit Price. mean (s.d.) & $53.11(95.41)$ & & $47.62(75.07)$ & & $47.56(75.02)$ & \\
\hline & \# Purchasing PBs & 391 & & 312 & & 313 & \\
\hline & \# Observations & 775 & & 583 & & 584 & \\
\hline \multirow{9}{*}{ Sign Board / Banner } & Frame Type & 7 categories & 667 & 3 categories & 586 & 5 categories & 586 \\
\hline & Material & 11 categories & 445 & 7 categories & 391 & 10 categories & 391 \\
\hline & Number of Colors & 6 categories & 723 & $2.8(1.23)$ & 643 & $2.8(1.23)$ & 643 \\
\hline & Number of Rings & 12 categories & 692 & $4.4(4.05)$ & 1055 & $4.4(4.05)$ & 1055 \\
\hline & Print on Both Sides & 3 categories & 625 & 2 categories & 550 & 2 categories & 551 \\
\hline & Area & 85 categories & 732 & $44.2(355.64)$ & 644 & $44.2(355.64)$ & 644 \\
\hline & With Rope & 2 categories & 598 & 2 categories & 523 & 2 categories & 523 \\
\hline & With Stand & 2 categories & 598 & 2 categories & 519 & 2 categories & 519 \\
\hline & With Stick & 2 categories & 590 & 2 categories & 511 & 2 categories & 511 \\
\hline
\end{tabular}


Table D.15: POPS Data Cleaning

\begin{tabular}{|c|c|c|c|c|c|c|c|}
\hline \multirow[b]{2}{*}{ Item } & \multirow[b]{2}{*}{ Attributes } & \multicolumn{2}{|c|}{ Raw Data } & \multicolumn{2}{|c|}{ Regression Data } & \multicolumn{2}{|c|}{ Machine Learning Data } \\
\hline & & $\begin{array}{c}\text { mean (s.d.) / } \\
\text { \#categories }\end{array}$ & \# missing & $\begin{array}{c}\text { mean (s.d.) / } \\
\text { \#categories }\end{array}$ & \# missing & $\begin{array}{c}\text { mean (s.d.) / } \\
\text { \#categories }\end{array}$ & \# missing \\
\hline & Unit Price. mean (s.d.) & $1,262.06(1,881$ & & $1,170.37(1,557$ & & $1,170.37(1,557$ & \\
\hline & \# Purchasing PBs & 442 & & 402 & & 402 & \\
\hline & \# Observations & 1391 & & 1256 & & 1256 & \\
\hline \multirow{5}{*}{ Stapler } & Brand \& Model & 60 categories & 584 & 15 categories & 176 & 28 categories & 149 \\
\hline & Size & 9 categories & 566 & 4 categories & 123 & 4 categories & 141 \\
\hline & Unit Price. mean (s.d.) & \multicolumn{2}{|l|}{$587.33(816.28)$} & \multicolumn{2}{|l|}{$507.08(621.07)$} & \multicolumn{2}{|l|}{$504.22(614.41)$} \\
\hline & \# Purchasing PBs & \multicolumn{2}{|c|}{539} & \multicolumn{2}{|l|}{364} & \multicolumn{2}{|c|}{372} \\
\hline & \# Observations & \multicolumn{2}{|c|}{1024} & \multicolumn{2}{|c|}{549} & \multicolumn{2}{|c|}{567} \\
\hline \multirow{11}{*}{ Photocopying } & Color & 2 categories & 1119 & 2 categories & 307 & 2 categories & 307 \\
\hline & Double-sided & 3 categories & 1248 & 3 categories & 395 & 3 categories & 395 \\
\hline & On Generator Power & 3 categories & 1175 & 3 categories & 370 & 3 categories & 370 \\
\hline & Paper Quality & 9 categories & 1693 & 3 categories & 831 & 7 categories & 831 \\
\hline & Size & 19 categories & 1043 & 3 categories & 221 & 12 categories & 215 \\
\hline & With Binding & 4 categories & 1585 & 3 categories & 725 & 3 categories & 725 \\
\hline & Unit Price. mean (s.d.) & $3.33(7.65)$ & & $2.69(2.76)$ & & $2.69(2.76)$ & \\
\hline & \# Purchasing PBs & \multicolumn{2}{|l|}{470} & \multicolumn{2}{|c|}{401} & \multicolumn{2}{|c|}{401} \\
\hline & \# Observations & \multicolumn{2}{|c|}{3185} & \multicolumn{2}{|c|}{2249} & \multicolumn{2}{|c|}{2249} \\
\hline & Brand \& Model & 180 categories & 1280 & 57 categories & 581 & 31 categories & 581 \\
\hline & Refill or New & 7 categories & 935 & 5 categories & 241 & 5 categories & 241 \\
\hline
\end{tabular}


Table D.15: POPS Data Cleaning

\begin{tabular}{|c|c|c|c|c|c|c|c|}
\hline \multirow[b]{2}{*}{ Item } & \multirow[b]{2}{*}{ Attributes } & \multicolumn{2}{|c|}{ Raw Data } & \multicolumn{2}{|c|}{ Regression Data } & \multicolumn{2}{|c|}{ Machine Learning Data } \\
\hline & & $\begin{array}{c}\text { mean (s.d.) / } \\
\text { \#categories }\end{array}$ & \# missing & $\begin{array}{c}\text { mean (s.d.) / } \\
\text { \#categories }\end{array}$ & \# missing & $\begin{array}{c}\text { mean (s.d.) / } \\
\text { \#categories }\end{array}$ & \# missing \\
\hline & Unit Price. mean (s.d.) & \multicolumn{2}{|c|}{$4,630.16(4,257.79)$} & \multicolumn{2}{|l|}{$4,449.26(3,873.94)$} & \multicolumn{2}{|l|}{$4,449.26(3,873.94)$} \\
\hline & \# Purchasing PBs & \multicolumn{2}{|c|}{505} & \multicolumn{2}{|l|}{449} & \multicolumn{2}{|l|}{449} \\
\hline & \# Observations & \multicolumn{2}{|c|}{3814} & \multicolumn{2}{|l|}{2980} & \multicolumn{2}{|l|}{2980} \\
\hline \multirow{7}{*}{ Envelope } & Material & 12 categories & 789 & 7 categories & 417 & 10 categories & 417 \\
\hline & Printed & 5 categories & 983 & 4 categories & 583 & 4 categories & 583 \\
\hline & Area & 5 categories & 983 & 4 categories & 583 & 4 categories & 583 \\
\hline & With Zip & 2 categories & 1112 & 2 categories & 726 & 2 categories & 727 \\
\hline & Unit Price. mean (s.d.) & $9.31(32.16)$ & & $6.40(14.18)$ & & $6.38(14.16)$ & \\
\hline & \# Purchasing PBs & \multicolumn{2}{|l|}{512} & \multicolumn{2}{|l|}{427} & \multicolumn{2}{|l|}{427} \\
\hline & \# Observations & \multicolumn{2}{|c|}{1891} & \multicolumn{2}{|l|}{1433} & \multicolumn{2}{|l|}{1438} \\
\hline \multirow{7}{*}{ Soap } & Antiseptic & 2 categories & 690 & 2 categories & 418 & 2 categories & 420 \\
\hline & Brand & 36 categories & 436 & 20 categories & 209 & 30 categories & 192 \\
\hline & State & 3 categories & 419 & 3 categories & 181 & 3 categories & 183 \\
\hline & Type & 19 categories & 544 & 9 categories & 314 & 11 categories & 318 \\
\hline & Bar Size & 67 categories & 0 & $198.1(137.86)$ & 0 & 198.0 (137.75) & 0 \\
\hline & Bottle Size & 67 categories & 0 & $0.9(0.71)$ & 0 & $0.9(0.71)$ & 0 \\
\hline & Packet Size & 67 categories & 0 & $1072.1(2461.58)$ & 0 & $1072.0(2459.27)$ & 0 \\
\hline
\end{tabular}


Table D.15: POPS Data Cleaning

\begin{tabular}{|c|c|c|c|c|c|c|c|}
\hline \multirow[b]{2}{*}{ Item } & \multirow[b]{2}{*}{ Attributes } & \multicolumn{2}{|c|}{ Raw Data } & \multicolumn{2}{|c|}{ Regression Data } & \multicolumn{2}{|c|}{ Machine Learning Data } \\
\hline & & $\begin{array}{c}\text { mean (s.d.) / } \\
\text { \#categories }\end{array}$ & \# missing & $\begin{array}{c}\text { mean (s.d.) / } \\
\text { \#categories }\end{array}$ & \# missing & $\begin{array}{c}\text { mean (s.d.) / } \\
\text { \#categories }\end{array}$ & \# missing \\
\hline & Unit Price. mean (s.d.) & $3.73(17.96)$ & & $2.17(11.14)$ & & $2.17(11.12)$ & \\
\hline & \# Purchasing PBs & 518 & & 446 & & 447 & \\
\hline & \# Observations & 1476 & & 1155 & & 1158 & \\
\hline \multirow{8}{*}{ Light Bulb } & Brand & 53 categories & 959 & 12 categories & 434 & 31 categories & 386 \\
\hline & Type & 28 categories & 772 & 9 categories & 224 & 22 categories & 209 \\
\hline & Wattage & 47 categories & 814 & 12 categories & 232 & $35.4(65.15)$ & 252 \\
\hline & With Fitting & 3 categories & 1505 & 2 categories & 862 & 2 categories & 882 \\
\hline & With Fixture & 3 categories & 1463 & 2 categories & 818 & 2 categories & 838 \\
\hline & Unit Price. mean (s.d.) & \multicolumn{2}{|l|}{$697.49(1,142.68)$} & \multicolumn{2}{|l|}{$541.53(747.52)$} & \multicolumn{2}{|l|}{$563.52(782.47)$} \\
\hline & \# Purchasing PBs & \multicolumn{2}{|l|}{530} & \multicolumn{2}{|l|}{446} & \multicolumn{2}{|l|}{446} \\
\hline & \# Observations & \multicolumn{2}{|l|}{1818} & \multicolumn{2}{|l|}{1173} & \multicolumn{2}{|l|}{1193} \\
\hline \multirow{8}{*}{ Broom } & Brand & 8 categories & 846 & 4 categories & 380 & 8 categories & 369 \\
\hline & Handle Length & 10 categories & 815 & $3.1(1.57)$ & 878 & $3.1(1.57)$ & 878 \\
\hline & Handle Material & 4 categories & 838 & 4 categories & 351 & 4 categories & 351 \\
\hline & Type & 23 categories & 588 & 10 categories & 139 & 15 categories & 121 \\
\hline & Unit Price. mean (s.d.) & $79.90(108.92)$ & & $76.36(102.71)$ & & $76.36(102.71)$ & \\
\hline & \# Purchasing PBs & 586 & & 455 & & 455 & \\
\hline & \# Observations & 1702 & & 1159 & & 1159 & \\
\hline & Name & 57 categories & 2129 & 23 categories & 0 & 29 categories & 0 \\
\hline
\end{tabular}

Newspaper 
Table D.15: POPS Data Cleaning

\begin{tabular}{|c|c|c|c|c|c|c|c|}
\hline \multirow[b]{2}{*}{ Item } & \multirow[b]{2}{*}{ Attributes } & \multicolumn{2}{|c|}{ Raw Data } & \multicolumn{2}{|c|}{ Regression Data } & \multicolumn{2}{|c|}{ Machine Learning Data } \\
\hline & & $\begin{array}{c}\text { mean (s.d.) / } \\
\text { \#categories }\end{array}$ & \# missing & $\begin{array}{c}\text { mean (s.d.) / } \\
\text { \#categories }\end{array}$ & \# missing & $\begin{array}{c}\text { mean (s.d.) / } \\
\text { \#categories }\end{array}$ & \# missing \\
\hline & Unit Price. mean (s.d.) & $14.74(6.09)$ & & $14.29(3.72)$ & & $14.29(3.72)$ & \\
\hline & \# Purchasing PBs & 717 & & 617 & & 618 & \\
\hline & Unit Price. mean (s.d.) & $14.74(6.09)$ & & $14.29(3.72)$ & & $14.29(3.72)$ & \\
\hline & \# Purchasing PBs & 717 & & 617 & & 618 & \\
\hline & \# Observations & 9400 & & 6647 & & 6683 & \\
\hline \multirow{11}{*}{ Register } & Binding & 15 categories & 2917 & 13 categories & 1633 & 10 categories & 1635 \\
\hline & Brand & 54 categories & 3209 & 19 categories & 1979 & 49 categories & 1920 \\
\hline & Colored Pages & 6 categories & 2933 & 2 categories & 1675 & 2 categories & 1677 \\
\hline & Customized Printing & 3 categories & 3011 & 2 categories & 1732 & 2 categories & 1734 \\
\hline & Number of Pages & 80 categories & 2939 & $185.1(169.65)$ & 1641 & $185.1(169.65)$ & 1643 \\
\hline & Page Size & 82 categories & 2874 & 26 categories & 1552 & 51 categories & 1554 \\
\hline & Page Weight & 14 categories & 4456 & 12 categories & 2602 & 14 categories & 2604 \\
\hline & Type & 114 categories & 1776 & 28 categories & 523 & 44 categories & 525 \\
\hline & Unit Price. mean (s.d.) & $14.74(6.09)$ & & $314.93(239.41)$ & & $314.84(239.38)$ & \\
\hline & \# Purchasing PBs & 717 & & 717 & & 718 & \\
\hline & \# Observations & 5176 & & 3705 & & 3707 & \\
\hline
\end{tabular}


Table D.15: POPS Data Cleaning

\begin{tabular}{|c|c|c|c|c|c|c|c|}
\hline \multirow[b]{2}{*}{ Item } & \multirow[b]{2}{*}{ Attributes } & \multicolumn{2}{|c|}{ Raw Data } & \multicolumn{2}{|c|}{ Regression Data } & \multicolumn{2}{|c|}{ Machine Learning Data } \\
\hline & & $\begin{array}{c}\text { mean (s.d.) / } \\
\text { \#categories }\end{array}$ & \# missing & $\begin{array}{c}\text { mean (s.d.) / } \\
\text { \#categories }\end{array}$ & \# missing & $\begin{array}{c}\text { mean (s.d.) / } \\
\text { \#categories }\end{array}$ & \# missing \\
\hline \multirow{7}{*}{ Printer Paper } & Brand & 33 categories & 1127 & 14 categories & 693 & 31 categories & 638 \\
\hline & Colored Pages & 3 categories & 1014 & 2 categories & 531 & 2 categories & 532 \\
\hline & Page Size & 21 categories & 1123 & 7 categories & 547 & 15 categories & 547 \\
\hline & Page Weight & 25 categories & 898 & 13 categories & 360 & $77.54(5.99)$ & 361 \\
\hline & Unit Price. mean (s.d.) & $1.30(1.49)$ & & $1.19(0.28)$ & & $1.19(0.28)$ & \\
\hline & \# Purchasing PBs & \multicolumn{2}{|l|}{837} & \multicolumn{2}{|l|}{746} & \multicolumn{2}{|l|}{746} \\
\hline & \# Observations & \multicolumn{2}{|c|}{4570} & \multicolumn{2}{|l|}{3842} & \multicolumn{2}{|l|}{3843} \\
\hline \multirow{7}{*}{ Pen } & Color & 15 categories & 1579 & 11 categories & 911 & 8 categories & 912 \\
\hline & Model & 59 categories & 1560 & 29 categories & 916 & 30 categories & 887 \\
\hline & Type & 15 categories & 978 & 8 categories & 349 & 9 categories & 350 \\
\hline & Thickness & 23 categories & 2188 & $1.1(1.04)$ & 1443 & $1.1(1.04)$ & 1444 \\
\hline & Unit Price. mean (s.d.) & $49.10(126.38)$ & & $40.26(58.98)$ & & $40.27(58.98)$ & \\
\hline & \# Purchasing PBs & \multicolumn{2}{|l|}{814} & \multicolumn{2}{|l|}{719} & \multicolumn{2}{|l|}{719} \\
\hline & \# Observations & \multicolumn{2}{|c|}{4298} & \multicolumn{2}{|l|}{3386} & \multicolumn{2}{|l|}{3387} \\
\hline \multirow{3}{*}{ Towel } & Size & 24 categories & 517 & $1137.6(446.45)$ & 334 & $1137.6(446.45)$ & 334 \\
\hline & Towel Material & 3 categories & 283 & 2 categories & 109 & 2 categories & 109 \\
\hline & Type & 7 categories & 198 & 4 categories & 32 & 4 categories & 32 \\
\hline
\end{tabular}


Table D.15: POPS Data Cleaning

\begin{tabular}{|c|c|c|c|c|c|c|c|}
\hline \multirow[b]{2}{*}{ Item } & \multirow[b]{2}{*}{ Attributes } & \multicolumn{2}{|c|}{ Raw Data } & \multicolumn{2}{|c|}{ Regression Data } & \multicolumn{2}{|c|}{ Machine Learning Data } \\
\hline & & $\begin{array}{c}\text { mean (s.d.) / } \\
\text { \#categories }\end{array}$ & \# missing & $\begin{array}{c}\text { mean (s.d.) / } \\
\text { \#categories }\end{array}$ & \# missing & $\begin{array}{c}\text { mean (s.d.) / } \\
\text { \#categories }\end{array}$ & \# missing \\
\hline & Unit Price. mean (s.d.) & $458.19(225.20)$ & & $469.73(206.82)$ & & $469.73(206.82)$ & \\
\hline & \# Purchasing PBs & 362 & & 273 & & 273 & \\
\hline & \# Observations & 617 & & 427 & & 427 & \\
\hline \multirow{8}{*}{ Pipe } & Diameter & 60 categories & 365 & $2.0(3.59)$ & 207 & $1.9(3.58)$ & 207 \\
\hline & Manufacturer & 32 categories & 414 & 10 categories & 273 & 22 categories & 243 \\
\hline & Material & 3 categories & 283 & 5 categories & 94 & 13 categories & 81 \\
\hline & Size & 62 categories & 441 & 15 categories & 316 & $607.5(1068.00)$ & 316 \\
\hline & Type & 41 categories & 326 & 39 categories & 162 & 30 categories & 162 \\
\hline & Unit Price. mean (s.d.) & $2.30(8.63)$ & & $1.87(6.26)$ & & $1.87(6.26)$ & \\
\hline & \# Purchasing PBs & \multicolumn{2}{|l|}{372} & \multicolumn{2}{|l|}{319} & \multicolumn{2}{|l|}{319} \\
\hline & \# Observations & \multicolumn{2}{|l|}{807} & \multicolumn{2}{|l|}{609} & \multicolumn{2}{|l|}{610} \\
\hline TOTAL & \# Observations & \multicolumn{2}{|c|}{49,461} & \multicolumn{2}{|c|}{36,950} & \multicolumn{2}{|c|}{37,039} \\
\hline
\end{tabular}

